\title{
EFFECTS OF MICROBIAL PROCESSES ON GAS GENERATION UNDER EXPECTED WIPP REPOSITORY CONDITIONS: Annual Report Through 1992
}

\author{
A. J. Francis and J. B. Gillow \\ Prepared for: \\ Sandia National Laboratories \\ Waste Isolation Pilot Plant Gas Generation Program \\ Albuquerque, New Mexico \\ under \\ U.S. DOE Contract No. 67-8602 \\ by \\ Brookhaven National Laboratory \\ Upton, NY 11973
}

Under Contract No. DE-AC02-76CH00016 with the U.S. Department of Energy. 
Printed September 1993

BNL - 49518

SAND93-7036

UC-721

Informal Report

\title{
EFFECTS OF MICROBIAL PROCESSES ON GAS GENERATION UNDER EXPECTED WIPP REPOSITORY CONDITIONS: Annual Report Through 1992
}

\author{
A. J. Francis and J. B. Gillow \\ Prepared for: \\ Sandia National Laboratories \\ Waste Isolation Pilot Plant Gas Generation Program. \\ Albuquerque, New Mexico \\ under \\ U.S. DOE Contract No. 67-8602 \\ by \\ Brookhaven National Laboratory \\ Upton, NY 11973
}

\begin{abstract}
Microbial processes involved in gas generation from degradation of the organic constituents of transuranic waste under conditions expected at the Waste Isolation Pilot Plant (WIPP) repository are being investigated at Brookhaven National Laboratory. These laboratory studies are part of the Sandia National Laboratories - WIPP Gas Generation Program. Gas generation due to microbial degradation of representative cellulosic waste was investigated in short-term (< 6 months) and long-term ( $>6$ months) experiments by incubating representative paper (filter paper, paper towels, and tissue) in WIPP brine under initially aerobic (air) and anaerobic (nitrogen) conditions. Samples from the WIPP surficial environment and underground workings harbor gas-producing halophilic microorganisms, the activities of which were studied in short-term experiments. The microorganisms metabolized a variety of organic compounds including cellulose under aerobic, anaerobic, and denitrifying conditions. In long-term experiments, the effects of added nutrients (trace
\end{abstract}


amounts of ammonium nitrate, phosphate, and yeast extract), no nutrients, and nutrients plus excess nitrate on gas production from cellulose degradation. Results to date (up to 200 days of incubation) show that: (i) gas production was not detected in abiotic control samples; (ii) cellulose incubated without nutrients produced limited but sustained gas production; (iii) the addition of a nutrient solution enhanced the biodegradation of cellulose as evidenced by an increase in the production of total gas, carbon dioxide, and nitrous oxide; (iv) in the presence of excess nitrate, gas production was the highest and nitrous oxide accumulated to varying amounts; (v) the addition of bentonite increased the background carbon dioxide concentration and appeared to stimulate microbial activity; and (vi) in addition to total gas and carbon dioxide production, cellulose degradation in nutrientamended samples was evidenced by the gradual bleaching of brown paper towel, the formation of gas bubbles, the formation of paper pulp, and the appearance of a red color at the bottom of the sample bottles, indicating the growth of halophilic microorganisms. Estimates of the total gas production on the basis of initial results ranged from $0.001 \mathrm{~mL}$ $\mathrm{g}^{-1}$ cellulose day ${ }^{-1}$ to $0.039 \mathrm{~mL} \mathrm{~g}^{-1}$ cellulose day ${ }^{-1}$. 


\section{CONTENTS}

1.0 INTRODUCTION .........................................................................................

1.1 Background ............................................................................................................

1.2 Biochemistry of Cellulose Degradation ............................................................ 3

1.2.1 Biodegradation of Cellulose ...................................................................... 3

1.2.2 Metabolic Diversity of Halophilic Microorganisms .............................. 8

2.0 EXPERIMENTAL APPROACH ...................................................................... 10

3.0 SHORT-TERM EXPERIMENTS .......................................................................

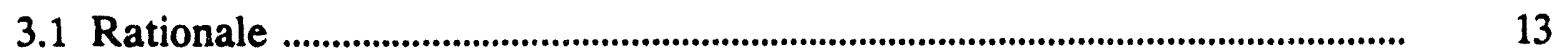

3.2 Methodology .........................................................................................................

3.2.1 Sample Collection ...................................................................................

3.2.2 Direct Counts of Bacteria ............................................................................. 14

3.2.3 Activity Measurements ..................................................................................

3.2.4 Denitrification Studies ........................................................................... is

3.3 Results and Discussion ................................................................................... 18

3.3.1 Direct Counts of Bacteria ........................................................................... 18

3.3.2 Activity Measurements ................................................................................. 18

3.3.3 Denitrification Studies ................................................................................. 28

3.4 Summary, Short-Term Experiments .................................................................. 37

4.0 LONG-TERM EXPERIMENTS ........................................................................... 41

4.1 Objective ...................................................................................................... 41

4.2 Rationale ................................................................................................. 42

4.2.1 Aerobic (Sealed) Treatments ....................................................................... 43

4.2.2 Anaerobic Treatments ..........................................................................

4.3 Materials and Methods ....................................................................................... 45

4.3.1 Cellulose ...................................................................................................... 45

4.3.2 WIPP Brine ..................................................................................... 50

4.3.3 Bentonite .............................................................................................................. 50

4.3.4 Inoculum ..................................................................................................... 50

4.4 Sample Treatments .............................................................................................. 53

4.4.1 Anaerobic Sample Preparation ................................................................. 53

4.4.2 Aerobic Sample Preparation ...................................................................... 53

4.4.3 Gas Analyses .................................................................................................. 54 


\section{CONTENTS (Continued)}

5.0 Results and Discussion (Long-Term Inundated Experiment) …………………... $\quad 54$

5.1 Aerobic Treatments...........................................................................................

5.1.1 Total Gas Production .............................................................................. 55

5.1.2 Carbon Dioxide Production .................................................................... 58

5.1.3 Nitrous Oxide Production ...................................................................... 61

5.2 Anaerobic Treatments .................................................................................... 63

5.2.1 Total Gas ..............................................................................................

5.2.2 Carbon Dioxide Production .......................................................................... 66

5.2.3 Nitrous Oxide Production ....................................................................... $\quad 70$

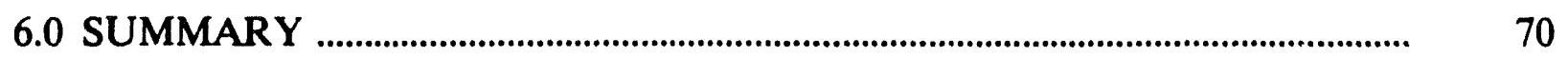

7.0 REFERENCES …………...........................................................................................

APPENDIX A -- Details of the Short-Term Activity Measurements........................... A-1

APPENDIX B -. Gas Analyses......................................................................................... B-1

APPENDIX C -- Details of Long-Term Experiment.................................................... C-1

APPENDIX D -- Gas Production Data (Gross and Net) for the Long-Term Inundated Experiment

D-1

APPENDIX E -- Mixed Inoculum Activity Measurements ……………………........... E- E-1 


\subsection{INTRODUCTION}

Transuranic (TRU) wastes contain alpha-emitting transuranium nuclides with half-lives greater than twenty years and concentrations greater than $100 \mathrm{nCi}$ per gram. TRU wastes are generated from nuclear weapons production and other related nuclear processing procedures. The wastes include adsorbed liquids, sludges, organics, and cemented materials containing the following radionuclides: ${ }^{232} \mathrm{Th},{ }^{233} \mathrm{U},{ }^{235} \mathrm{U},{ }^{238} \mathrm{U},{ }^{237} \mathrm{~Np},{ }^{238} \mathrm{Pu},{ }^{239} \mathrm{Pu},{ }^{240} \mathrm{Pu},{ }^{241} \mathrm{Pu}$, ${ }^{242} \mathrm{Pu},{ }^{241} \mathrm{Am},{ }^{244} \mathrm{Cm},{ }^{252} \mathrm{Cf}$, and a variety of metals. Typically, TRU waste is classified as either contact-handled $(\mathrm{CH})$, which does not require shielding, or remote-handled (RH), which requires shielding because of the hazard of gamma radiation exposure. The Waste Isolation Pilot Plant (WIPP) is a mined, geologic repository developed to demonstrate that radioactive transuranic wastes generated in defense-related activities can be safely and permanently disposed of underground. The WIPP is a U.S. Department of Energy facility located in southeastern New Mexico, about $2150 \mathrm{ft}(656 \mathrm{~m})$ below the surface, in a bedded salt, evaporite Permian formation. A major long-term concern is the potential for gas generation from the corrosion of $\mathrm{Fe}$ and $\mathrm{Fe}$-based alloys, microbial degradation of cellulosic, plastic, and rubber materials, and radiolysis of brine and waste material by alpha-emitting radionuclides (Molecke, 1979 and Brush, 1990). Gas generation can cause pressurization and the formation of fractures which could allow the radionuclides to migrate away from the disposal site.

Anoxic corrosion and microbiological activity are the two most important processes that may generate appreciable amounts of gas. The current estimate of gas production due to anoxic corrosion is 900 moles per drum of waste (Brush, 1991). Caldwell et al. (1979) reported that microbial gas production due to biodegradation of TRU waste could be significant. Recently, Lappin et al. (1989) estimated such production rates at 1 mole of gas per drum of waste per year for 600 years. Brush 1991; and Brush et al., (1990) proposed a minimum and maximum range at 0 to 5 moles per drum per year, as did the earlier estimates by Molecke (1979). 
Laboratory studies are under way to determine the rate and extent of gas production due to radiolysis, corrosion, and microbial activity, to support the Sandia National Laboratories-WIPP Gas Generation Program efforts to assess the long-term performance of the WIPP repository. Studies of the effects of microbial processes have been underway at Brookhaven National Laboratory since 1991. These laboratory studies are funded under Sandia National Laboratories contract no. 67-8602. "This report summarizes the progress and status of the WIPP-funded work at BNL. The microbiological data obtained from the laboratory studies from initiation through 1992 are presented.

\subsection{Background}

The WIPP waste repository is located $2150 \mathrm{ft}(656 \mathrm{~m})$ below ground surface, with 56 rooms planned or under construction in a bedded salt formation. About 6,800 drums of waste in 55-gallon (208-L) containers will be placed in each room of 3,640-m $\mathrm{m}^{3}$ capacity. Each drum will contain, on average, about $10 \mathrm{~kg}$ of cellulosic waste (approx. $70,000 \mathrm{~kg}$ of cellulosic per room), $70 \%$ of which is paper (Brush, 1990). The rest of the potentially biodegradable portion of the waste consists of plastic and rubber, and other organic compounds. Wastes consisting of inorganic process sludges from secondary waste treatment, containing a total of -3 million moles of nitrate and a much smaller amount of phosphate, will also be emplaced in the WIPP (Brush, 1990; Brush et al., 1991).

Microorganisms can enter the WIPP from several sources, including: (i) association with the TRU waste; (ii) the surface environment via the mine ventilation systems and human intrusion; and (iii) resident populations in the salt crystals and brine formations. Alpha radiation from TRU waste is not expected to have significant effects on microbial activity (Barnhart et al., 1980; Francis, 1990). Previous studies of low-level radioactive wastes and waste leachates have shown that microbes in the wastes can metabolize organic carbon compounds (Francis et al., 1980a,b; Francis, 1985). Halotolerant and halophilic microorganisms ( $10^{1}$ to $10^{5}$ colony forming units $/ \mathrm{mL}$ ) including aerobic, nitrate-reducing, and anaerobic bacteria were detected in the WIPP surficial environment and underground 
workings (work of R. Vreeland, West Chester University, to be published). Cellulosedegrading extreme halophiles from the underground workings also have been isolated (work of $\mathbf{R}$. Vreeland, West Chester University, to be published). Introduced microorganisms, as well as resident or indigenous halotolerant and halophilic bacteria, can metabolize organic compounds and nitrate in the waste, and may generate metabolic byproducts, such as organic acids, alcohols, carbon dioxide, nitrous oxide, nitrogen, hydrogen sulfide, and methane.

\section{Blochemistry of Cellulose Degradation}

\subsubsection{Blodegradation of Cellulose}

The cellulosic portion of the TRU waste will approximately be comprised of the following (Brush, 1990): paper (70\%), cloth (4\%), plywood (10\%), and lumber (16\%) (untreated: $10 \%$ and, treated: $6 \%$ ). In addition, the waste contains plastic materials (primarily polyethylene and polyvinyl chlorides) and rubber materials (primarily neoprene and hypalon), their characteristics may be altered by alpha-irradiation, which may enhance their biodegradability and potential for gas generation.

Cellulose, hemicellulose, and lignin make up the three major components of plant vascular material, lignocellulose. Lignin is a highly branched, constitutionally undefined aromatic polymer that makes up 15 to $38 \%$ of hardwood and softwood trees. It is considered highly resistant to biodegradation, although thermochemically modified lignin has been shown to biodegrade (Colberg and Young, 1982).

Cellulose is an unbranched polymer of several thousand D-glucose units linked together by $\beta-1,4$ glucosicic bonds. The strength of the polymer is derived from the multitude of hydrogen bonds, with concentrations of hydrogen bonds in microcrystalline regions and fewer bonds in amorphous regions. Cellulose is insoluble; therefore, hydrolysis is a 
prerequisite to microbial degradation. Hydrolysis of cellulose results in the formation of cellobiose, which is then hydrolyzed to glucose (see Figure 1).

Biodegradation of cellulose by white-rot fungus Trichoderma reesei and the bacteria Cellulomonas has provided insights into the enzymology, the mechanisms of action, and the pathways of cellulose degradation. Several extracellular enzymes are involved in the breakdown of cellulose. The cellulase enzymes, consisting of exoglucanase (exoenzyme) and endoglucanase (endoenzyme), break the cellulose chains into various smaller fragments, starting with: (i) different 1,4- $\beta$-endoglucanases that attack the 1,4- $\beta$-linkages, randomly depolymerizing internal units; (ii) 1,4- $\beta$-exoglucanases that remove cellobiose from the nonreducing chain end of the molecule, and (iii) 1,4- $\beta$-glucosidases (cellobiase), that hydrolyze cellobiose to glucose (Priest, 1984). Amorphous regions of cellulose are degraded by both the endo- and exo-glucanases separately. Synergistic action of the two enzymes is necessary for degrading crystalline cellulose (Poulsen and Peterson, 1992). These enzymes (produced by a variety of aerobic and anaerobic bacteria, fungi and protozoa) coordinate to hydrolyze cellulose into soluble components, which then are converted into a variety of end products. Bacteria, including aerobes such as Cellulomonas sp. and Cellvibrio gilvus (Bott and Kaplan, 1991), and anaerobes, such as Clostridium sp. (Benoit et al., 1992), Clostridium thermocellum (Lynd et al., 1989), Acetovibrio celluloyticus (Laube and Martin, 1981), and Ruminococcus albus (Pavlostathis et al., 1988) produce extracellular cellulase enzymes in the presence of cellulosics. These enzymes are induced by the presence of substrate (Hrmova et al., 1991) and are attenuated by soil and other absorptive materials (Hope and Burns, 1985). Close proximity of the cell to the substrate is necessary for degradation. A purified enzyme extract of $T$. reesei was shown to effectively degrade cellulose (Priest, 1984), and non-oxygen labile endoglucanase from Clostridium thermocellum was shown to strongly absorb to native cellulose ( $\mathrm{Ng}$ et al., 1977). The rate of enzyme induction also depends upon the presence of the necessary nutrients, nitrogen and phosphorus (Skujins, 1976). Upon induction, hydrolysis by the cellulases is the rate-limiting step which, once achieved, follows first-order kinetics (Pavlostathis, 1991). The available surface area is an important determinant of the 


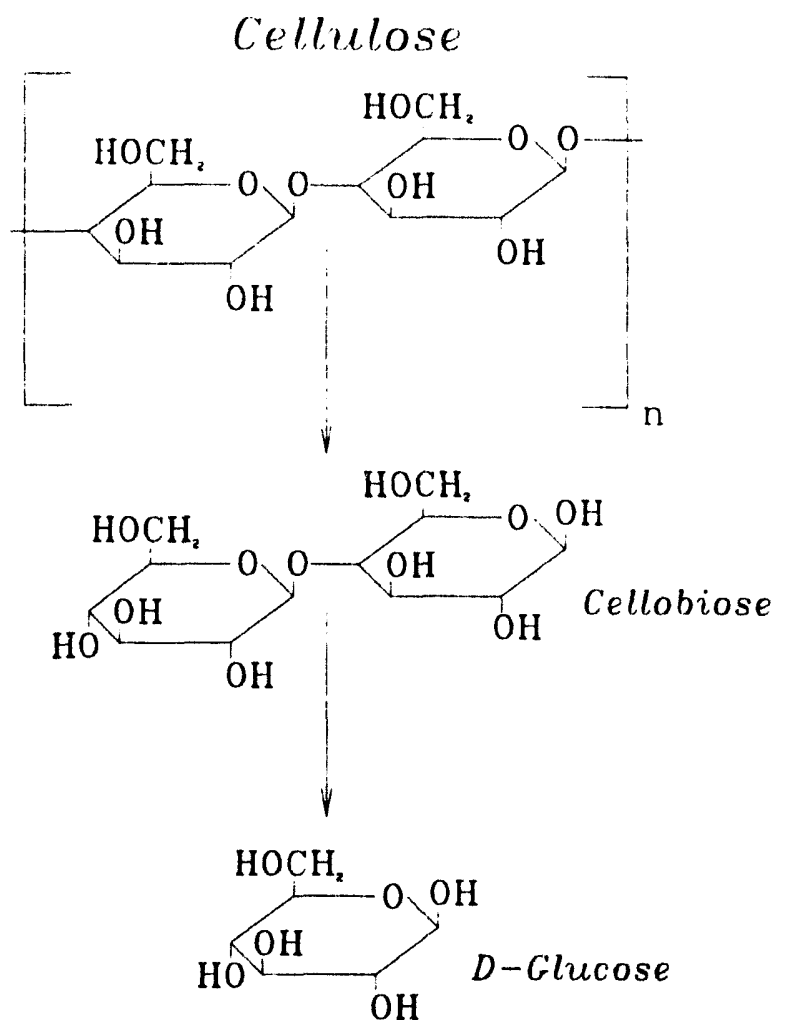

Figure 1. Cellulose Degradation Pathway. 
rate of digestion of cellulose. Studies of cellulytic bacteria in the rumen demonstrated the importance for degradation of adherence of microbial cells to the cellulose surface, with fermentation rates correlated to surface area (Weimer et al., 1990). The primary hydrolysis products of cellulose are cellobiose and glucose, which then are converted to organic acids, carbon dioxide, hydrogen, and methane by various microbial processes.

Glucose, generated from cellulose, is readily used by a variety of microorganisms. The specific process depends on the availability of electron acceptors such as oxygen, nitrate, sulfate, and $\mathrm{CO}_{2}$. In the presence of oxygen, carbon dioxide and water are formed during the oxidation of glucose.

$$
\mathrm{C}_{6} \mathrm{H}_{12} \mathrm{O}_{6}+6 \mathrm{O}_{2} \rightarrow 6 \mathrm{CO}_{2}+6 \mathrm{H}_{2} \mathrm{O}+\text { energy }
$$

As oxygen is consumed, the alternate electron acceptors are used: nitrate, iron (III) oxides and hydroxides, manganese (IV) oxides and hydroxides, sulfate, and carbon dioxide. In the case of nitrate, dissimilatory reduction transforms nitrate to ammonium (dissimilatory nitrate reduction to ammonium (DNRA)) or to nitrous oxide, and then nitrogen (denitrification):

$$
\begin{gathered}
\mathrm{NO}_{3}^{-} \rightarrow \mathrm{NO}_{2}^{-} \rightarrow \mathrm{NH}_{4}^{+}(\text {DNRA) } \\
\mathrm{NO}_{3}+\mathrm{NO}_{2}^{-} \rightarrow \mathrm{N}_{2} \mathrm{O} \rightarrow \mathrm{N}_{2} \text { (Denitrification) }
\end{gathered}
$$

Both processes are affected by the concentration of oxygen; the organisms catalyzing these transformations are microaerophiles or facultative anaerobes, capable of metabolism under low oxygen conditions or in its absence. Denitrification will slow down or cease with higher oxygen concentrations which inhibit the production of specific enzymes (Tiedje, 1988). Denitrifiers use several substrates, such as glucose and low molecular weight organic acids and alcohols. The use of nitrate as an alternate electron acceptor may be significant in the WIPP because of the presence of nitrate in the waste, predominantly from process sludges. 
In the absence of oxygen and nitrate, anaerobic microorganisms will dissipate electrons via fermentation of the carbohydrate:

$$
\begin{aligned}
& \mathrm{C}_{6} \mathrm{H}_{12} \mathrm{O}_{6} \rightarrow 2 \mathrm{C}_{3} \mathrm{H}_{4} \mathrm{O}_{3} \text { (pyruvic acid) }+4 \mathrm{H}^{+} \\
& 4 \mathrm{H}^{+}+2 \mathrm{C}_{3} \mathrm{H}_{4} \mathrm{O}_{3} \rightarrow 2 \mathrm{C}_{3} \mathrm{H}_{6} \mathrm{O}_{3} \text { (lactic acid) }
\end{aligned}
$$

Fermentation products, such as low molecular weight organic acids and alcohols are available for preferential use by denitrifiers, sulfate reducers, and methanogens. Brines from the WIPP contain 160 to $300 \mathrm{mM}$ sulfate (Brush, 1990); sulfate-reduction could be significant in the presence of metabolizable carbon. It occurs under reducing conditions (Eh -150 to $-200 \mathrm{mV}, \mathrm{pH}=7.00)$, resulting in a change in $\mathrm{Eh}(-250 \mathrm{mV})$ with growth and sulfide formation (Postgate, 1984):

$$
2 \text { lactate }+\mathrm{SO}_{4}=2 \text { acetate }+2 \mathrm{CO}_{2}+2 \mathrm{H}_{2} \mathrm{O}+\mathrm{S}^{=}
$$

Sulfate reduction results in the formation of $\mathrm{H}_{2} \mathrm{~S}$ and insoluble metal sulfides. Sulfatereducing bacteria (SRB) convert lactate, pyruvate, alcohols, amino acids, and acids of the tricarboxylic acid cycle to acetate and $\mathrm{CO}_{2}$. Glucose and other sugars seldom seem to be used directly by SRB.

The presence of $\mathrm{CO}_{2}, \mathrm{H}_{2}$, organic acids, and a low Eh generated by these anaerobic microbial processes provide a conducive environment for the growth of methanogenic bacteria. Methanogens can use (i) acetate; (ii) methanol; or (iii) carbon dioxide and hydrogen and produce methane:

(i) $\mathrm{CH}_{3} \mathrm{COO}+\mathrm{H}^{+} \rightarrow \mathrm{CH}_{4}+\mathrm{CO}_{2}$

(ii) $4 \mathrm{CH}_{3} \mathrm{OH} \rightarrow 3 \mathrm{CH}_{4}+\mathrm{CO}_{2}+2 \mathrm{H}_{2} \mathrm{O}$

(iii) $4 \mathrm{H}_{2}+\mathrm{CO}_{2} \rightarrow \mathrm{CH}_{4}+2 \mathrm{H}_{2} \mathrm{O}$

Approximately $70 \%$ of the methane formed in sludge and freshwater sediments is due to reaction (i), whereas halophiles predominantly carry out reaction (ii). 
Additionally, iron(III) reduction may be a significant process in the WIPP because of the presence of metallic and oxidized forms of iron $\left(5 \times 10^{6}\right.$ moles). Iron reduction involves the oxidation of organic carbon concomitant with the reduction of iron, whereby iron is used as the electron acceptor in the absence of oxygen, resulting in the dissolution of $\mathrm{Fe}$ (III) to $\mathrm{Fe}$ (II). Manganese reduction results in the formation of soluble $\mathrm{Mn}$ (II) from $\mathrm{Mn}(\mathrm{IV})$. Soluble uranyl ions can be reduced to insoluble U(IV) by anaerobic bacteria (Francis et al., 1991; Lovely, 1992). Corrosion caused by microbes could transform metal ions at a passive surface, resulting in metal sulfide precipitates (Kearns et al., 1992). The use of hydrogen solely from passivation can result in the formation of methane by methanogens, accelerating cathodic depolarization and increasing corrosion (Lorowitz et al., 1992). Figure 2 shows microbiologically mediated redox processes.

\subsubsection{Metabolic Diversity of Halophillic Microorganisms}

Halobacteria isolated from hypersaline environments can metabole a wide variety of organic compounds under aerobic and anaerobic conditions. Most of the extreme halophiles are archaebacteria; that is, they are a distinct group of microorganisms, apart from the eubacteria that make up the majority of prokaryotes, with an ancient lineage composed of other types of organisms adapted to extreme environments, such as alkaliphiles, thermophiles, and methanogens. Moderate halophiles grow best in an environment containing 0.5 to $2.5 \mathrm{M} \mathrm{NaCl}$, while extreme halophiles grow best in 2.5 to $5.2 \mathrm{M} \mathrm{NaCl}$ (Kusher and Kamekur, 1988; Ventosa, 1988). Brines in the WIPP repository consist of 5.15.3 $\mathrm{M}$ chloride and 1.83-4 $\mathrm{M}$ sodium, 0.63-1.44 $\mathrm{M}$ magnesium, and 0.04-0.30 $\mathrm{M}$ potassium (Brush, 1990; Molecke, 1983).

Halophiles grow anaerobically by: (i) fermenting glucose, fructose, glycerol, citrate, and lactate (Javor, 1984); (ii) reducing nitrate to nitrogen gas using a variety of carbohydrates (Tomlinson et al., 1986); (iii) degrading chitin; and (iv) producing methane from methylamines, $\mathrm{CO}_{2}$ and $\mathrm{H}_{2}$ (Zhilina and Zavarzin, 1990). In hypersaline environments acetate-utilizing methanogens have been difficult to isolate (Zhilina and Zavarzin, 1990). 


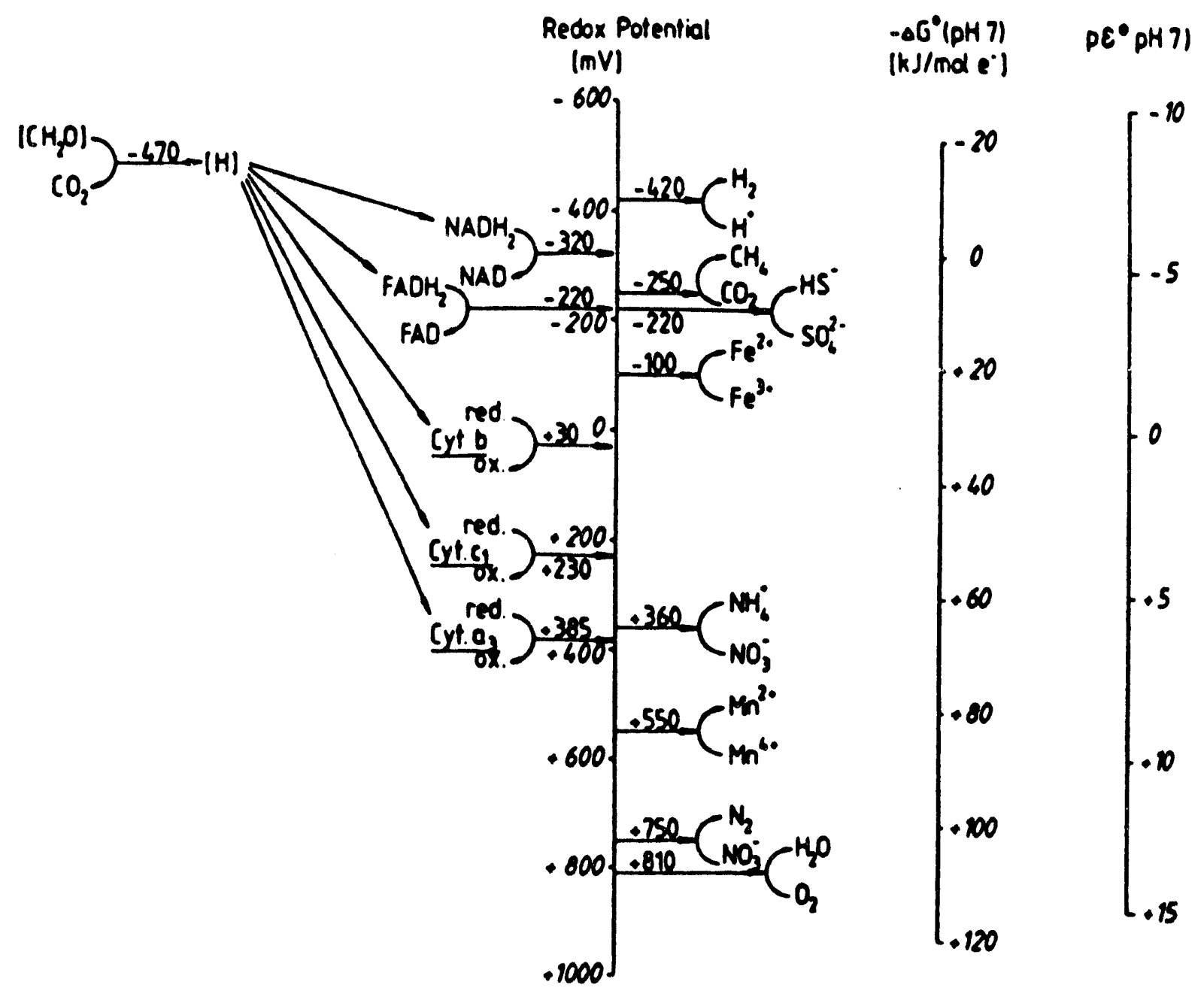

Figure 2. Electron-free energy for biologically mediated redox sequence with organic carbon $\left(\mathrm{CH}_{2} \mathrm{O}\right)$ acting as the electron donor. Calculated for standard conditions at $\mathrm{pH}$ 7. $\left(\mathrm{CH}_{2} \mathrm{O}\right)$ represents one-sixth of glucose (i.e. $-153 \mathrm{~kJ} \mathrm{~mol}^{-1}$ ), from Zehnder, A.J., and W. Stumm. 1988. "Geochemistry and Biogeochemistry of Anaerobic Habitats," Biology of Anaerobic Microorganisms. Ed. A. J. Zehnder. New York, NY: John Wiley and Sons. 19. 
Sulfate reducer also have been difficult to isolate, although saltmarsh sediments harbor abundant SRB populations (Dicker and Smith, 1985). The WIPP site contains a variety of halotolerant and halophilic bacterial populations. Isolates from underground brine seepages and salt crystals, and from brine and sediment from surficial lakes near the WIPP site, revealed a great diversity of colony characteristics when grown on solid media (work of $\mathbf{R}$. Vreeland, West Chester University, to be published). These isolates were shown to use amino acids, glucose, and cellulose.

\subsection{EXPERIMENTAL APPROACH}

Laboratory experiments were designed to determine the potential gas generation due to biodegradation of cellulose under conditions expected in the WIPP repository (Figure 3). The experiments were divided into short-term ( $<6$ months) and long-term ( $>2$ years). In the short-term experiments, we examined the influence of electron donors and acceptors on the activities of specific microbial processes relevant to the WIPP disposal environment. In the long-term experiments, we measured gas generation due to biodegradation of cellulose under realistic conditions expected in the WIPP repository after the waste was in place. The conditions include humid and inundated, and initially aerobic and anaerobic environments. The effects of addition of nutrients and bentonite also was ịvestigated. 
Effects of Microbial Processes on

Gas Generation under WIPP

Repository Relevant Test Conditions
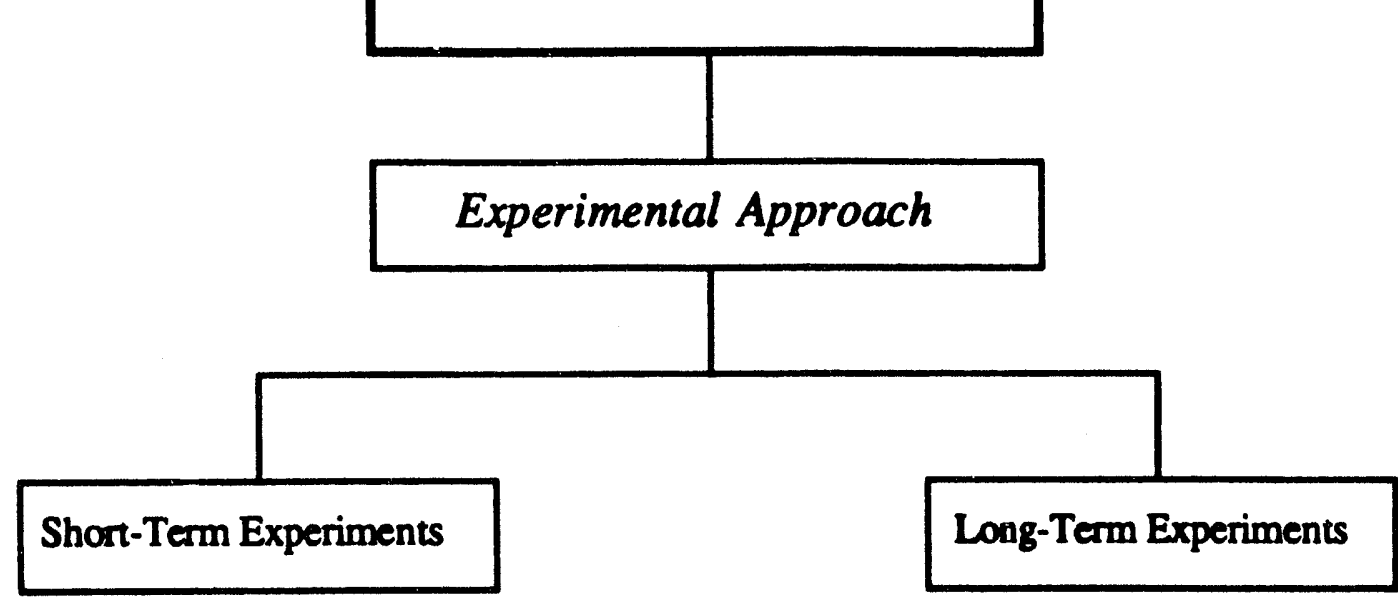

- 3 to 6 months.

- Quantify microbial gas production under accelerated WIPP repository test conditions.

- Focus on specific microbial processes.
- >2 years.

- Quantify microbial gas production under realistic WIPP repository test conditions.

- Focus on gas production due to cellulase biodegradation under inundated and humid conditions.

Figure 3. Experimental Approach 


\subsection{SHORT-TERM EXPERIMENTS}

\subsection{Rationale}

The two main objectives of the short-term experiments were: (i) to determine gas production due to the activity of aerobes and anaerobes in the presence of specific electron donors (cellulose, glucose, succinate) and acceptors (oxygen, nitrate, sulfate) under hypersaline conditions; and (ii) to evaluate the suitability of inocula for use in the long-term experiments.

Anaerobic microbial processes were emphasized in the short-term experiments because they are expected to have the greatest impact on the long-term performance of the WIPP repository. These experiments provided an opportunity to specify aspects of the long-term investigations by manipulating the experimental variables. The microbes tested include those present in the brine collected from WIPP underground workings, surficial sediment slurries from the surrounding lakes at the WIPP site, and in axenic (pure) or mixed cultures isolated from these sources. In addition, analytical methods were tested and standardized during this phase.

\subsection{Methodology}

\subsubsection{Sample Collection}

Sediment and water samples from Nash Draw (near the WIPP site) and muck pile salt, rib salt, and brine (from the WIPP underground workings) were collected from August 21 to 25, 1991. Core samples of mud from Laguna Cinco, Quatro, Tres, and Surprise Springs, all in Nash Draw, were obtained using sterile iron pipes. Air was excluded by driving the core deep into the mud and capping it while submersed. Corrosion of iron end-caps also prevented contamination $b_{j}$; oxygen. Lake brine samples were collected in sterile polyethylene containers from the four lakes as well as from Lindsay Lake, also in Nash 
Draw. Mud and brine from all the lakes were also collected with sterile glass serum bottles, which were then stoppered and crimped to exclude air. Salt from the WIPP underground was collected using sterile spatulas and sterile containers. G-Seep brine from the WTPP underground was co..ected in sterile polyethylene bottles by Glen Barker, SNL.

The samples were shipped to BNL within two days after collection. The mud samples were extruded in a nitrogen-filled glove box and transferred to sterile serum bottles, fitted with butyl rubber stoppers, and stored at $4^{\circ} \mathrm{C}$. Brine from Lindsay Lake and the WIPP site was also stored at $4^{\circ} \mathrm{C}$. Viable bacteria in these samples were counted by Russell Vreeland, West Chester University, and the total number of bacteria and microbial activity were determined at BNL.

\subsubsection{Direct Counts of Bacteria}

Samples were shaken on a wrist-action shaker for 45 minutes to disperse the contents. One $\mathrm{mL}$ was removed with a sterile needle and syringe, dispensed into a snap-cap vial and preserved with 5\% (v/v) glutaraldehyde. Double-stranded DNA specific stain 4'6-diamidino2 phenylindole dihydrochloride (DAPI, Polysciences, Inc.) was added to the sample and it was incubated for seven minutes in the dark. The sample was filtered through a $0.2 \mu \mathrm{m}$ black membrane filter (Poretics Corp.), and then placed on a slide and examined under oilimmersion at $1875 \mathrm{x}$ magnification. Slides were prepared in triplicate for each sample, the blue-fluorescing cells were counted directly using a calibrated grid eyepiece under epifluorescent light. The DAPI stain differentiated the cells from salt grains: DNA-containing material was blue and the salt yellow (Coleman, 1980).

\subsubsection{Acthity Measurements}

Production of gas by aerobes, anaerobes, and denitrifiers in a mixed inoculum of WIPP salt and brine and Nash Draw brine and sediment was determined. The carbon sources tested included glucose $\left(\mathrm{C}_{6} \mathrm{H}_{12} \mathrm{O}_{6}\right)$, cellulose $\left(\left[\mathrm{C}_{6} \mathrm{H}_{12} \mathrm{O}_{6}\right]_{\mathrm{n}}\right)$, and succinate $\left(\mathrm{C}_{4} \mathrm{H}_{6} \mathrm{O}_{4}\right)$. 
Two hundred g of S2180, W30 WIPP muck-pile salt were dissolved in sterile deionized water and diluted to $1 \mathrm{~L}$. To a $450 \mathrm{~mL}$ aliquot of the solution, $10 \mathrm{~mL}$ of Laguna Cinco mud slurry and $40 \mathrm{~mL}$ of Laguna Cinco lake water were added. The mixture was kept in an anaerobic glove box. Nine and a half $\mathrm{mL}$ of the mixture were added with a sterile syringe to $20 \mathrm{~mL}$ sterile serum bottles containing $0.5 \mathrm{~mL}$ of a sterile concentrated nutrient stock solution containing $5 \mathrm{mg}$ yeast extract, $10 \mathrm{mg}$ potassium phosphate, $125 \mu \mathrm{mol}$ ammonium nitrate, and $275 \mu \mathrm{mol}$ glucose (See Appendix A). Aerobic samples were incubated with an initial headspace of air in sealed containers, whereas anaerobic samples were incubated in a nitrogen atmosphere after purging the samples several times with nitrogen. The serum bottles were fitted and sealed with butyl rubber stoppers. Denitrification activity was determined by adding a nutrient solution containing $5 \mathrm{mg}$ yeast extract, $10 \mathrm{mg}$ potassium phosphate, $125 \mu \mathrm{mol}$ nitrate added as ammonium nitrate, $99 \mu \mathrm{mol}$ nitrate added as potassium nitrate, and $185 \mu \mathrm{mol}$ of succinate. These samples contained a total of $224 \mu \mathrm{mol}$ of nitrate and were prepared anaerobically. A set of aerobe, anaerobe, and denitrifier treatments were also prepared by including approximately $0.5 \mathrm{~g}$ filter paper instead of the respective carbon sources, glucose and succinate.

Six samples were prepared for each treatment, two of which were treated with $1 \mathrm{~mL}$ of $10 \%$ formaldehyde to serve as abiotic controls. Brine samples without nutrients were also prepared, and two were treated with formalin to determine endogenous activity. The headspace gas of all the samples was analyzed after 48, 83, and 147 days of incubation at $30^{\circ} \mathrm{C}$, and the total volume of gas, carbon dioxide, and nitrous oxide in the headspace determined (see Appendix B).

\subsubsection{Denitrification Studies}

In the absence of oxygen and in the presence of metabolizable organic carbon, some aerobic bacteria can use nitrate as an alternate electron acceptor. This process, called 
denitrification, or the reduction of nitrate, converts $80 \%$ or more of the available nitrate- $\mathrm{N}$ to nitrogen gas (Tiedje, 1988). Nitrate is reduced to nitrogen by denitrifying bacteria via the following steps:

$$
\mathrm{NO}_{3}{ }^{-} \rightarrow \mathrm{NO}_{2}^{-} \rightarrow \mathrm{N}_{2} \mathrm{O} \rightarrow \mathrm{N}_{2}
$$

Nitrate is also reduced by dissimilatory nitrate reduction to ammonium, but with either incomplete conversion to nitrogen or a far lesser yield of nitrogen (Tiedje, 1988). Nitrous oxide is an intermediate product and does not generally accumulate, although some halophiles accumulate nitrous oxide under certain conditions (Tomlinson et al., 1986).

Denitrification was observed in Nash Draw sediment slurry, G-seep, and a pure culture by the acetylene blockage technique (Yoshinari and Knowles, 1976). Acetylene inhibits the conversion (reduction) of $\mathrm{N}_{2} \mathrm{O}$ to $\mathrm{N}_{2}$, resulting in the stoichiometric accumulation of $\mathrm{N}_{2} \mathrm{O}$ in the headspace (Balderston et al., 1976):

$$
\begin{aligned}
& \mathrm{NO}_{3}^{-} \rightarrow \mathrm{NO}_{2}^{-} \rightarrow \mathrm{N}_{2} \mathrm{O}-\iint \rightarrow \mathrm{N}_{2} \\
& \mathrm{C}_{2} \mathrm{H}_{2}
\end{aligned}
$$

Acetylene was injected into the duplicate samples of each treatment to give a final concentration of $10 \%$. Nitrous oxide in the headspace of each sample was measured with a gas chromatograph equipped with a ${ }^{63} \mathrm{Ni}$ electron capture detector (see Appendix B). Samples were analyzed at 0,21 , and 43 hours, and at appropriate intervals thereafter.

\subsubsection{DENITRIFICATION IN SEDIMENT SLURRY SAMPLE}

Laguna Cinco sediment (collected on August 22, 1991 and stored anoxically at $4^{\circ} \mathrm{C}$ for two months), and a fresh sample from the same site (collected on December 10,1991) were examined for denitrifier activity. The fresh sample was examined within 48 hours of collection. The sample was mixed well, and a $1 \mathrm{~mL}$ slurry (August: $0.56 \pm 0.01 \mathrm{~g}$ dry sediment; December: $0.59 \pm 0.01 \mathrm{~g}$ dry sediment) was pipetted into sterile $20 \mathrm{~mL}$ serum 
bottles in a glove box filled with nitrogen. One $\mathrm{mL}$ of filter-sterilized $(0.22 \mu \mathrm{m})$ brine $(20 \%$ $\mathrm{w} / \mathrm{v}$ WIPP halite) were added to the slurries resulting in a final volume of $2 \mathrm{~mL}$. The slurry contained the following nutrients: (i) no additions (unamended); (ii) $3 \mu \mathrm{mol}$ succinate (carbon-amended); (iii) $300 \mathrm{nmol}$ nitrate (nitrate-amended); and (iv) $3 \mu \mathrm{mol}$ succinate and $300 \mathrm{nmol}$ nitrate (carbon-and nitrate-amended at a C:N ratio of 10:1). Succinate was used as the carbon source to discourage the growth of fermentative organisms. Triplicate samples of each treatment were prepared. The $\mathrm{pH}$ of each treatment was measured at the beginning and end of the experiment. Formaldehyde-treated samples served as controls. The serum bottles containing samples were sealed with rubber stoppers in the glove box in a nitrogen atmosphere and incubated at $30^{\circ} \mathrm{C}$. Denitrification was determined by the acetylene blockage technique.

\subsubsection{DENITRIFICATION IN G-SEEP}

G-Seep brine collected on December 10, 1991 from the WIPP underground workings was prepared within 48 hours of collection to assay for denitrification activity. Five $\mathrm{mL}$ aliquots of G-Seep brine were transferred into sterile serum bottles in an anaerobic glove box. One $\mathrm{mL}$ of filter-sterilized $(0.22 \mu \mathrm{m})$ brine $(20 \% \mathrm{w} / \mathrm{v}$ WIPP halite) with nutrients was added. The G-Seep samples contained the following nutrients: (i) no additions (unamended); (ii) $1.5 \mu \mathrm{mol}$ succinate (carbon-amended); (iii) $150 \mathrm{nmol}$ nitrate (nitrateamended); and (iv) $1.5 \mu \mathrm{mol}$ succinate and $150 \mathrm{nmol}$ nitrate (carbon- and nitrate-amended). Formaldehyde-treated samples served as controls. Triplicate samples of each treatment were prepared, sealed with butyl rubber stoppers in the glove box in a nitrogen atmosphere, and incubated at $30^{\circ} \mathrm{C}$. Denitrification was determined by the acetylene blockage technique. Samples were analyzed after $0,3,30$, and 60 days. 


\subsection{RESULTS AND DISCUSSION}

\subsubsection{Bacterial Population}

Table 1 shows the numbers of bacteria, both viable and non-viable in brine samples from Nash Draw and in G-Seep from the WIPP underground. The direct counts of bacteria in Nash Draw samples range from $5.5 \times 10^{6}$ to $1.0 \times 10^{7}$ cells $/ \mathrm{mL}$. The G-Seep brine contained $7.2 \times 10^{4}$ to $3.2 \times 10^{6}$ cells $/ \mathrm{mL}$.

\subsubsection{Activity Measurements}

\subsubsection{AEROBIC}

Table 2 shows the total gas, carbon dioxide, and nitrous-oxide production in the mixed inoculum slurry samples incubated initially under aerobic conditions with glucose, ammonium nitrate, yeast extract, and potassium phosphate. In the control samples, there was a slight increase in carbon dioxide due to abiotic reactions, but no nitrous oxide was detected. In amended samples, the concentration of both carbon dioxide and nitrous oxide increased.

\subsubsection{ANAEROBIC GLUCOSE METABOLISM}

Mixed inoculum incubated anaerobically with glucose, ammonium nitrate, yeast extract, and potassium phosphate showed little activity (Table 3). There was no significant production of carbon dioxide in amended samples. The reason for the lack of anaerobic metabolism of glucose in these samples is not known. 
Table 1. Bacterial Populations in Nash Draw and G-Seep Samples

Brine Source

Number of Cells/mL

Nash Draw

Surprise Springs

$5.5 \times 10^{6}$

Laguna Cinco

$6.8 \times 10^{6}$

Lindsay Lake

Laguna Tres South

$7.0 \times 10^{6}$

Laguna Quatro

$9.0 \times 10^{6}$

$1.0 \times 10^{7}$

WIPP Underground Workings

G-Seep \#9

$7.2 \times 10^{4}$

G-Seep \#23

$3.4 \times 10^{6}$ 
Table 2. Aerobic Glucose Metabolism by Mixed Inoculum.

\begin{tabular}{|c|c|c|c|c|c|c|c|c|c|}
\hline \multirow[t]{2}{*}{ Treatment* } & \multicolumn{3}{|c|}{$\frac{48}{\text { Gas Produced }^{* *}}$} & \multicolumn{3}{|c|}{$\frac{83}{\text { Gas Produced }^{* *}}$} & \multicolumn{3}{|c|}{$\frac{147}{\text { Gas Produced }^{* *}}$} \\
\hline & $\begin{array}{l}\text { Total } \\
\text { (ml) }\end{array}$ & $\underset{(\mu \text { moles })}{\mathrm{CO}_{2}}$ & $\underset{(\mu \text { moles })}{\mathrm{N}_{2} \mathrm{O}}$ & $\begin{array}{l}\text { Total } \\
\text { (ml) }\end{array}$ & $\underset{(\mu \text { moles })}{\mathrm{CO}_{2}}$ & $\underset{(\mu \text { moles })}{\mathrm{N}_{2} \mathrm{O}}$ & $\begin{array}{l}\text { Total } \\
\text { (ml) }\end{array}$ & $\underset{\text { ( } \mu \text { moles) }}{\mathrm{CO}_{2}}$ & $\underset{(\mu \text { moles })}{\mathrm{N}_{2} \mathrm{O}}$ \\
\hline $\begin{array}{l}\text { Control }(n=2) \\
\text { [Formalin treated] }\end{array}$ & $0.80 \pm 0.10$ & $14.0 \pm 0.6$ & nd & $1.31 \pm 0.57$ & $15.8 \pm 0.2$ & nd & $0.79 \pm 0.60$ & $20.1 \pm 0.1$ & nd \\
\hline Amended $(n=4)$ & $0.20 \pm 0.20$ & $76.9 \pm 6.2$ & $7.20 \pm 4.58$ & $0.83 \pm 0.48$ & $83.0 \pm 15.3$ & $8.75 \pm 6.14$ & $0.55 \pm 0.43$ & $80.4 \pm 14.8$ & $8.27 \pm 5.71$ \\
\hline
\end{tabular}

* Each sample contained $125 \mu$ moles of ammonium nitrate, $278 \mu$ moles of glucose, $5 \mathrm{mg}$ yeast extract, and $10 \mathrm{mg}$ potassium phosphate ** Dissolved gas concentration not included nd $=$ not detected 
Table 3. Anaerobic Glucose Metabolism by Mixed Inoculum.

\begin{tabular}{|c|c|c|c|c|c|c|c|c|c|}
\hline \multirow{3}{*}{ Treatment* } & \multicolumn{9}{|c|}{ Incubation Time (Days) } \\
\hline & \multicolumn{3}{|c|}{$\frac{48}{\text { Gas Produced }^{* *}}$} & \multicolumn{3}{|c|}{$\frac{83}{\text { Gas Produced } * *}$} & \multicolumn{3}{|c|}{147} \\
\hline & $\begin{array}{l}\text { Total } \\
(\mathrm{ml})\end{array}$ & $\underset{(\mu \text { moles })}{\mathrm{CO}_{2}}$ & $\underset{(\mu \text { moles })}{\mathrm{N}_{2} \mathrm{O}}$ & $\begin{array}{l}\text { Total } \\
(\mathrm{ml})\end{array}$ & $\underset{(\mu \text { moles })}{\mathrm{CO}_{2}}$ & $\frac{\mathrm{N}_{2} \mathrm{O}}{(\mu \text { moles })}$ & $\begin{array}{l}\text { Total } \\
(\mathrm{ml})\end{array}$ & $\underset{(\mu \text { moles })}{\mathrm{CO}_{2}}$ & $\frac{\mathrm{N}_{2} \mathrm{O}}{(\mu \text { moles })}$ \\
\hline $\begin{array}{l}\text { Control }(\mathrm{n}=2) \\
\text { [Formalin treated] }\end{array}$ & $0.60 \pm 0.50$ & $12.6 \pm 0.3$ & nd & $1.03 \pm 0.23$ & $13.5 \pm 0.2$ & nd & $0.13 \pm 0.14$ & $16.2 \pm 0.1$ & nd \\
\hline Amended $(n=4)$ & nd & $5.6 \pm 0.15$ & nd & $0.34 \pm 0.20$ & $7.72 \pm 0.18$ & $0.478 \pm 0.030$ & $-0.12 \pm 0.12$ & $8.00 \pm 0.20$ & $2.32 \pm 1.59$ \\
\hline
\end{tabular}

* Each sample contained $125 \mu$ moles of ammonium nitrate, $278 \mu$ moles of glucose, $5 \mathrm{mg}$ yeast extract, and $10 \mathrm{mg}$ potassium phosphate

** Dissolved gas concentration not included

nd $=$ not detected 


\subsubsection{CELLULOSE DEGRADATION}

\subsection{Aerobic}

Table 4 shows cellulose degradation in samples incubated initially under aerobic conditions with filter paper, ammonium nitrate, yeast extract, and potassium phosphate. Control samples showed no activity: A significant increase in carbon dioxide was observed after 83 days in amended samples. One sample produced $136 \mu \mathrm{mol}$ of carbon dioxide, and the pressure increased to 4.47 psi. The paper in the bottle showed disintegration, and dissolution. Blackening of specific samples was noted after 147 days, indicative of sulfate reduction.

\subsection{Anaerobic}

Samples incubated anaerobically with filter paper, ammonium nitrate, yeast extract, and potassium phosphate showed a significant increase in activity after 48 days (Table 5). Nitrous oxide was detected in amended samples, but not in the controls. An increase in carbon dioxide was observed after 83 days. There was a large variation in gas production of anaerobic samples, one sample produced $103 \mu \mathrm{mol}$ of carbon dioxide and the pressure reached 5.12 psi. The filter paper in this sample also disintegrated.

\subsection{Cellulose Degraciation in the Presence of Excess Nitrate}

Mixed inoculum incubated anaerobically with filter paper, ammonium nitrate, yeast extract, potassium phosphate, and excess nitrate produced less nitrous oxide than the succinate-amended samples (Table 6). Only $20 \%$ of the nitrate was converted to nitrous oxide in the samples with acetylene. Carbon dioxide production was not significant until 147 days. 
Table 4. Cellulose Degradation by Mixed Inoculum Under Aerobic Conditions.

\begin{tabular}{|c|c|c|c|c|c|c|c|c|c|}
\hline \multirow[t]{2}{*}{ Treatment* } & \multicolumn{3}{|c|}{$\frac{48}{\text { Gas Produced }^{* *}}$} & \multicolumn{3}{|c|}{$\frac{83}{\text { Gas Produced }^{* *}}$} & \multicolumn{3}{|c|}{$\frac{147}{\text { Gas Produced }}$} \\
\hline & $\begin{array}{l}\text { Total } \\
(\mathrm{ml})\end{array}$ & $\underset{(\mu \text { moles })}{\mathrm{CO}_{2}}$ & $\underset{(\mu \text { moles })}{\mathrm{N}_{2} \mathrm{O}}$ & $\begin{array}{l}\text { Total } \\
(\mathrm{ml})\end{array}$ & $\underset{(\mu \mathrm{moles})}{\mathrm{CO}_{2}}$ & $\frac{\mathrm{N}_{2} \mathrm{O}}{(\mu \text { moles })}$ & $\begin{array}{l}\text { Total } \\
\text { (ml) }\end{array}$ & $\underset{(\mu \text { moles })}{\mathrm{CO}_{2}}$ & $\frac{\mathrm{N}_{2} \mathrm{O}}{(\mu \text { moles })}$ \\
\hline $\begin{array}{l}\text { Control }(n=2) \\
\text { [Formalin treated] }\end{array}$ & $0.90 \pm 0.20$ & $10.9 \pm 0.5$ & nd & $1.65 \pm 0.49$ & $12.7 \pm 0.1$ & nd & $1.00 \pm 0.43$ & $14.7 \pm 0.0$ & nd \\
\hline Amended $(n=4)^{* * *}$ & nd & $32.0 \pm 1.9$ & $7.29 \pm 1.84$ & $0.95 \pm 0.61$ & $57.1 \pm 22.8$ & $4.12 \pm 1.38$ & nd & $63.9 \pm 20.7$ & $5.97 \pm 2.12$ \\
\hline
\end{tabular}

* Each sample contained $125 \mu$ moles of ammonium nitrate, 0.5 grams of filter paper, $5 \mathrm{mg}$ yeast extract, and $10 \mathrm{mg}$ potassium phosphate

** Dissolved gas concentration not included

*** Samples exhibited disintegration of the filter paper at 83 days

nd $=$ not detected 
Table 5. Cellulose Degradation by Mixed Inoculum Under Anaerobic Conditions.

\begin{tabular}{|c|c|c|c|c|c|c|c|c|c|}
\hline \multirow{3}{*}{ Treatment $^{*}$} & \multicolumn{9}{|c|}{ Incubation Time (Days) } \\
\hline & \multicolumn{3}{|c|}{$\frac{48}{\text { Gas Produced }^{* *}}$} & \multicolumn{3}{|c|}{$\frac{83}{\text { Gas Produced }^{* *}}$} & \multicolumn{3}{|c|}{147} \\
\hline & $\begin{array}{l}\text { Total } \\
(\mathrm{ml})\end{array}$ & $\underset{(\mu \text { moles })}{\mathrm{CO}_{2}}$ & $\underset{(\mu \text { moles })}{\mathrm{N}_{2} \mathrm{O}}$ & $\begin{array}{l}\text { Total } \\
(\mathrm{ml})\end{array}$ & $\underset{(\mu \mathrm{moles})}{\mathrm{CO}_{2}}$ & $\frac{\mathrm{N}_{2} \mathrm{O}}{(\mu \mathrm{moles})}$ & $\begin{array}{l}\text { Total } \\
(\mathrm{ml})\end{array}$ & $\underset{(\mu \text { moles })}{\mathrm{CO}_{2}}$ & $\frac{\mathrm{N}_{2} \mathrm{O}}{(\mu \text { moles })}$ \\
\hline $\begin{array}{l}\text { Control }(n=2) \\
\text { [Formalin treated] }\end{array}$ & $0.60 \pm 0.00$ & $11.3 \pm 0.1$ & nd & $1.02 \pm 0.22$ & $12.5 \pm 0$ & nd & $0.17 \pm 0.17$ & $14.3 \pm 0.0$ & nd \\
\hline Amended $(n=4)$ & & & & & & & & & \\
\hline 1 & nd & 8.85 & 9.29 & 0.12 & 10.7 & 5.79 & 0.05 & 13.1 & nd \\
\hline $2^{* * *}$ & nd & 6.83 & 10.7 & 3.48 & 65.0 & nd & 1.90 & 95.6 & nd \\
\hline $3 * * *$ & nd & 9.12 & nd & 3.76 & 103 & nd & 0.77 & 90.8 & nd \\
\hline $4 * * *$ & nd & 9.73 & 9.43 & 2.18 & 53.0 & nd & 3.81 & 105 & nd \\
\hline Mean & nd & $8.63 \pm 0.54$ & $7.36 \pm 2.14$ & $2.39 \pm 0.72$ & $57.9 \pm 16.5$ & $1.45 \pm 1.25$ & $1.63 \pm 0.71$ & $76.1 \pm 18.4$ & nd \\
\hline
\end{tabular}

* Each sample contained $125 \mu$ moles of ammonium nitrate, 0.5 grams of filter paper, 5 mg yeast extract, and 10 mg potassium phosphate

* Dissolved gas concentration not included

*** At 83 days, samples exhibited disintegration of filter paper

nd $=$ not detected 
Table 6. Cellulose Degradation by Mixed Inoculum in the Presence of Excess Nitrate.

\begin{tabular}{|c|c|c|c|c|c|c|c|c|c|c|}
\hline \multirow{4}{*}{ Treatment* } & \multicolumn{10}{|c|}{ Incubation Time (Days) } \\
\hline & \multirow{2}{*}{\multicolumn{3}{|c|}{$\frac{48}{\text { Gas Produced }^{* *}}$}} & \multirow{2}{*}{\multicolumn{4}{|c|}{$\frac{83}{\text { Gas Produced }^{* *}}$}} & \multirow{2}{*}{\multicolumn{3}{|c|}{$\frac{147}{\text { Gas Produced }^{* *}}$}} \\
\hline & & & & & & & & & & \\
\hline & $\begin{array}{l}\text { Total } \\
(\mathrm{ml})\end{array}$ & $\underset{(\mu \text { moles })}{\mathrm{CO}_{2}}$ & $\underset{(\mu \text { moles })}{\mathrm{N}_{2} \mathrm{O}}$ & & $\begin{array}{l}\text { Total } \\
(\mathrm{ml})\end{array}$ & $\frac{\mathrm{CO}_{2}}{(\mu \text { moles })}$ & $\underset{(\mu \text { moles })}{\mathrm{N}_{2} \mathrm{O}}$ & $\begin{array}{l}\text { Total } \\
\text { (ml) }\end{array}$ & $\underset{(\mu \text { moles })}{\mathrm{CO}_{2}}$ & $\underset{(\mu \text { moles })}{\mathrm{N}_{2} \mathrm{O}}$ \\
\hline \multicolumn{11}{|c|}{$\operatorname{Control}(n=2$. [Formalin treated] } \\
\hline (w/acetyl.) & nd & 8.93 & nd & 1.03 & & 11.9 & nd & 0.73 & 12.7 & nd \\
\hline (w/o acetyl.) & nd & 9.90 & nd & 0.24 & & 10.9 & nd & -0.44 & 12.0 & nd \\
\hline \multicolumn{11}{|l|}{ Amended $(n=4)$} \\
\hline (w/acetyl., $n=2$ ) & nd & $5.24 \pm 0.40$ & $23.6 \pm 1.2$ & 0.38 & \pm 0.27 & $20.3 \pm 11.4$ & $19.5 \pm 2.1$ & $1.39 \pm 1.97$ & $56.7 \pm 36.2$ & $14.4 \pm 1.7$ \\
\hline (w/o acetyl., $n=2$ ) & nd & $8.00 \pm 0.95$ & $5.59 \pm 4.00$ & 0.06 & \pm 0.02 & $8.13 \pm 0.41$ & $4.94 \pm 0.78$ & $3.62 \pm 0.88$ & $78.0 \pm 5.2$ & nd \\
\hline
\end{tabular}

* Each sample contained $224 \mu$ moles of nitrate, 0.5 grams of filter paper, $5 \mathrm{mg}$ yeast extract, and $10 \mathrm{mg}$ potassium phosphate

** Dissolved gas concentration not included

nd $=$ not detected 
Cellulose degradation by mixed inoculum was observed in samples incubated under aerobic and anaerobic conditions and in the presence of excess nitrate. Disintegration of the filter paper in aerobic and anaerobic samples was noted after 83 days, indicating cellulose degradation. Analysis of these samples showed an increase in total gas, carbon dioxide, and nitrous-oxide production (Tables 4 and 5). The filter paper exhibited areas of thinning and clearing at 83 days in samples containing excess nitrate. At 147 days, the filter paper had fully disintegrated and carbon dioxide content had increased (Table 6). Aerobic samples containing cellulose showed little increase in carbon dioxide at 147 days; one sample turned black, possibly indicating the onset of sulfate reduction. This sample was checked after 220 days and the presence of hydrogen sulfide was confirmed by gas chromatography. Anaerobic samples also produced gas at 147 days, and one sample showed blackening (Sample 2, Table 5).

\subsubsection{DENITRIFICATION}

Mixed inoculum samples incubated anaerobically with succinate, ammonium nitrate, yeast extract, potassium phosphate, and excess nitrate exhibited denitrification activity. Complete conversion of nitrate $(224 \mu \mathrm{mol})$ to nitrous oxide $(129 \mu \mathrm{mol})$ was noted in the presence of acetylene after 48 days of incubation (Table 7). The accumulation of nitrous oxide in amended samples without acetylene was much less than in the samples containing acetylene, indicating that nitrous oxide was converted to nitrogen. Control samples showed no activity. Additional studies on denitrification by WIPP sediment slurry brine and an axenic culture isolated from the brine are described next.

\subsubsection{Denltrification Studiee}

\subsubsection{DENITRIFICATION IN SEDIMENT}

Microbial denitrification was analyzed in freshly collected sediment and stored sediment. Nitrous oxide was both being produced and converted to $\mathrm{N}_{2}$ at the same time (acetylene was 
Table 7. Denitrification Activity by Mixed Inoculum.

\begin{tabular}{|c|c|c|c|c|c|c|c|c|c|}
\hline \multirow{4}{*}{ Treatment* } & \multicolumn{9}{|c|}{ Incubation Time (Days) } \\
\hline & \multicolumn{3}{|c|}{$\frac{48}{\text { Gas Produced }^{* *}}$} & \multicolumn{3}{|c|}{$\frac{83}{\text { Gas Produced ** }^{*}}$} & \multicolumn{3}{|c|}{147} \\
\hline & \multicolumn{3}{|c|}{ Gas Produced $* *$} & \multicolumn{3}{|c|}{ Gas Produced** } & \multicolumn{3}{|c|}{ Gas Produced ${ }^{*}$} \\
\hline & $\begin{array}{l}\text { Total } \\
(\mathrm{ml})\end{array}$ & $\begin{array}{c}\mathrm{CO}_{2} \\
\text { (umoles) }\end{array}$ & 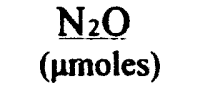 & $\begin{array}{l}\text { Total } \\
(\mathrm{ml})\end{array}$ & $\underset{\text { ( } \mu \text { moles) }}{\mathrm{CO}_{2}}$ & $\frac{\mathrm{N}_{2} \mathrm{O}}{\text { (umoles) }}$ & $\begin{array}{l}\text { Total } \\
(\mathrm{ml})\end{array}$ & $\frac{\mathrm{CO}_{2}}{\text { (umoles) }}$ & $\frac{\mathrm{N}_{2} \mathrm{O}}{(\mu \text { moles })}$ \\
\hline \multicolumn{10}{|c|}{ Control( $n=2$ [Formalin treated] } \\
\hline (w/acetyl.) & nd & 8.93 & nd & 1.37 & 10.2 & nd & 1.08 & 11.8 & nd \\
\hline (w/o acetyl.) & nd & 8.26 & nd & nd & 11.5 & nd & nd & 12.9 & nd \\
\hline \multicolumn{10}{|l|}{ Amended $(n=4)$} \\
\hline (w/acetyl., $n=2$ ) & nd & $3.43 \pm 0.24$ & $129 \pm 2$ & $0.50 \pm 0.20$ & $6.41 \pm 0.05$ & $114 \pm 5$ & $-0.12 \pm 0.24$ & na & na \\
\hline (w/o acetyl., $n=2$ ) & nd & $51.0 \pm 36.1$ & $6.97 \pm 2.12$ & $1.07 \pm 0.20$ & $30.4 \pm 21.5$ & $12.1 \pm 2.0$ & $1.01 \pm 0.39$ & na & nd \\
\hline
\end{tabular}

* Each sample contained $224 \mu$ moles of nitrate, $185 \mu$ moles of succinate, 5 mg yeast extract, and 10 mg potassium phosphate ** Dissolved gas concentration not included

nd $=$ not detected

na $=$ not analyzed 
not added to the samples) as shown in Figures 4A and 4B. The nitrous oxide concentrations reported in these studies do not include $\mathrm{N}_{2} \mathrm{O}$ dissolved in the brine solution. Nitrous oxide was not detected in the control sample, which had been treated with formaldehyde. In unamended samples and samples amended with succinate, $-5 \mathrm{nmol}$ of $\mathrm{N}_{2} \mathrm{O}$ was detected at about 45 hours of incubation, and $\mathrm{N}_{2} \mathrm{O}$ was not detected in the headspace thereafter. In samples amended with nitrate, the $\mathrm{N}_{2} \mathrm{O}$ concentration reached its maximum ( $30 \mathrm{nmol} \mathrm{gdw}^{-1}$ ) at about 200 hours and then disappeared rapidly by conversion to $\mathrm{N}_{\mathbf{2}}$ (Figure $4 \mathrm{~A}$ ). In the succinate and nitrate amended samples, much less $\mathrm{N}_{2} \mathrm{O}$ was detected than in the nitrateamended samples. Freshly collected samples showed little accumulation of $\mathrm{N}_{2} \mathrm{O}$ in the headspace (Figure 4B), most probably due to rapid and complete denitrification.

The rates of denitrification in the unamended and amended (succinate and nitrate) sediment samples were determined by the acetylene blockage technique. Addition of acetylene inhibits the reduction of $\mathrm{N}_{2} \mathrm{O}$ to $\mathrm{N}_{2}$ and allows $\mathrm{N}_{2} \mathrm{O}$ to accumulate in the headspace which is analyzed by gas chromatography. In Figures 5A and 5B and Table 8a and $8 \mathrm{~b}$, denitrification in stored ( 2 months) and freshly collected (assayed within 48 hours) samples are compared. In the stored samples, Figures 5A and 5B, denitrifying activity initially in the unamended sample was minimal. After lag phase, denitrification proceeded at about $0.14 \mathrm{nmol} \mathrm{N}_{2} \mathrm{O} \mathrm{gdw^{-1 }} \mathrm{h}^{-1}$. The rate is presented in Table 9a. The sediment contained sufficient indigenous carbon and nitrate to produce 23 nmoles of $\mathrm{N}_{2} \mathrm{O} \mathrm{gdw}^{-1}$. Denitrification in the stored, carbon- amended samples was similar to that in the unamended samples $\left(0.22 \mathrm{nmol} \mathrm{N}_{2} \mathrm{Ogdw}^{-1} \mathrm{~h}^{-1}\right)$. Denitrification activity in the stored sample was stimulated by the addition of nitrate. After an initial lag, the rate of denitrification was $1.36 \mathrm{nmol}$ nitrous oxide $\mathrm{gdw}^{-1} \mathrm{~h}^{-1}$.

A stimulatory effect on the rate and extent of denitrification was seen in both stored and fresh samples when carbon and nitrate were added. Denitrification proceeded at $1.78 \mathrm{nmol}$ $\mathrm{N}_{2} \mathrm{O} \mathrm{gdw}^{-1} \mathrm{~h}^{-1}$, finally producing $209 \mathrm{nmol}$ nitrous oxide $\mathrm{gdw}^{-1}$ in the stored sample, translating to denitrification of $80 \%$ of the added nitrate. In the freshly collected sediment, without added carbon or nitrate, 205 nmoles of nitrous oxide $\mathrm{gdw}^{-1}$ were produced at a rate 

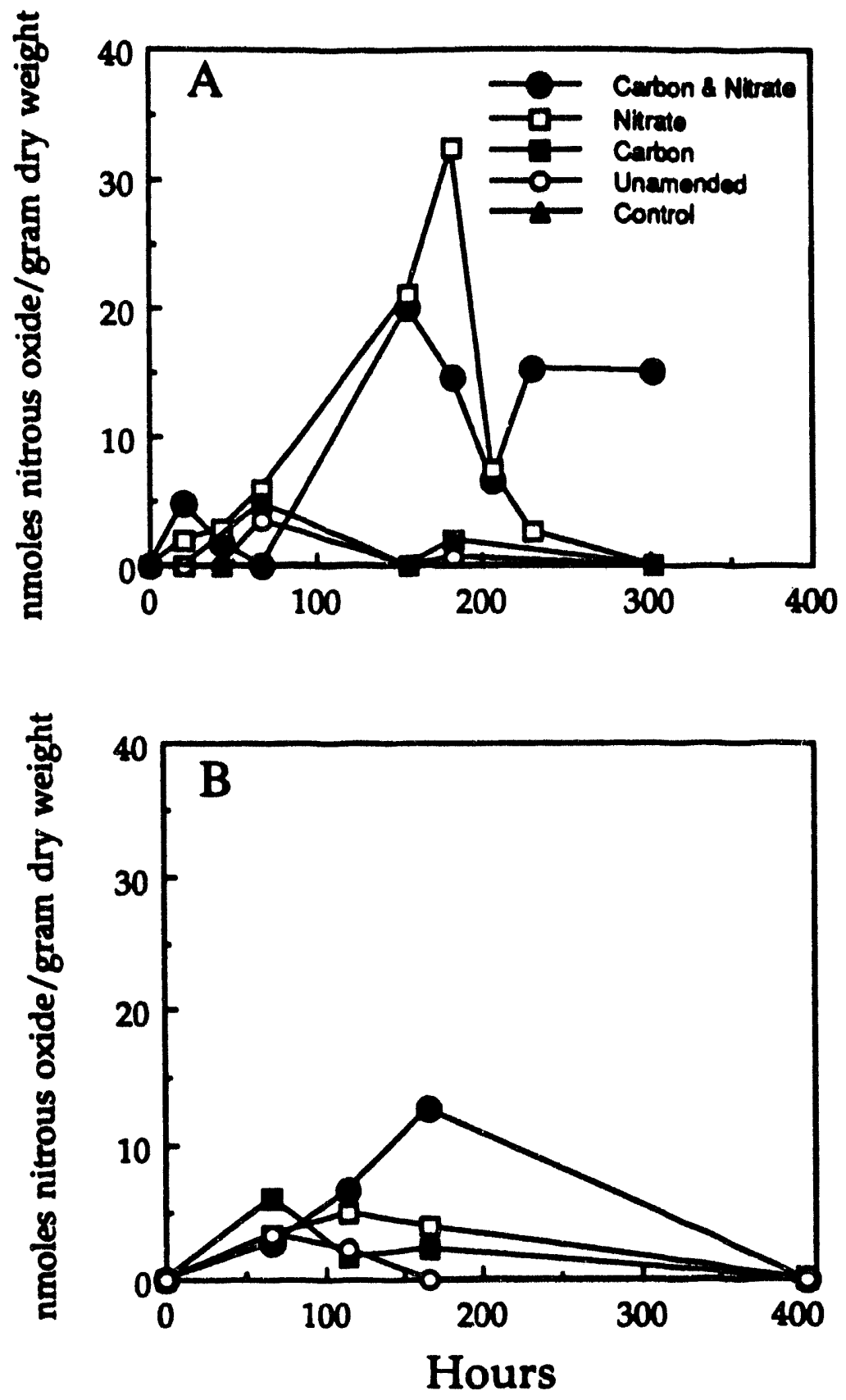

Figure 4. Denitrification by Laguna Cinco sediment; (A) stored sample, (B) fresh sample 

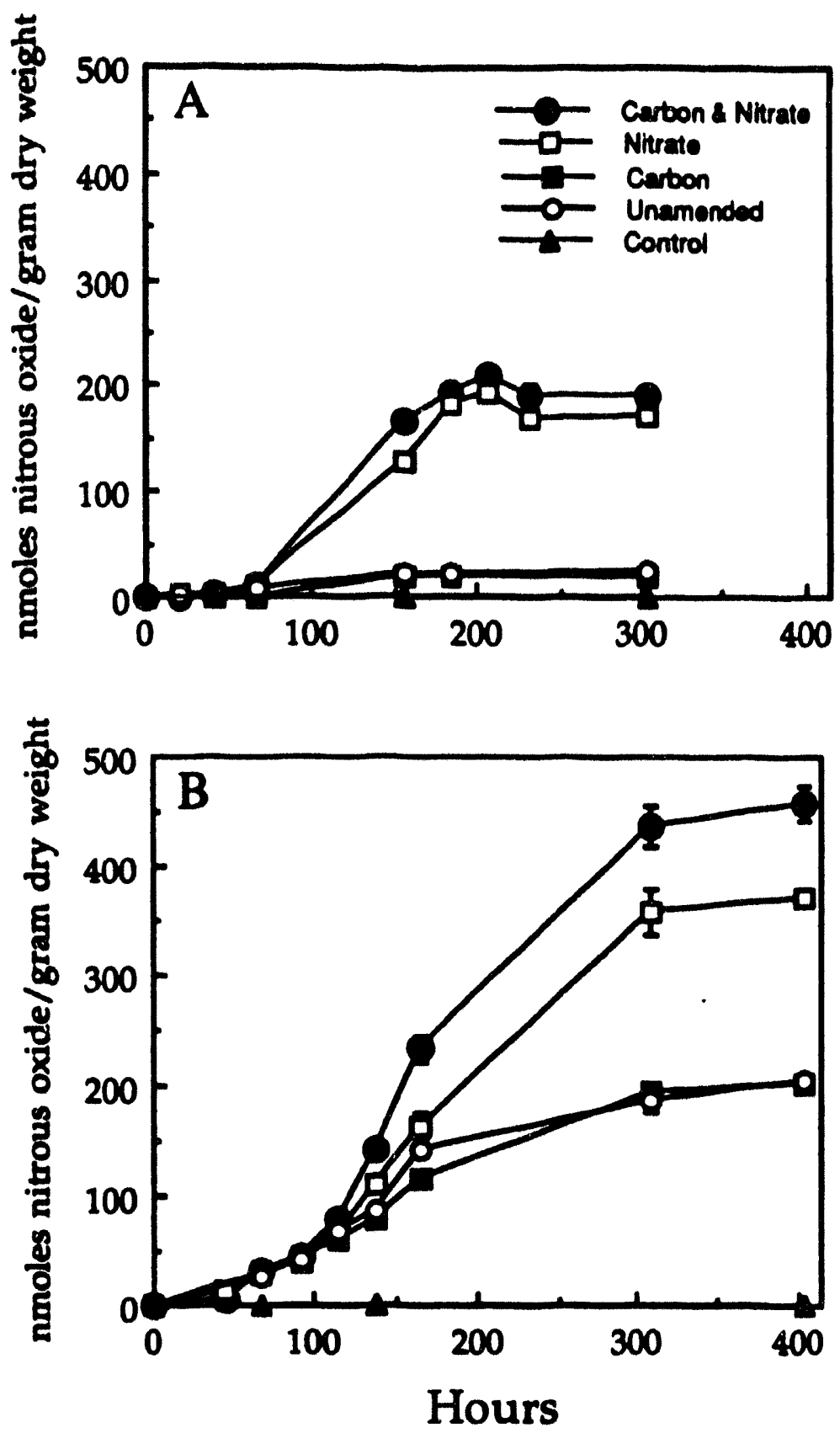

Figure 5. Denitrification determined by the acetylene blockage technique in (A) stored sample, (B) fresh sample 
Table 8a. Denitrification in Laguna Cinco Sediment (Stored 2 Months)

\begin{tabular}{|c|c|c|c|c|c|}
\hline \multicolumn{6}{|c|}{ Addition } \\
\hline Time & Control* & None & Carbon & Nitrate & Carbon \& Nitrate \\
\hline \multicolumn{6}{|c|}{ (Hours) } \\
\hline 0 & nd & nd & nd & nd & nd \\
\hline 21 & & $1.96 \pm 0.58$ & 2.16 & $1.50 \pm 0.11$ & 0.514 \\
\hline 42.5 & nd & $3.44 \pm 0.64$ & na & 3.21 & $3.86 \pm 0.22$ \\
\hline 67 & & 8.16 & $0.00 \pm 0.00$ & $9.64 \pm 0.74$ & 9.64 \\
\hline 155 & nd & $20.7 \pm 1.4$ & $19.6 \pm 0.1$ & $129 \pm 5$ & $166 \pm 6$ \\
\hline 183 & & $22.3 \pm 3.0$ & $19.4 \pm 0.9$ & $183 \pm 0$ & $194 \pm 2$ \\
\hline 207 & & na & na & $192 \pm 0$ & $209 \pm 2$ \\
\hline 231 & & na & na & $168 \pm 4$ & $191 \pm 9$ \\
\hline 303 & nd & $23.3 \pm 1.5$ & $18.3 \pm 0.2$ & $171 \pm 8$ & $191 \pm 5$ \\
\hline
\end{tabular}

Table 8b. Denitrification in Laguna Cinco Sediment (Assayed Within 48 Hours)

\begin{tabular}{|c|c|c|c|c|c|}
\hline Time & Control $^{*}$ & None & $\begin{array}{l}\text { Addition } \\
\text { Carbon }\end{array}$ & Nitrate & Carbon \& Nitrate \\
\hline \multicolumn{6}{|c|}{ (Hours) } \\
\hline 0 & nd & nd & nd & nd & nd \\
\hline 45 & & na & na & $13.6 \pm 0.1$ & $5.58 \pm 3.94$ \\
\hline 66 & nd & $26.5 \pm 1.1$ & $29.0 \pm 1.0$ & 30.5 & 30.5 \\
\hline 91.5 & & $43.0 \pm 0.3$ & $44.2 \pm 4.6$ & $39.4 \pm 1.2$ & $45.2 \pm 0.5$ \\
\hline 114 & nd & $68.6 \pm 3.1$ & $61.6 \pm 1.8$ & $65.6 \pm 2.1$ & $79.6 \pm 1.2$ \\
\hline 138 & & $86.0 \pm 3.7$ & $78.1 \pm 1.5$ & $110 \pm 3$ & $141 \pm 5$ \\
\hline 165 & & $142 \pm 5$ & $115 \pm 3$ & $164 \pm 12$ & $233 \pm 12$ \\
\hline 309 & & $188 \pm 11$ & $194 \pm 2$ & $357 \pm 21$ & $436 \pm 18$ \\
\hline 405 & nd & $205 \pm 1$ & $202 \pm 8$ & $372 \pm 3$ & $458 \pm 15$ \\
\hline
\end{tabular}

* Formalin treated samples

** Dissolved gas concentration not included

nd $=$ none detected

$\mathrm{na}=$ not analyzed 
Table 9a. Denitrification Rate (Stored Sample)*

\begin{tabular}{lc}
\hline Addition & Rate \\
& (nmol nitrous oxide/g dry weight/hour) \\
\hline None (Unamended) & 0.14 \\
Carbon & 0.22 \\
Nitrate & 1.36 \\
Carbon and Nitrate & 1.78 \\
& \\
\hline
\end{tabular}

*Rate after lag phase, from 67 to 155 hours (see Table 8a).

Table 9b. Denitrification Rate (Fresh Sample)*

\begin{tabular}{lc}
\hline Addition & Rate \\
& (nmol nitrous oxide/g dry weight/hour) \\
\hline & \\
None (Unamended) & 1.17 \\
Carbon & 0.87 \\
Nitrate & 1.93 \\
Carbon and Nitrate & 3.00 \\
& \\
\hline
\end{tabular}

*Rate after lag phase, from 66 to 165 hours (see Table 8b). 
of $1.44 \mathrm{nmol}$ nitrous oxide $\mathrm{gdw}^{-1} \mathrm{~h}^{-1}$, as shown in Table $9 \mathrm{~b}$. These samples are not carbonlimited. Addition of nitrate, however, increased $\mathrm{N}_{2} \mathrm{O}$ production, suggesting that these samples are nitrate-limited. In the absence of carbon or nitrate limitations in the freshly collected sediment, denitrification proceeded at $3.00 \mathrm{nmol} \mathrm{N}_{2} \mathrm{O} \mathrm{gdw}^{-1} \mathrm{~h}^{-1}$, and resulted in the production of $458 \mathrm{nmol}$ nitrous oxide $\mathrm{gdw}^{-1}$ (Table $8 \mathrm{~b}$ ); all of the total nitrate present was reduced.

These experiments show that microorganisms present in mud from Laguna Cinco denitrified $70-80 \%$ of the added nitrate in nitrate-amended samples and $80 \%-100 \%$ of the

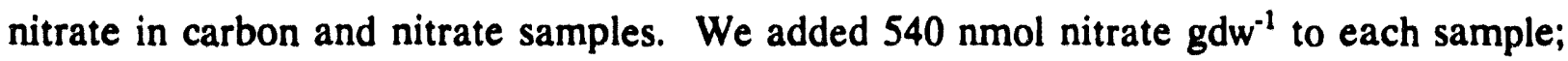
therefore, complete conversion of the nitrate to nitrous oxide should yield $270 \mathrm{nmol} \mathrm{N}_{2} \mathrm{O}$ $\mathrm{gdw}^{-1}$. About $70 \%$ of the added nitrate was reduced to nitrous oxide in the stored sample, or $192 \mathrm{nmoles} \mathrm{N}_{2} \mathrm{O} \mathrm{gdw}^{-1}$ was produced. Freshly collected sediment with added nitrate produced 372 nmoles $\mathrm{N}_{2} \mathrm{O} \mathrm{gdw}^{-1} ; 81 \%$ of the total nitrate present was reduced. This sediment contained a large quantity of indigenous nitrate.

Denitrification in unamended samples provides information about the nutrient conditions in the sediment. If all the available indigenous nitrate was converted to nitrous oxide in the carbon-amended sample, then the stored sediment contained about $40 \mathrm{nmoles}$ of nitrate $\mathrm{gdw}^{-1}$, and the fresh sediment contained $410 \mathrm{nmol} \mathrm{gdw}^{-1}$. Similar conversions of nitrate to nitrous oxide using a pure culture were used to determine sub-ppb concentrations of nitrate in lake waters (Christensen and Tiedje, 1988). Thus, the assay can be used not only to detect the presence and activities of denitrifying organisms, but also to detect easily metabolizable low-molecular-weight organic carbon compounds in the environment (Francis et al., 1989).

The presence of metabolizable carbon and nitrogen compounds in the WIPP surficial environments has important implications. For example, a steady mix of microbial populations can be actively maintained when presented with an adequate supply of a 
limiting nutrient. From the standpoint of the long-term experiment, we have shown in part that the organisms are active in the proposed inoculum.

The results also show that active denitrification under anaerobic conditions occurred in Laguna Cinco mud collected in August 1991 and stored for two months, and in mud collected in December 1991, and assayed within 48 hours. Therefore, the stored and fresh samples contain viable organisms that can be used as an inoculum for the long-term experiment.

\subsubsection{DENITRIFICATION IN G-SEEP}

Figure 6 and Table 10 show denitrification in G-Seep brine. In the carbon and nitrogen amended samples $\sim 84 \%$ of the added nitrate ( 150 nmoles) was converted to $\mathrm{N}_{2} \mathrm{O}$ (62.7 nmoles) after two months of incubation. The dissolved $\mathrm{N}_{2} \mathrm{O}$ in the brine was not determined; hence the $\mathrm{N}_{2} \mathrm{O}$ values reported are not corrected for $\mathrm{N}_{2}$ solubility. Lack of $\mathrm{N}_{2} \mathrm{O}$ production in the unamended and carbon amended samples suggests that G-Seep brine is nitrate-limited. However, in the nitrate amended samples, $45 \%$ of the added nitrate was converted to $\mathrm{N}_{2} \mathrm{O}$, indicating metabolizable carbon is present which eventually became limiting. These results also suggest that the microbes in the brine were able to readily metabolize the added carbon and nitrate via denitrification.

\subsubsection{DENITRIFICATION BY AN AXENIC PURE CULTURE}

A pure culture of a denitrifying bacterium was isolated from the sediment slurry sample during the initial denitrification experiments. The isolate was grown in the following medium: sodium succinate, 5 g; potassium nitrate, $1 \mathrm{~g}$; yeast extract, $0.5 \mathrm{~g}$; WIPP salt ( $20 \%$ $w / v), 1000 \mathrm{~mL} ; \mathrm{pH} 6.85$. The isolate, designated as BWFG-1, was a gram-negative rod, facultative anaerobe, and grew rapidly within 48 hours in the liquid medium. On solid medium, the culture produced circular, convex, light-orange colonies with entire margins. 


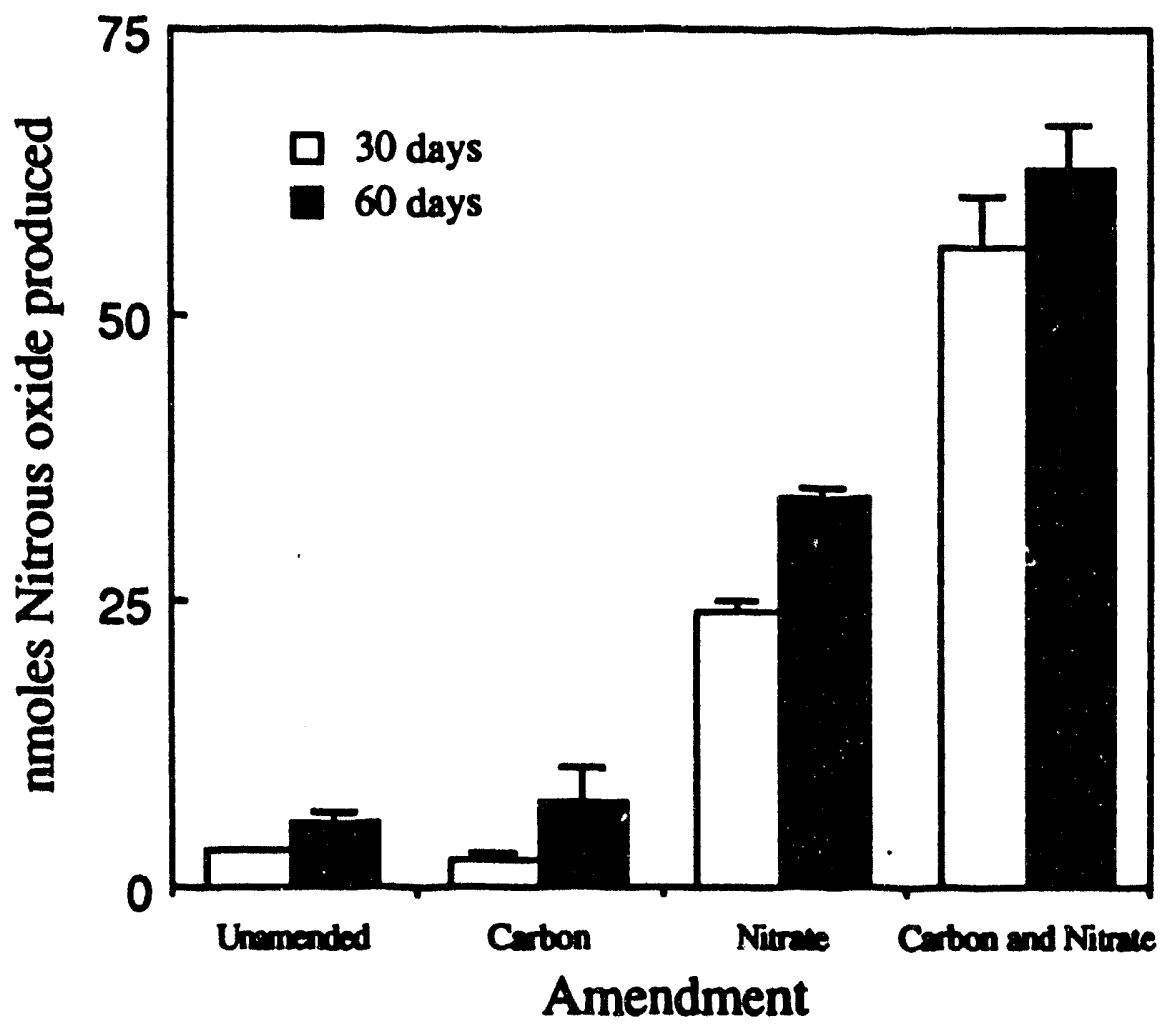

Figure 6. Denitrification in G-Seep Brine. [In C\&N amended samples, $84 \%$ of the added nitrate was converted to nitrous oxide] 
Table 10. Denitrification in G-Seep Brine

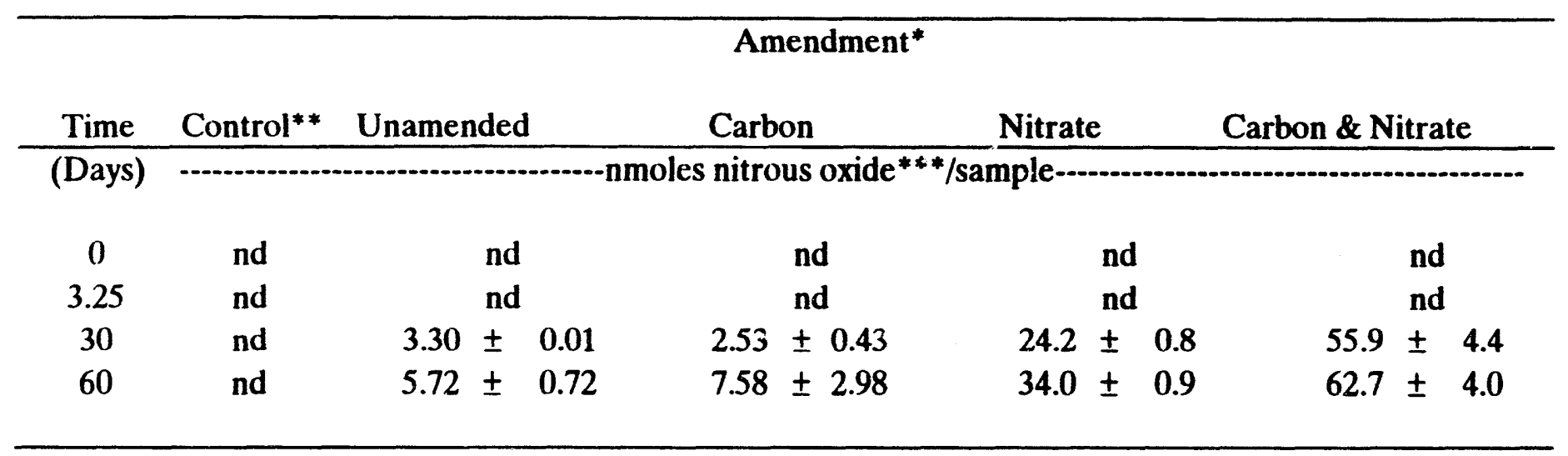

Samples injected with acetylene to accumulate nitrous oxide

* Amendment: Carbon $=1.5$ umol succinate, Nitrate $=150 \mathrm{nmol}$

** Formalin treated samples

*** Dissolved gas concentration not included

nd $=$ none detected 
BWFG-1 is an archaebacterium. It was confirmed by hybridization with fluorescently labeled oligodeoxynucleotide probes complementary to the 16S ribosomal RNA segment specific for archaebacteria (DeLong et al., 1989). Extreme halophiles were previously described in the literature as being archaebacteria, placing them in a distinct phylogenetic group of organisms that contains other genera from extreme environments, such as methanogens, thermoacidophiles, and alkalophiles (Ross et al., 1981).

The rate of denitrification by BWFG-1 was determined by adding $2.5 \mathrm{~mL}$ of a $24 \mathrm{~h}$ culture to $40 \mathrm{~mL}$ of medium in the presence of acetylene. Control samples included uninoculated medium, inoculated samples treated with $0.5 \% \mathrm{v} / \mathrm{v}$ formaldehyde, and inoculated samples without acetylene. Triplicate samples were incubated anaerobically at $30^{\circ} \mathrm{C}$. The number of bacterial cells were counted using the DAPI method.

Production of nitrous oxide by the pure culture of $\left(25 \mu \mathrm{mol} \mathrm{h}^{-1}\right)$ is shown in Figure 7 and Table 11. The bacterium denitrified nitrate at a rate $2.5 \mu \mathrm{mol} \mathrm{h}^{-1}$. About $72 \%$ of the added nitrate $(392 \mu \mathrm{mol})$ was converted to $\mathrm{N}_{2} \mathrm{O}(142 \mu \mathrm{mol})$ in about three days; these $\mathrm{N}_{2}$ values do not include the amount of $\mathrm{N}_{2} \mathrm{O}$ dissolved in the growth medium. There was no accumulation of nitrous oxide in samples incubated without acetylene, indicating complete reduction of nitrate to $\mathrm{N}_{2}$. In Figure 8, the direct counts of the bacteria during the course of denitrification are presented. A marked increase in the number of cells corresponding to nitrous oxide production was observed. The $\mathrm{pH}$ of the growth medium increased from 6.85 to 8.00 after three days, and turbidity measured spectrophotometrically at $600 \mathrm{~nm}$ was 0.08 at $0 \mathrm{~h}, 0.58$ at $29 \mathrm{~h}$, and 0.80 at $50 \mathrm{~h}$.

\subsection{Summary, Short-Term Experimenis}

1. Direct microscopic examination of brine from Nash Draw lakes and from G-Seep showed that between $10^{4}$ to $10^{7}$ cells $/ \mathrm{mL}$ bacteria are present. 


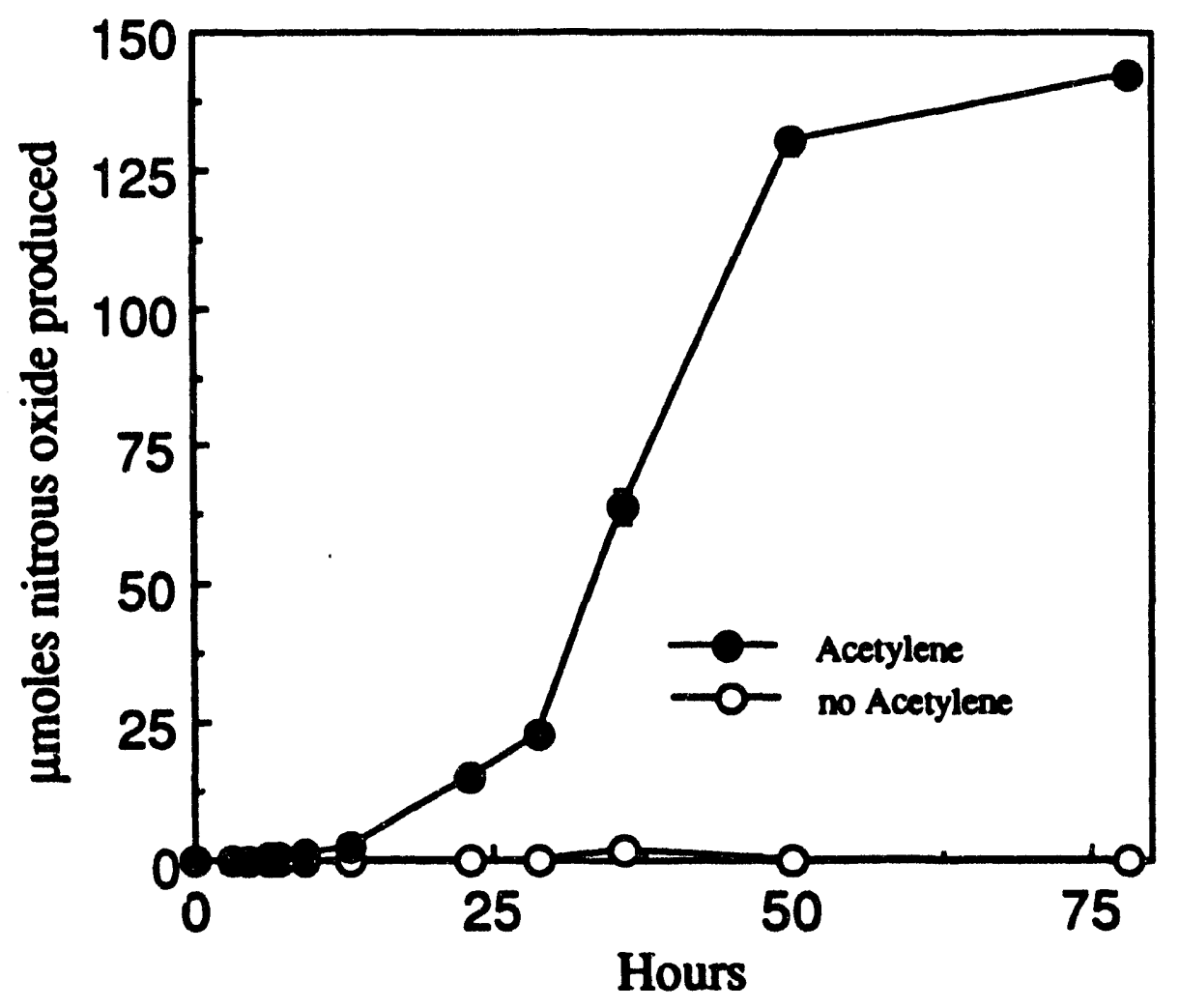

Figure 7. Denitrification by a pure culture of bacteria isolated from the WIPP site. [72\% of added nitrate was converted to nitrous oxide at a rate of $2.5 \mu \mathrm{moles} / \mathrm{h}$ ] 
Table 11. Denitrification by a Pure Culture Isolated from the WIPP Environment: Nitrous Oxide Production Over Time

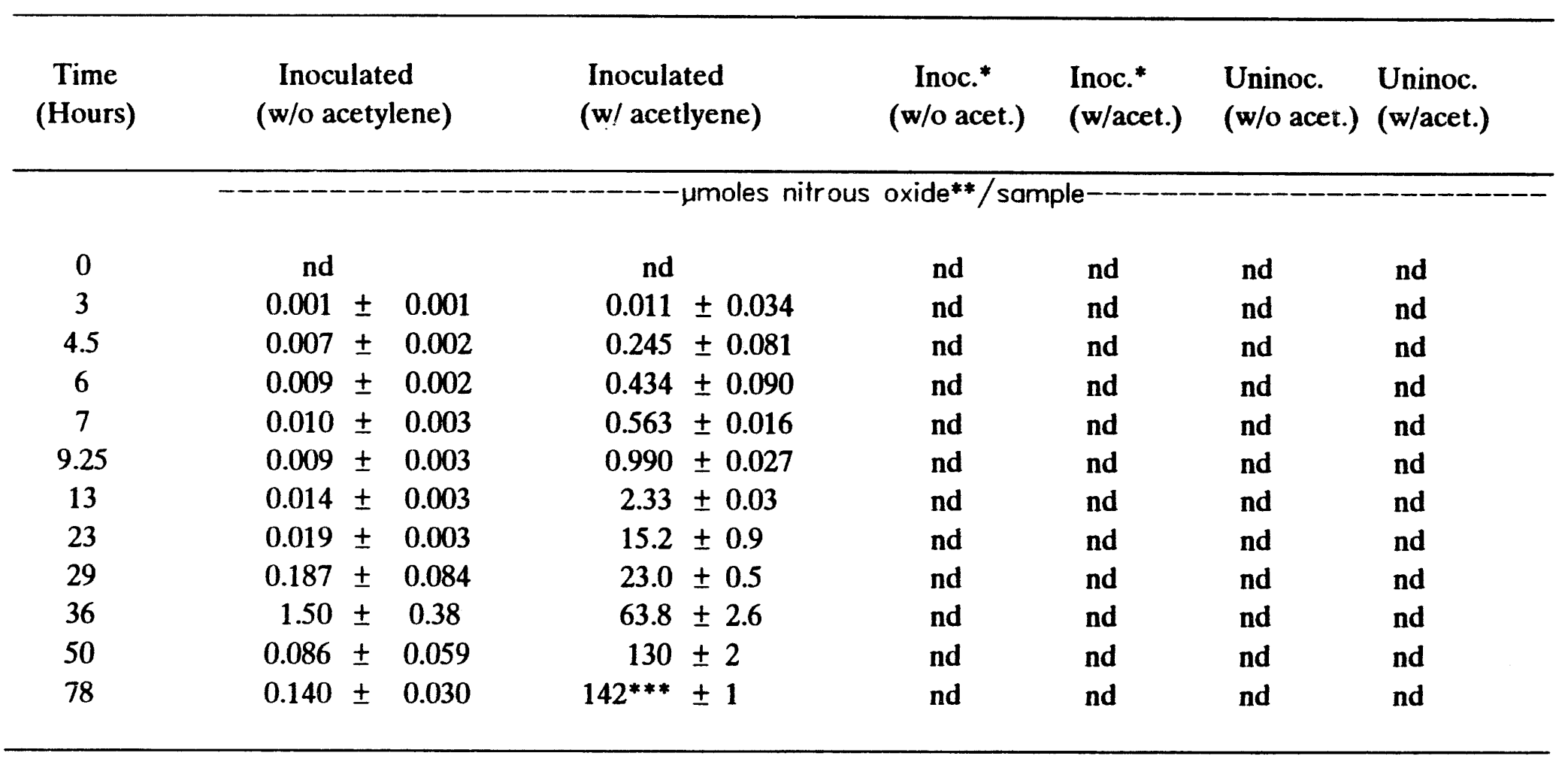

Defined culture medium (per sample): 740 umoles succinate, 392 umoles nitrate, $20 \% \mathrm{w} / \mathrm{v}$ WIPP salt.

* = Sample treated with formalin $(0.5 \%)$

** $=$ Dissolved gas concentration not included

*** $=72 \%$ of nitrate added converted to nitrous oxide

$\mathrm{ND}=$ none detected 


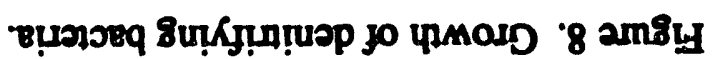

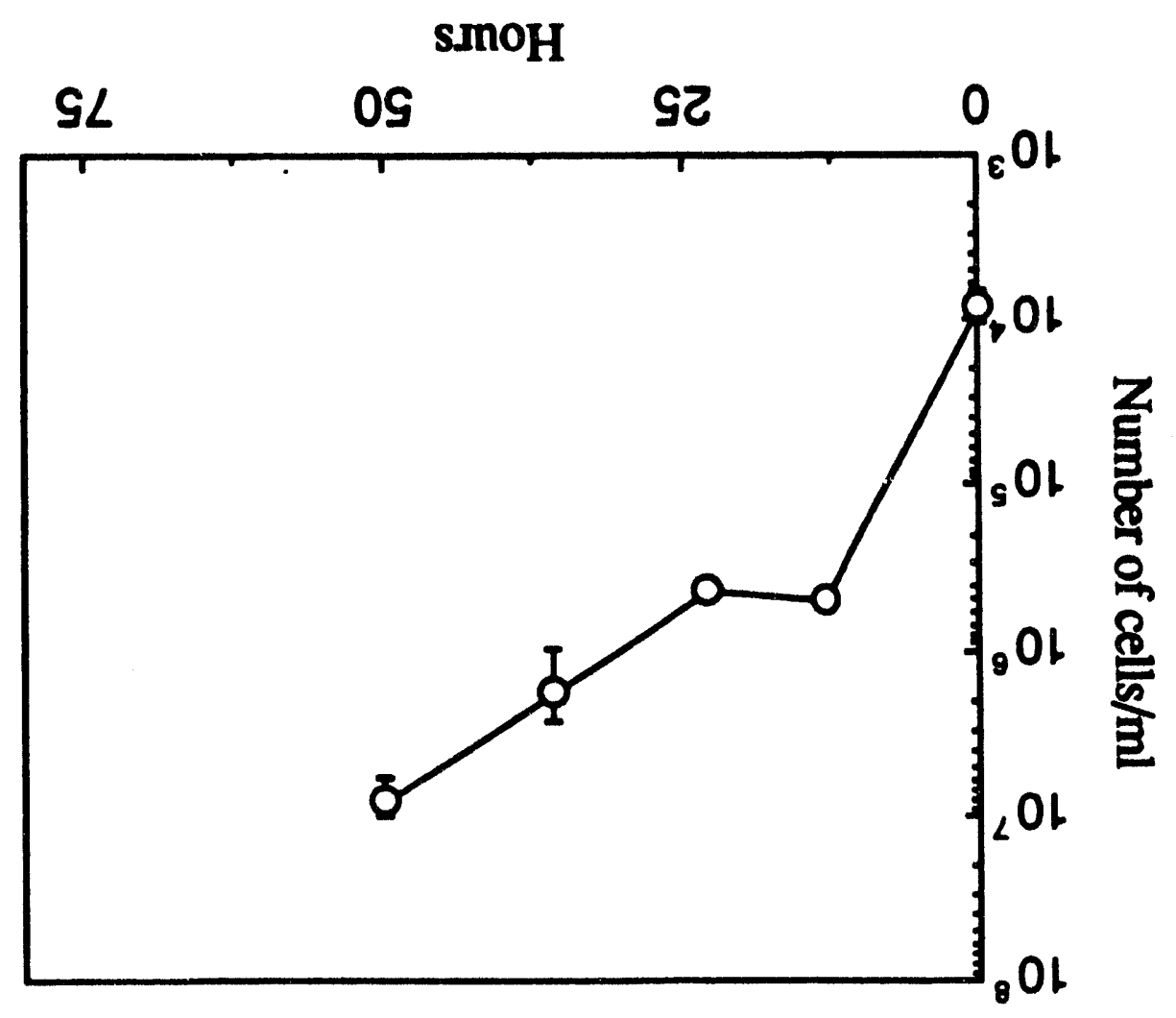


2. Cellulose was degraded by a mixed culture derived from samples consisting of Nash Draw sediment slurry, salt crystals, and G-Seep brine in the presence of added nutrients (nitrate, phosphate, and yeast extract). Cellulose degradation was confirmed by an increase in carbon dioxide production and disintegration of filter paper.

3. Storage of sediment and lake water at $4^{\circ} \mathrm{C}$ for about two months did not significantly affect the activity of microbes in the samples.

4. The denitrification assay is a useful method to rapidly determine the activity of dentrifying microbes in WIPP samples. The assay also confirmed the presence of metabolizable carbon in the sediment and in WIPP brine.

5. Denitrifiers were detected in G-Seep, although their source was not identified.

6. An axenic culture of archaebacteria was isolated from the WIPP site denitrified nitrate at a rate of $2.5 \mu \mathrm{mol} \mathrm{h}^{-1}$. The characteristics and growth rate of this culture have been elucidated for future studies to examine the influence of environmental variables on specific microbial processes in the WIPP repository.

7. Short-term experiments have provided useful information on microbial activity under accelerated test conditions that are relevant to the WIPP repository; further work will include examination of the other anaerobic processes such as fermentation, sulfate reduction, and methanogenesis.

\subsection{LONG-TERM EXPERIMENTS}

\subsection{Objective}

The objective of the long-term study is to determine the rate and extent of gas generation over the long term ( $>2$ years) from cellulose biodegradation under humid and inundated conditions, in the presence and absence of added nutrient. 


\section{Rationale}

The TRU waste that will be placed in the WIPP repository contains an average of about $10 \mathrm{~kg}$ of cellulosic material per drum, approximately $70 \%$ of which is paper (Brush 1990a). Initially, the repository will be ventilated, but the addition of backfill (salt, or bentonite/salt mixture to fill void spaces around waste containers) will seal the drums inside the disposal rooms. Initially, it will also be dry, but after sealing the repository, humid conditions will develop. The ambient humidity is expected to be 18 to $27 \mathrm{~g} / \mathrm{m}^{3}$ (about $74 \%$ relative humidity, RH), and the temperature about $30^{\circ} \mathrm{C}$ (Brush, 1990). Microenvironments of condensed liquid brine may exist under humid conditions. Diffusion of water vapor through high-efficiency particulate, HEPA, air filters on waste containers will result in humid conditions inside the containers. Eventually, corrosion or rupturing of the containers due to salt creep-room closure will expose the waste to salt and backfill. Process sludges from other breached waste containers are expected to be leached by the brine. This is presumed to be the major source of nitrate and phosphate (nutrients) in the repository. The accumulation of potentially intruding brines from the surrounding Salado Formation will most likely begin after sealing the rooms, which will inundate them. In the event of potential, inadvertent human intrusion, fluids may also seep in from the Castille Formation into the Salado Formation. The atmosphere inside the disposal environment will become anaerobic in the short-term (months to years) due to consumption of oxygen by corrosion, radiolysis, and microbial processes acting on the waste materials. Microenvironments of trapped air that contain oxygen will continue to exist after sealing. Radiolysis of organic wastes will deplete oxygen, whereas radiolysis of nitrate-bearing sludges will release oxygen. Radiolysis of brines may also produce some oxygen.

A succession of microbial processes will occur under the changing environmental conditions inside the repository. Environment changes from aerobic to anaerobic, humid to inundated (and possibly back to humid), and asaline to saline will stimulate the activities of (i) microbes initially present in the waste, and (ii) resident and indigenous halotolerant 
or halophilic bacteria in the brine and salt. To examine the influences of various microbial processes on gas generation, sample prepared were treated to simulate the following scenarios.

\subsubsection{Aerobic}

During the early stages of waste emplacement, the environment will be aerobic but will become anaerobic over a period of time after closure because of corrosion, aerobic microbial activity, and radiolytic processes. In these long-term experiments, the cellulose samples will be placed in serum bottles, sealed with air, and incubated. The conditions will be initially aerobic and become anaerobic with time due to consumption of oxygen by aerobes, thus paving the way for anaerobic microbial activity.

\subsubsection{SCENARIO 1}

After emplacement and sealing of waste containers in WIPP disposal rooms, the intact and nearly intact containers will be isolated from backfill and brine. The humidity inside the disposal rooms is expected to be 18 to $27 \mathrm{~g} / \mathrm{m}^{3}$ (about $74 \% \mathrm{RH}$ ), and humidity inside the containers is expected to reach equilibrium with the room environment. The cellulose will be in an asaline, humid, aerobic environment for possibly months, several years, or up to a few decades, as water vapor diffuses through the waste drum particulate filters. Microorganisms capable of cellulose degradation and gas production under these conditions will be active probably under a sub-optimal moisture content.

\subsubsection{SCENARIO 2}

Room closure and corrosion will breach many of the containers and expose the waste material to backfill, salt, and brine. The cellulose is expected to contact the salt and backfill material, and microbial degradation of the cellulose is expected to occur under saline, humid conditions. 


\subsubsection{SCENARIO 3}

Influx of intruding brines from the Salado Formation, brine capillary rise through the backfill, and brine dissolution will all tend to inundate some portion or all of the disposal rooms with brine. Brine inundation will accelerate the onset of anoxic conditions as any residual air pockets are flooded. Process sludge TRU wastes contain significant quantities of nitrate and lesser quantities of phosphate. The breach of these sludge containers and inundation by brine will then transport the nitrate and will bring nonhalophilic, halotolerant and halophilic microbes into contact with cellulose.

Inundation of the WIPP waste by brine by the above mentioned or other processes will accelerate the activities of halophilic and halotelerant microbes. In particular, dentrification activity under microaerophilic and anaerobic conditions could be significant and may contribute to the total quantity and to the proportion of gases produced $\left(\mathrm{N}_{2}, \mathrm{~N}_{2} \mathrm{O}\right.$, and $\left.\mathrm{CO}_{2}\right)$.

\subsubsection{Anaerobic}

At least a portion of the WIPP repository wastes will be anaerobic at the start (within their containers possibly due to radiolysis and microbial action at the initial stages) and remain anaerobic thereafter. Under these conditions, short-term (i.e., operational phase) and in the long-term, degradation of cellulosic waste by anaerobic microorganisms could be significant.

\subsubsection{SCENARIO 4}

Some of the cellulose in the disposal environment may become anaerobic before any significant aerobic microbial activity. Cessation of air flow from closure of the disposal rooms, and oxic corrosion plus radiolysis, may bring about anoxic conditions in a humid environment. If the cellulose is exposed to salt under humid conditions, halotolerant or halophilic microbes that can grow in humid and anoxic environments may be involved in 
degrading of cellulose. With the onset of anoxic conditions, alternate electron acceptors such as nitrate and sulfate will be used by microbes in the degradation of cellulose and its product intermediates.

\subsubsection{SCENARIO 5}

With the onset of brine intrusion in the disposal rooms, inundation will be more likely to cause anaerobiosis by forcing out any residual trapped air. Cellulose in contact with brine may undergo degradation by halophilic and halotolerant microbes present in the brine and waste. Because of the breaching of the waste containers, it is likely that nitrate originating in the sludges will be transported by the brine. It may come in contact with cellulosic wastes and enhance the degradation of cellulose.

Scenarios 3 and 5 will be examined in the long-term inundated experiment. Scenarios 1, 2 and 4 will be examined in a long-term humid experiment in CY1993. Figures 9 through 12 give the complete treatment matrix for the long-term inundated experiments.

\subsection{Materials and Methods}

\subsubsection{Cellulosics}

Simulated TRU cellulosic waste material was composed of four types of paper: (i) filter paper, (ii) white paper towel, (iii) brown paper towel, and (iv) Kimwipes (lintless tissue wipes). These papers are typical cellulosic wastes from laboratory and process activities. The four paper types were cut into strips in a large paper shredder, and then cut into $1 \mathrm{~cm}$ $x 1 \mathrm{~cm}$ squares.

Samples of shredded paper types, each weighing $1.25 \mathrm{~g}$, were thoroughly mixed and added to $160 \mathrm{~mL}$ acid washed $\left(10 \% \mathrm{HCl}\right.$ ), sterile (autoclaved at $120^{\circ} \mathrm{C}, 20 \mathrm{psi}$ for $20 \mathrm{~min}$ ) serum bottles. 


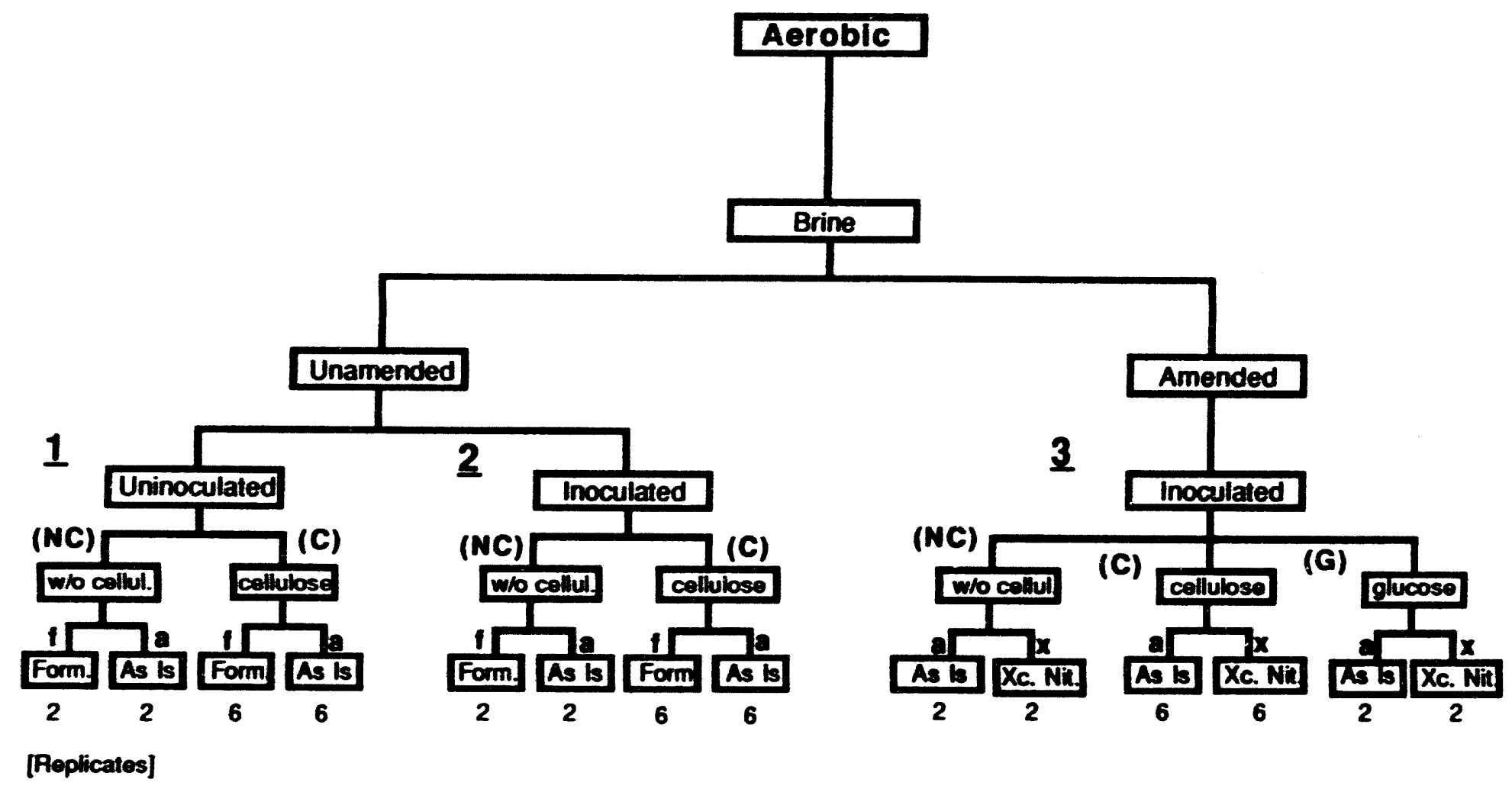

Figure 9. Long-term inundated experiment treatment matrix (acrobic samples). 


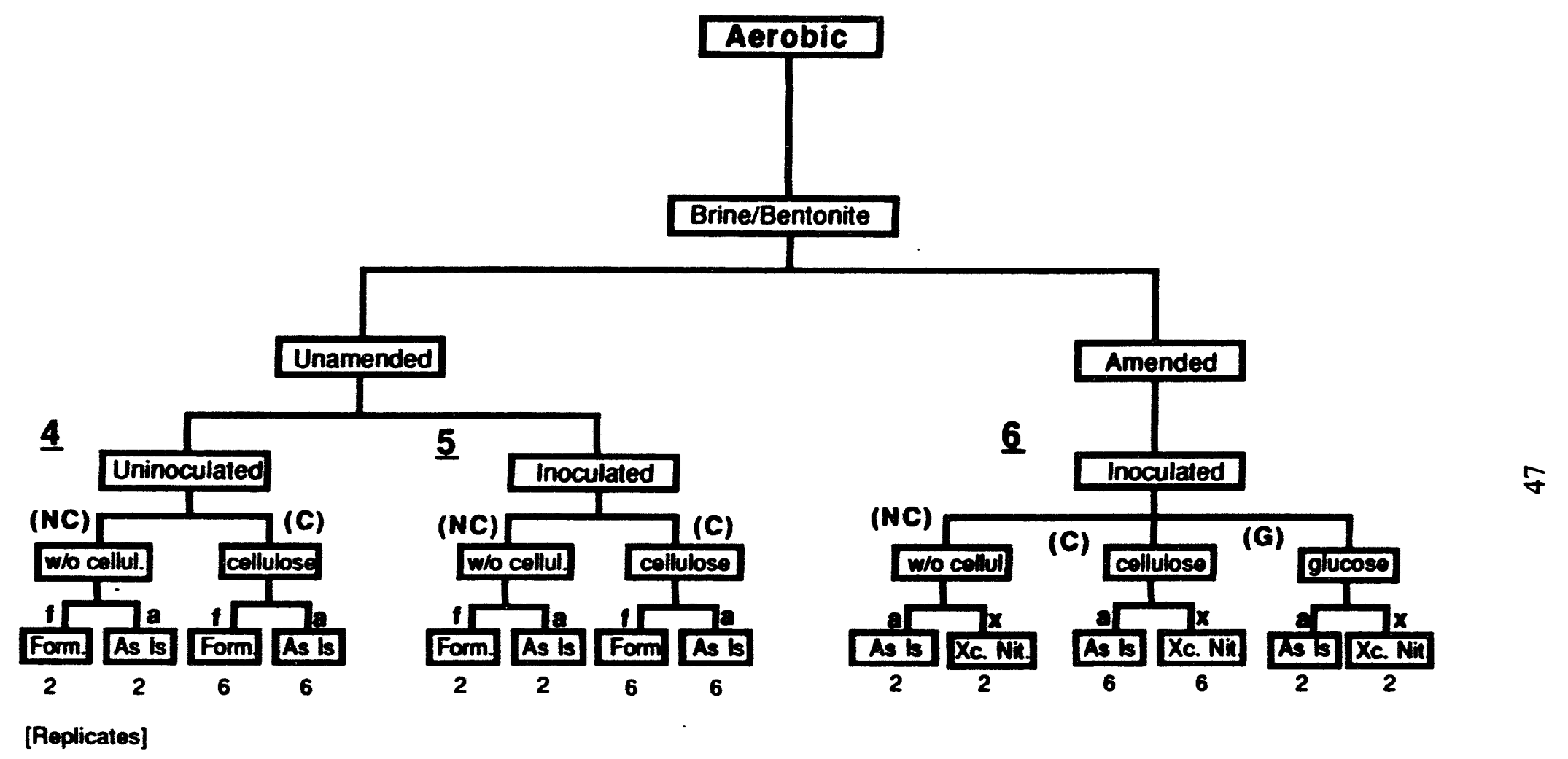

Figure 10. Long-term inundated experiment treatment matrix (aerobic samples containing bentonite). 


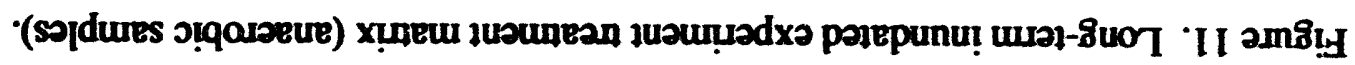

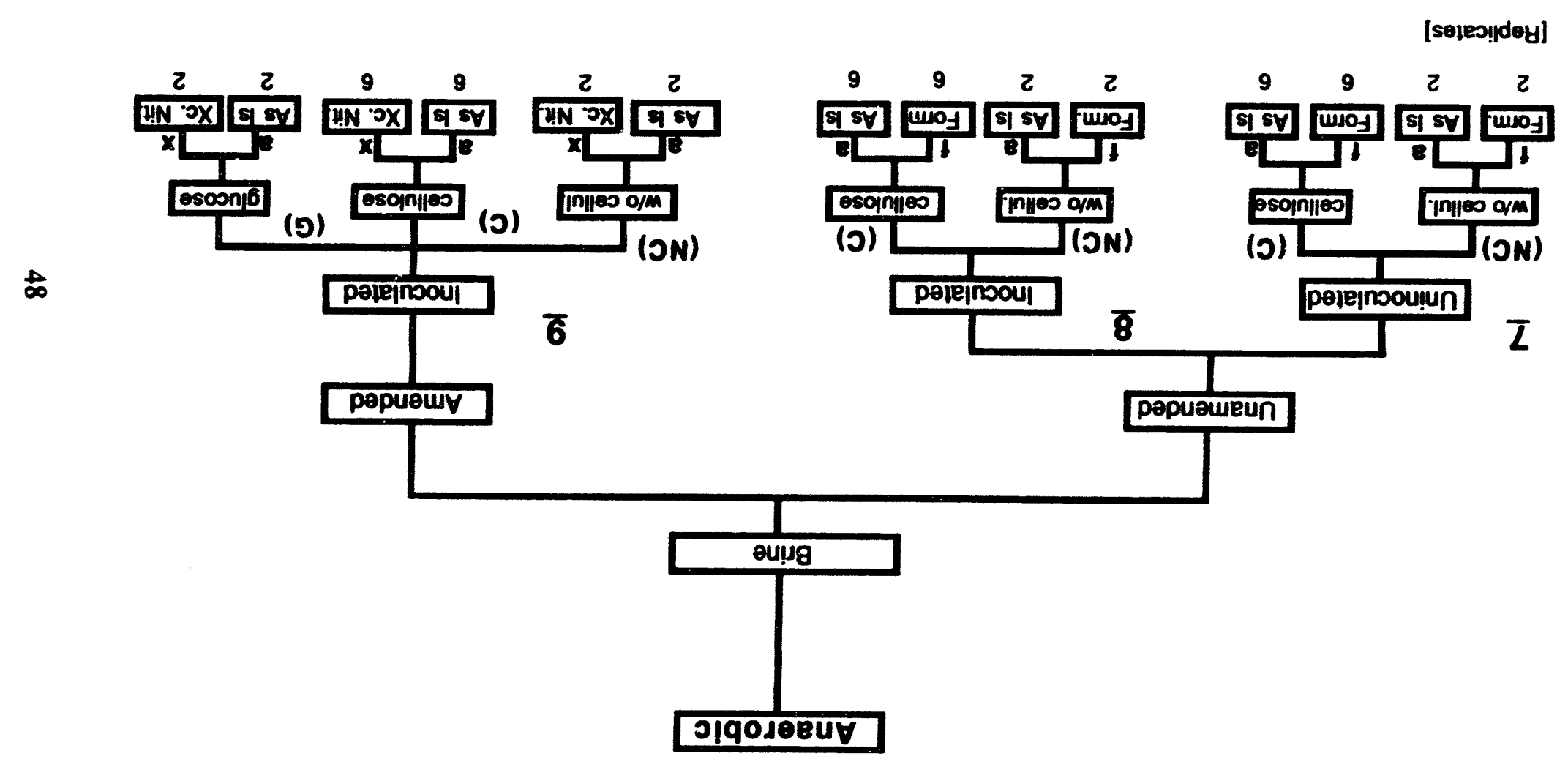




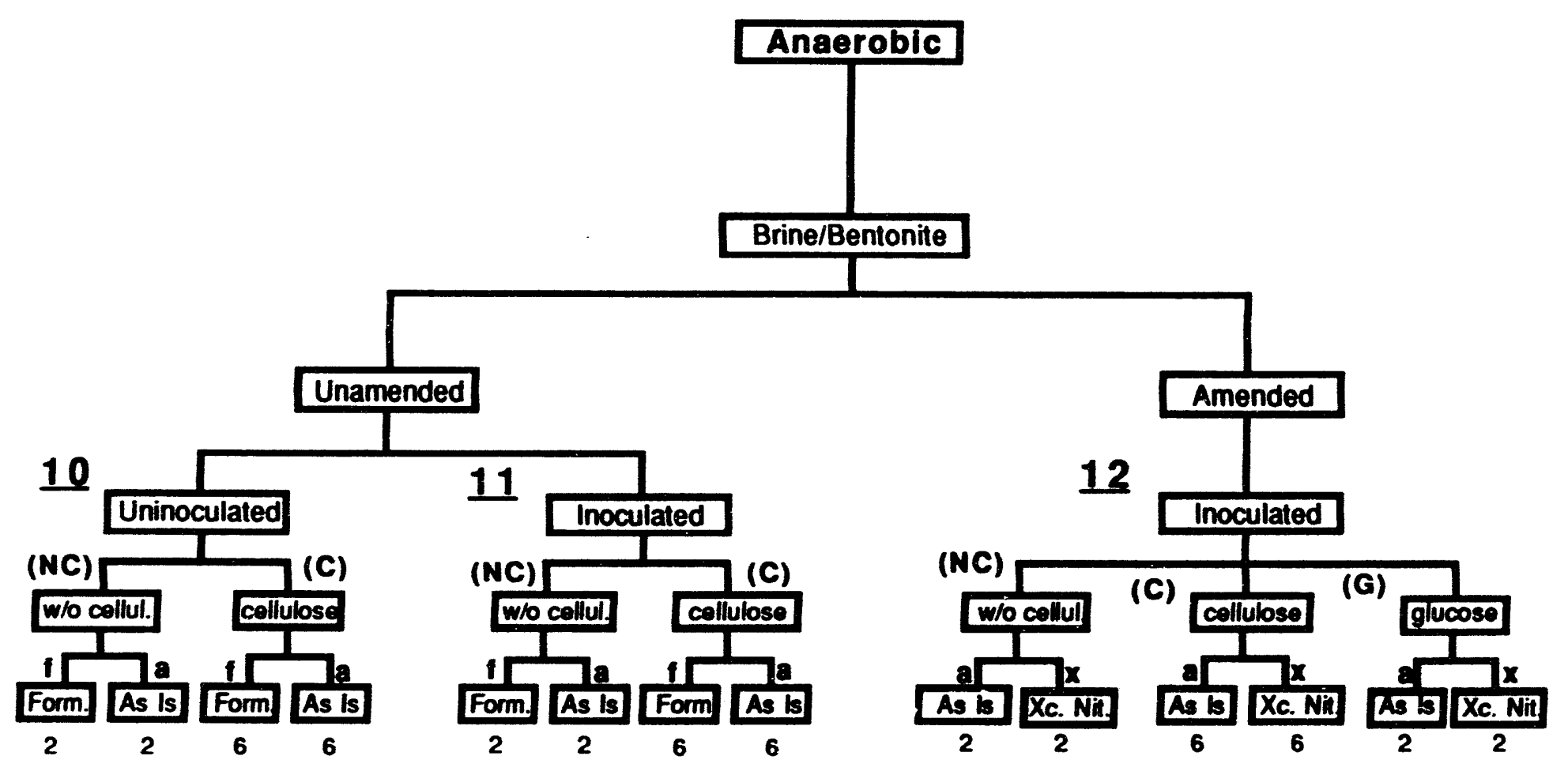

[Replicates]

Figure 12. Long-term inundated experiment treatment matrix (anaerobic samples containing bentonite). 


\subsubsection{WIPP Brine}

Fifteen liters of G-Seep \#9 brine were provided by SNL and stored at $4^{\circ} \mathrm{C}$ until use.

\subsubsection{Bentonite}

Bentonite clay in two one-L containers was provided by SNL. The bentonite was a granular MX-80 Volclay bentonite available from the American Colloid Company of Belle Fourche, SD (Table 12).

\subsection{4 inoculum}

The microbial inoculum used in these studies were obtained from the following three sources (Table 13): (i) mud and brine from Nash Draw: collected on December 12, 1991 and stored at $4^{\circ} \mathrm{C}$, the mud was stored anoxically in serum bottles, (mud samples were filtered through sterile cotton in a nitrogen-filled glove box to remove large particulates); (ii) brine from the WIPP underground workings: $200 \mathrm{~mL}$ of G-Seep were collected on December 12, 1991; and (iii) asaline inoculum from laboratory contamination: $2.5 \mathrm{~g}$ of dust containing asaline microorganisms was gathered from labs in Bldg. 318 at BNL.

The mud, brine, and dust samples were then mixed together in a sterile beaker in a nitrogen-filled glove box. The total volume of the mixed inoculum was $583 \mathrm{~mL}$. The activity of the mixed inoculum was examined by incubation under aerobic and anaerobic conditions in the presence of metabolizabled substrate. The results are presented in Appendix E. 
Table 12. Composition of Bentonite*.

Chemical

Composition

Montmorillonite

Content

Typical

Chemical

Analysis
$(\mathrm{NaCa})_{35}\left(\mathrm{Al}_{1.60} \mathrm{Fe}_{.15} \mathrm{Mg}_{.25}\right)$

$\left(\mathrm{Si}_{3.90} \mathrm{Al}_{.10}\right) 0_{10}(\mathrm{OH})_{2}$

90 Percent

Silica

Alumina

Iron (Ferric)

Iron (Ferrous)

Magnesium

Sodium and

Potassium

Calcium

Crystal Water

Trace Elements
$63.02 \% \mathrm{SiO}_{2}$ $21.08 \% \mathrm{Al}_{2} \mathrm{O}_{3}$

$3.25 \% \mathrm{Fe}_{2} \mathrm{O}_{3}$

$0.35 \% \mathrm{FeO}$

$2.67 \% \mathrm{MgO}$

$2.57 \% \mathrm{Na}_{2} \mathrm{O}$

$0.67 \% \mathrm{CaO}$

$5.64 \% \mathrm{H}_{2} \mathrm{O}$

$0.72 \%$
Exchangeable Ions

(Milli-equivalents/

$100 \mathrm{~g}$ )

Moisture Content

pH
Sodium

Calcium

Magnesium

$10 \%$ Maximum as Shipped

$8.5-10.5$
$55-65$

15-25

10-15

- Data provided by the American Colloid Company, Skokie, IL. 
Table 13. Composition of Mixed Inoculum.

\begin{tabular}{lcc} 
Source & $\begin{array}{c}\text { Mud Slurry } \\
(\mathrm{mL})\end{array}$ & $\begin{array}{c}\text { Brine } \\
(\mathrm{mL})\end{array}$ \\
\hline Laguna Quatro Mud and Brine & 60 & 40 \\
Laguna Cinco Mud and Brine & 35 & 40 \\
Laguna Tres South Mud and Brine & 13 & 40 \\
Lindsey Lake Mud and Brine & 50 & 40 \\
Surprise Springs Mud and Brine & 25 & 40 \\
G-Seep Brine & & 200 \\
\hline Total & 183 & 400 \\
\hline
\end{tabular}




\subsection{Sample Treatments}

The treatments consisted of (a) $100 \mathrm{~mL}$ of brine, and (b) $100 \mathrm{~mL}$ of brine and $5 \mathrm{~g}$ mixed cellulosic papers. The samples were incubated with and without nutrients, which consisted of yeast extract $(0.05 \%)$, potassium phosphate dibasic $(0.1 \%)$, and ammonium nitrate $(0.1 \%)$. Some samples also received excess nitrate in the form of potassium nitrate $(0.5 \%)$.

\subsubsection{Anaerobic Sample Preparation}

The serum bottles containing the mixed cellulosic papers were flushed with nitrogen and placed inside an anaerobic, nitrogen-containing glove box for 24 hours before inoculation to remove any trapped air. G-Seep brine $(10 \mathrm{~L})$ was removed from storage at $4^{\circ} \mathrm{C}$ and equilibrated overnight at room temperature. One hundred $\mathrm{mL}$ of the brine solutions (with and without nutrients or excess nitrate) were added to sample bottles with and without bentonite containing either no cellulose, cellulose, or glucose. Bentonite $(6 \mathrm{~g})$ was added to separate sample bottles inside the glove box to determine its influence on gas production. The samples were gently mixed to distribute the bentonite.

The microbial inoculum prepared from various sources was continually mixed and $4 \mathrm{~mL}$ was added to specific samples $(3.8 \% \mathrm{~V} / \mathrm{V}$ inoculum). The samples were gently mixed (to blend the inoculum) and then capped with butyl rubber stoppers. Control samples received $3 \mathrm{~mL}$ of $37 \%$ formaldehyde to give a final concentration of $1 \%$ formaldehyde.

\subsubsection{Aeroblc Sample Preparation}

Aerobic (sealed) samples were prepared as described above with the following exceptions: 1) brine solutions were not purged with ultra high-purity (UHP) $N_{2}, 2$ ) the mixed inoculum was removed from the glove box; 3) brine was added to the bottles, inoculated, and capped with butyl rubber stoppers outside of glove box, thereby sealing air 
in the headspace. Appendix $\mathrm{C}$ has a detailed description of all the treatments (aerobic and anaerobic) and the number of replicate samples. All samples were placed in a $30 \pm 2{ }^{\circ} \mathrm{C}$ incubator.

\subsubsection{Gas Analyses}

The headspace gas of select samples was analyzed for total gas production, carbon dioxide, and nitrous oxide at time 0 (January 29,1992$)$ and thereafter at monthly intervals. Control samples were analyzed less frequently. The methods used for the headspace gas analyses are presented in Appendix B.

\subsection{RESULTS AND DISCUSSION}

The treatments consist of cellulose samples which were (i) uninoculated, (ii) inoculated with a mixed inoculum, (iii) inoculated and amended with nutrients, (yeast extract $(0.05 \%)$, potassium phosphate $(0.1 \%)$, and ammonium nitrate $(0.1 \%)$ ), and (iv) inoculated with nutrients plus excess nitrate ( $0.5 \%$ potassium nitrate).

The results presented for aerobic and anaerobic samples represent the amount of gas produced per gram of cellulose (Figures 13 through 24). A detailed description of the procedure used to calculate the results are given in Appendix D. Tables 1 through 12 in Appendix D present data on a per sample basis, and Tables 13 through 24 in Appendix D present data on a per gram cellulose basis. Gas production rates on a per gram cellulose per day basis are presented in Table 14, and on per drum of waste per year basis in Table 15. 


\subsection{Aerobic Treatments}

\subsubsection{Total Gas Production}

Figure 13 shows the total gas produced in samples incubated with an initial atmosphere of air (aerobic). The formalin-treated control samples showed no increase in total gas production, and in fact showed a slight decrease. Likewise, uninoculated and inoculated samples which received no nutrients showed a slight decrease in total gas $\left(-0.18 \mathrm{~mL} \mathrm{~g}^{-1}\right.$ cellulose and $-0.34 \mathrm{~mL} \mathrm{~g}^{-1}$ cellulose respectively (Table 13 , Appendix D)). The decrease in total gas may be due, in part, to sampling. A decrease in gas production was more evident in inoculated samples because of oxygen consumption, indicating the start of microbial activity, (oxygen was not analyzed in these samples but is planned for the future). In the nutrient-amended inoculated samples, an initial decrease in gas volume $\left(-0.27 \mathrm{~mL} \mathrm{~g}^{-1}\right.$ cellulose at 45 days) was followed by an increase after 69 days to $0.86 \mathrm{~mL} \mathrm{~g}^{-1}$ cellulose at 200 days at a rate of $0.008 \mathrm{~g}^{-1}$ cellulose day ${ }^{-1}$. This rate was calculated from linear slope of gas production from 69 to 200 days. Excess nitrate stimulated the rate of gas production $\left(0.023 \mathrm{~mL} \mathrm{~g}^{-1}\right.$ cellulose day ${ }^{-1}$ after 69 days) resulting in a total of $4.42 \mathrm{~mL} \mathrm{~g}^{-1}$ cellulose at 200 days. This stimulatory effect was also evidenced by the lack of a long lag-phase (see Figure 13) and was a result of the metabolism of dissolved carbon in the presence of nitrate.

Total gas production in aerobic samples containing bentonite is presented in Figure 14. Uninoculated and inoculated samples, with no added nutrients, did not produce gas. Inoculated samples containing nutrients produced $4.38 \mathrm{~mL}$ of gas $\mathrm{g}^{-1}$ cellulose after 200 days (Table 14, Appendix D), at a rate of $0.028 \mathrm{~mL} \mathrm{~g}^{-1}$ cellulose day ${ }^{-1}$. In the presence of ex ess nitrate, the total production increased to $6.07 \mathrm{~g}^{-1}$ cellulose at 200 days at a rate of $0.034 \mathrm{~g}^{-1}$ cellulose day ${ }^{-1}$. Enhanced total gas production was seen in samples containing bentonite, and was apparently due to a combination of abiotic and biotic factors, which are evident upon examining carbon dioxide evolution in the presence of bentonite. 


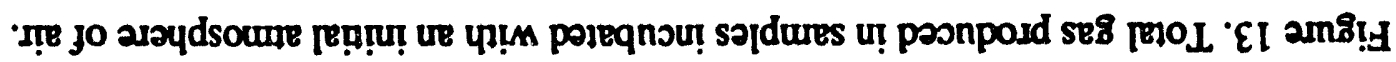

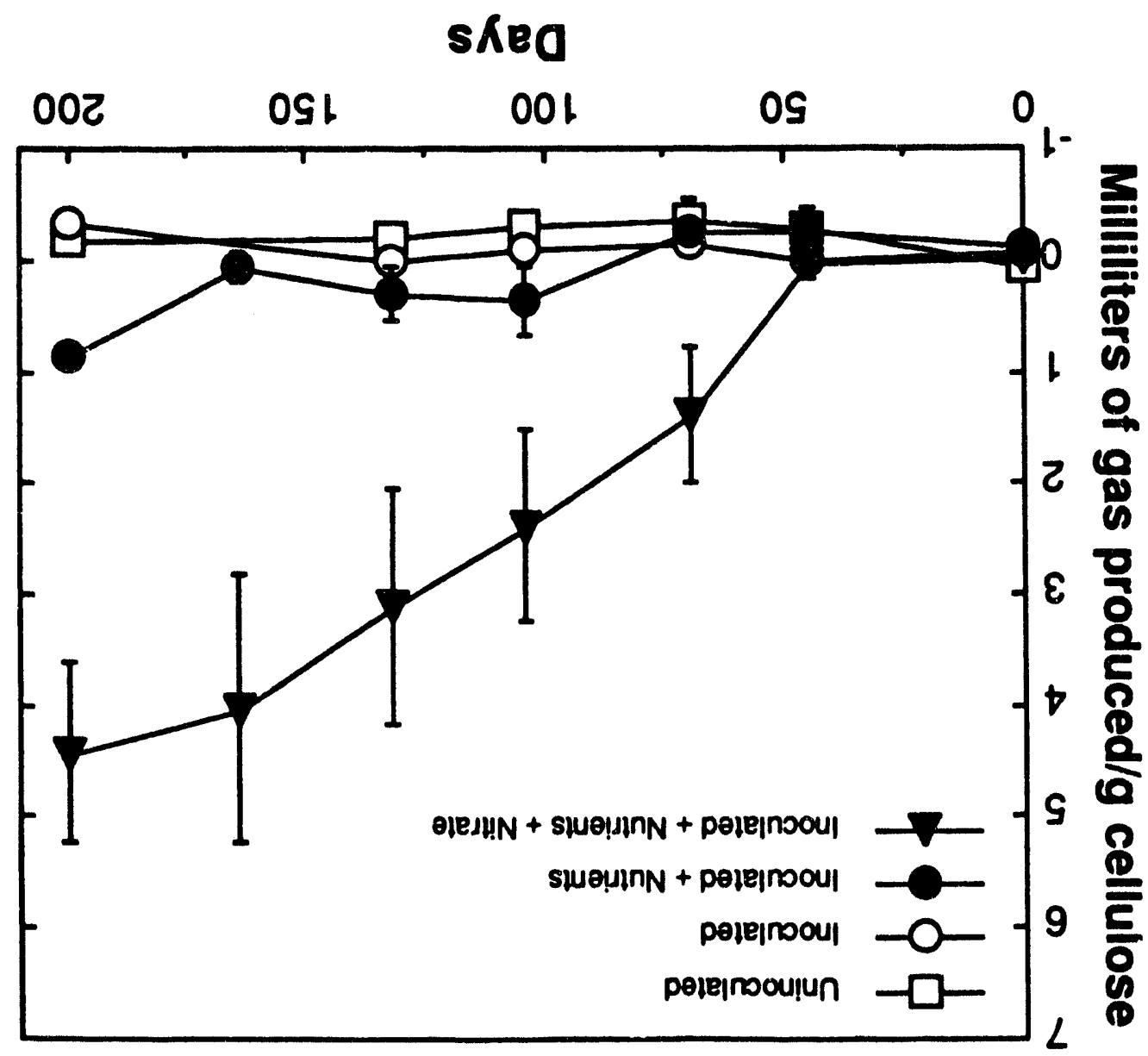




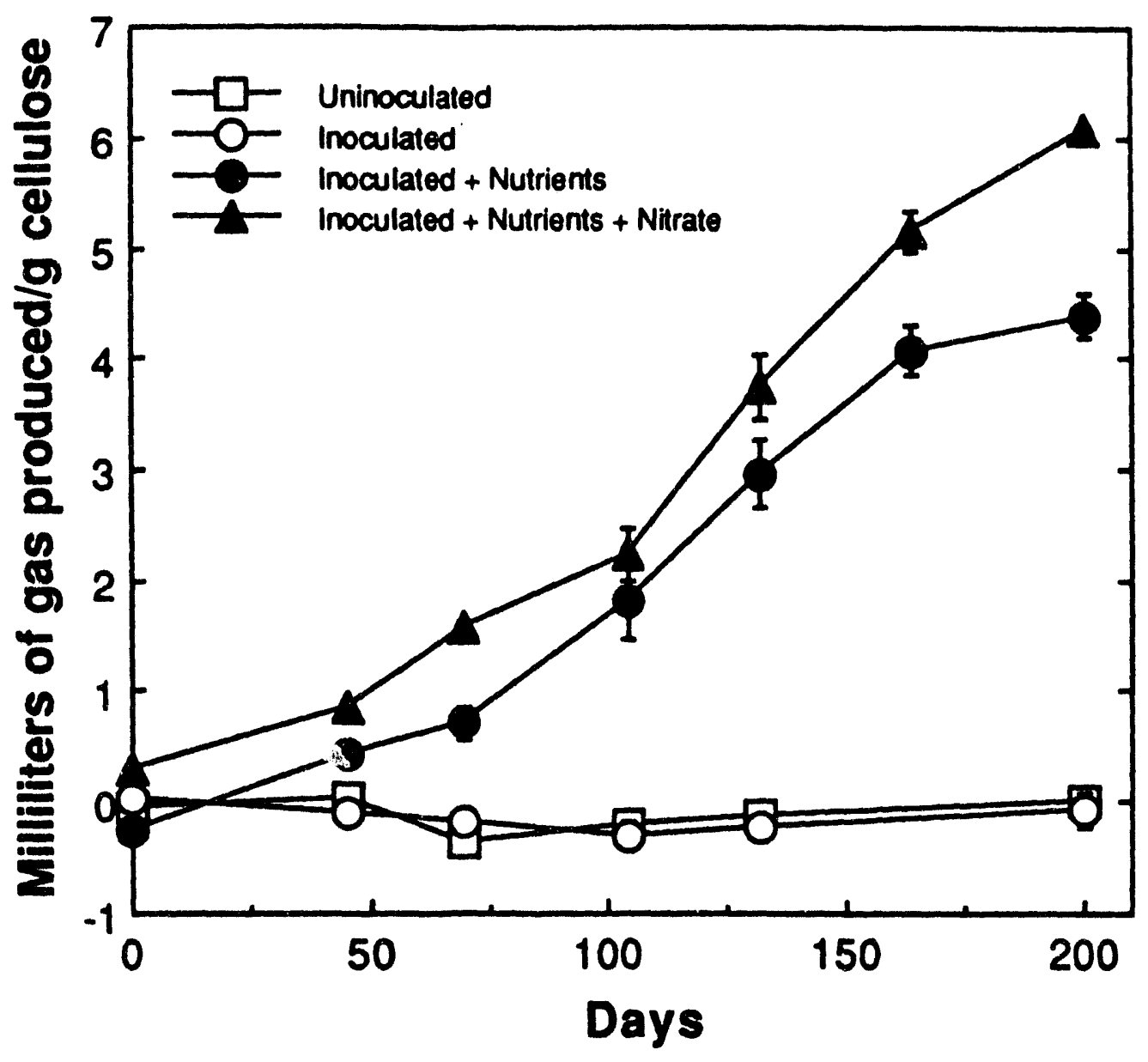

Figure 14. Total gas produced in samples containing bentonite incubated with an initial atmosphere of air. 
Extrapolation of the gas production rates from $\mathrm{mL}$ per $\mathrm{g}$ cellulose per day to $\mathrm{mol}$ per drum of waste per year is accomplished with the following conversion factors: for an assumed average drum of transuranic waste, with about $10 \mathrm{Kg}$ of cellulosic materials, a total gas generation rate of $0.01 \mathrm{~mL} \mathrm{~g}^{-1}$ cellulose day ${ }^{-1}$ corresponds to a gas generation rate of 1.6 mol gas per drum per year.

\subsubsection{Carbon Dioxide Production}

Uninoculated samples produced $4.00 \mu \mathrm{mol}$ of $\mathrm{CO}_{2} \mathrm{~g}^{-1}$ cellulose at 200 days, which was slightly less than the formalin treated controls $\left(7.62 \mu \mathrm{mol} \mathrm{g}_{\text {cellulose }}{ }^{-1}\right)$, as shown in Figure 15 (and Table 15, Appendix D). However, inoculated samples produced $8.30 \mu \mathrm{mol}$ of $\mathrm{CO}_{2}$ $\mathrm{g}^{-1}$ cellulose, slightly higher than uninoculated and formalin-treated controls, due to the onset of microbial activity. Inoculated samples containing nutrients produced $40.8 \mu \mathrm{mol}$ carbon dioxide $\mathrm{g}^{-1}$ cellulose at 200 days, at a rate of $0.283 \mu \mathrm{mol} \mathrm{g}^{-1}$ cellulose day ${ }^{-1}$. In the presence of excess nitrate, $95.6 \mu \mathrm{mol}$ carbon dioxide $\mathrm{g}^{-1}$ cellulose were produced at a rate of $0.484 \mu \mathrm{mol} \mathrm{g}^{-1}$ cellulose day ${ }^{-1}$, more than twice that of samples without excess nitrate. Evidence of the growth of halophilic bacteria was noted in nutrient-amended samples by a red/pink color at the bottom of the bottles. This red coloration, characteristic of halophiles, is caused by the presence of bacteriorhodopsin, a 50-carbon carotenoid pigment. This coloration was not seen in formalin-treated controls or unamended samples.

The addition of bentonite resulted in the production of a significant amount of abiotically produced carbon dioxide in samples without cellulose. Table 5, Appendix D shows that carbon dioxide increased from $17.7 \mu \mathrm{mol} \mathrm{sample}^{-1}$ to $40.0 \mu \mathrm{mol} \mathrm{sample}^{-1}$ without cellulose, inoculum and nutrients (sample $4(\mathrm{NC})-\mathrm{a}$ ), compared to the same treatment without bentonite. The latter treatment showed a slight increase, from 1.38 to $2.18 \mu \mathrm{mol}$ sample $^{-1}$ (see Table 2, Appendix D). Formalin-treated control samples also showed the same trend. The net effect was an increase in abiotically produced carbon dioxide (approximately $40 \mu \mathrm{mol} \mathrm{sample}{ }^{-1}$, (Table 5) by the addition of bentonite. Carbon dioxide production was insignificant in uninoculated unamended samples, (Figure 16). The 


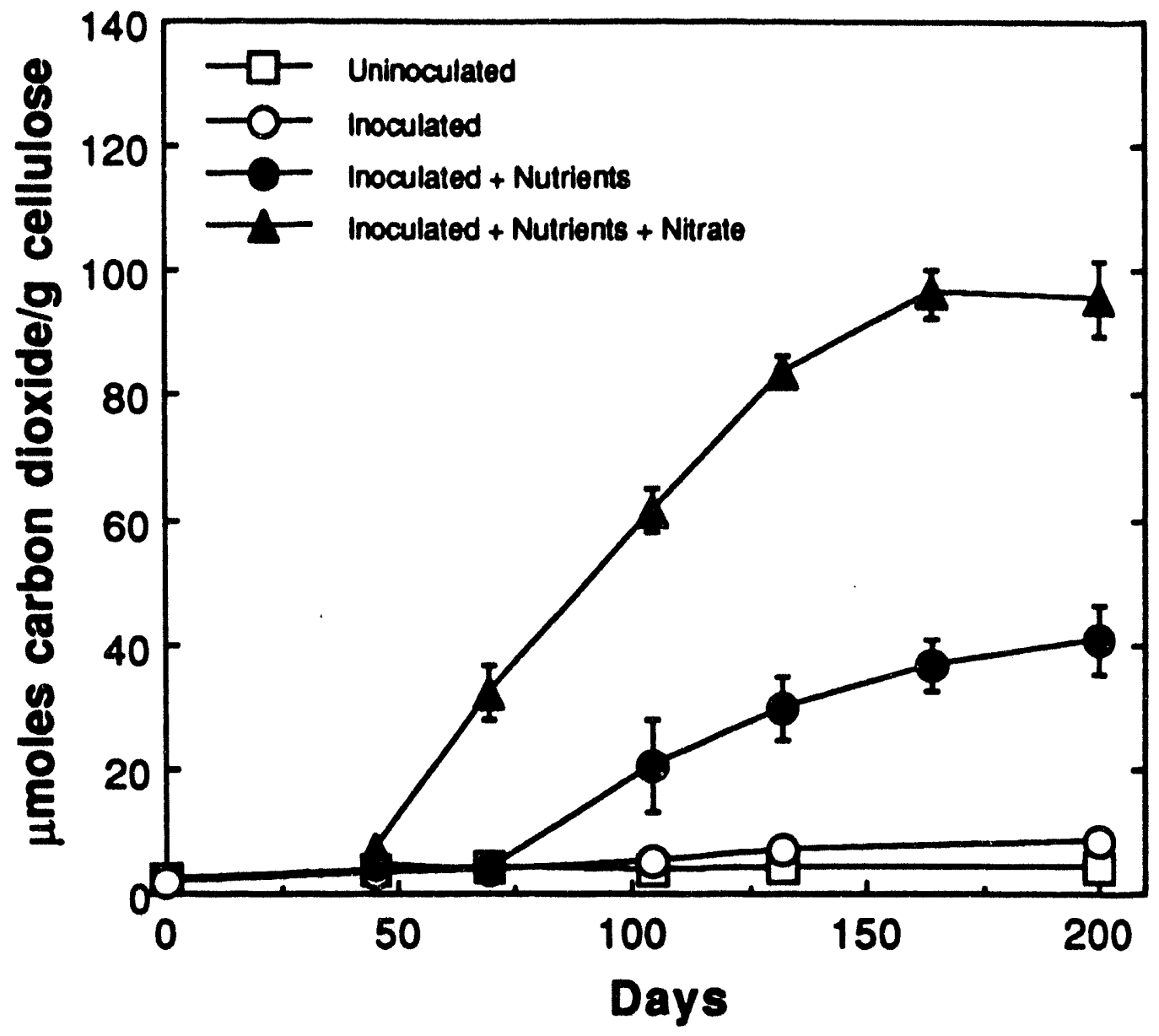

Figure 15. Carbon dioxide produced in samples incubated with an initial atmosphere of air. 


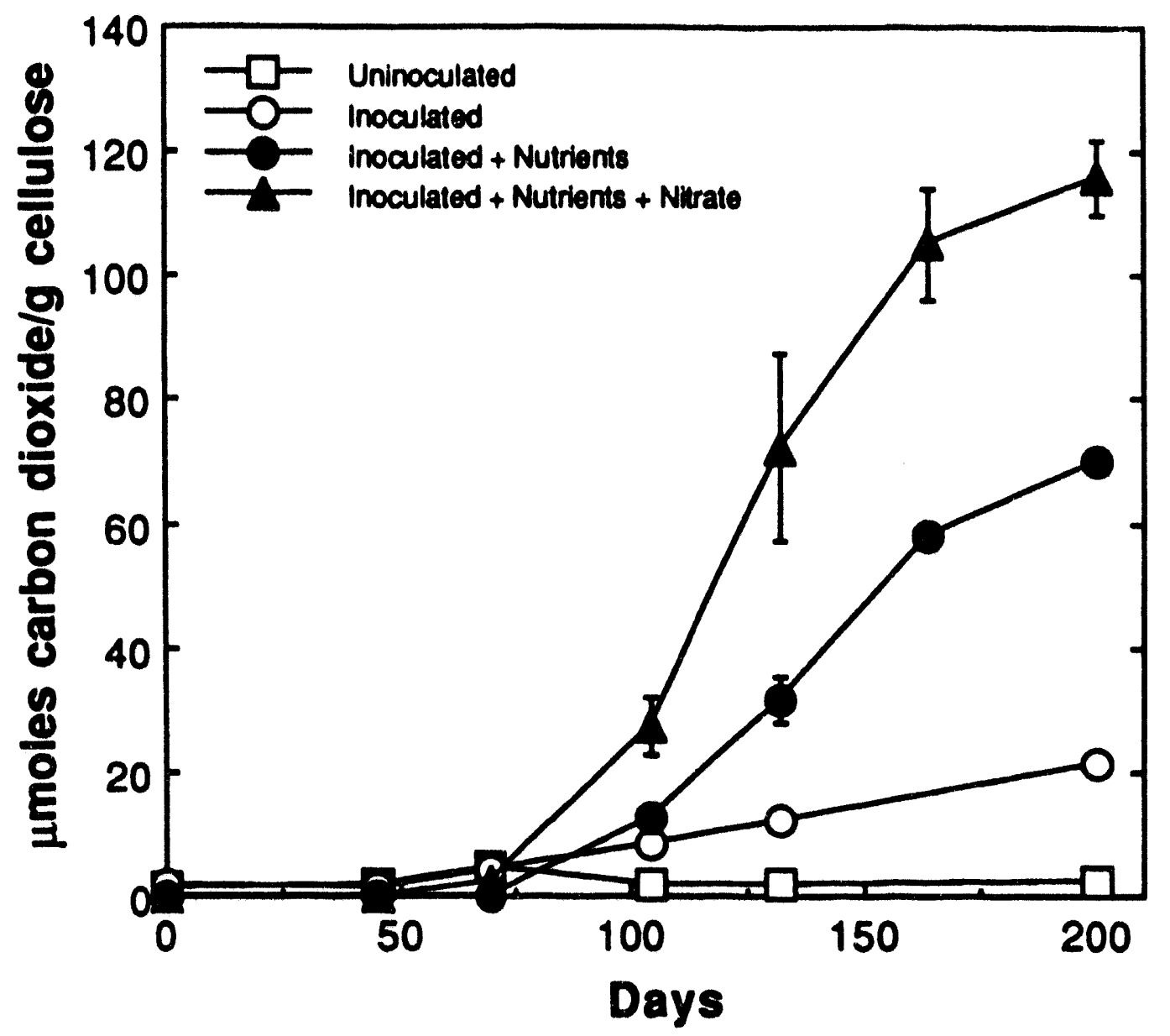

Figure 16. Carbon dioxide produced in samples containing bentonite incubated in an initial atmosphere of air. 
inoculated unamended samples with bentonite produced $21.5 \mu \mathrm{mol} \mathrm{g}^{-1}$ cellulose at 200 days (Figure 16), whereas the samples without bentonite produced $8.30 \mu \mathrm{mol} \mathrm{g}^{-1}$ cellulose (Table 15, Appendix D). Nutrient-amended inoculated samples produced $69.8 \mu \mathrm{mol}$ carbon dioxide $\mathrm{g}^{-1}$ cellulose, whereas nutrient-amended inoculated samples with excess nitrate produced 116 $\mu \mathrm{mol} \mathrm{g}^{-1}$ cellulose at 200 days. After an initial lag of 69 days, carbon dioxide was produced at a rate of 0.533 and $0.869 \mu \mathrm{mol} \mathrm{g}^{-1}$ cellulose day ${ }^{-1}$ in nutrient amended and nutrient amended plus excess nitrate samples, respectively. These rates of carbon dioxide production are higher than the same treatments without bentonite $\left(0.283\right.$ and $0.484 \mu \mathrm{mol} g$ cellulose ${ }^{-1}$ day $^{-1}$, respectively). The buffering effect of $\mathrm{CaCO}_{3}$, as well as minerals and trace elements including $\mathrm{Fe}, \mathrm{Al}, \mathrm{Si}$ and exchangeable cations $\left(\mathrm{Na}^{+}, \mathrm{Ca}^{2+}, \mathrm{Mg}^{2+}\right)$ and anions $\left(\mathrm{Cl} ; \mathrm{SO}_{4}{ }^{2-}\right)$

present in the bentonite (Wanner et. al., 1992), may enhance microbial activity. Bentonite also provides an attachment site for microorganisms that may favor growth.

Extrapolation of the carbon dioxide production rates from $\mu \mathrm{mol}$ per $\mathrm{g}^{-1}$ cellulose day $\mathrm{y}^{-1}$ to mol drums ${ }^{-1}$ of waste year ${ }^{-1}$ is accomplished with the following conversion factor: for an assumed average drum of transuranic waste, with about $10 \mathrm{Kg}$ of cellulosic materials, a carbon dioxide gas generation rate of $1.0 \mu \mathrm{mol} \mathrm{CO}_{2} \mathrm{~g}^{-1}$ cellulose day ${ }^{-1}$ corresponds to 3.7 mol of gas drum ${ }^{-1}$ year ${ }^{-1}$.

\subsubsection{Nitrous-Oxide Production}

Nutrient-amended samples contained $250 \mu \mathrm{mol}$ nitrate $\mathrm{g}^{-1}$ cellulose, while nutrientamended samples plus excess nitrate contained $1240 \mu \mathrm{mol}$ nitrate $\mathrm{g}^{-1}$ cellulose. Acetylene was not added to samples and therefore the nitrous oxide is both being produced and reduced to $\mathrm{N}_{2}$ in these samples. Nitrous oxide was not detected in uninoculated or inoculated samples without amendments, indicative of the lack of microbial activity (see Figure 17). Nitrous oxide accumulated in the inoculated nutrient-amended samples, with production peaking at $24.4 \mu \mathrm{mol} \mathrm{g}^{-1}$ cellulose at 132 days and then declining to $1.76 \mu \mathrm{mol}$ $\mathrm{g}^{-1}$ cellulose at 164 days (Table 17, Appendix D). Nitrous-oxide was produced at a rate of $0.674 \mu \mathrm{mol} \mathrm{g}^{-1}$ cellulose day ${ }^{-1}$ from 69 to 104 days. In the presence of excess nitrate, nitrous 


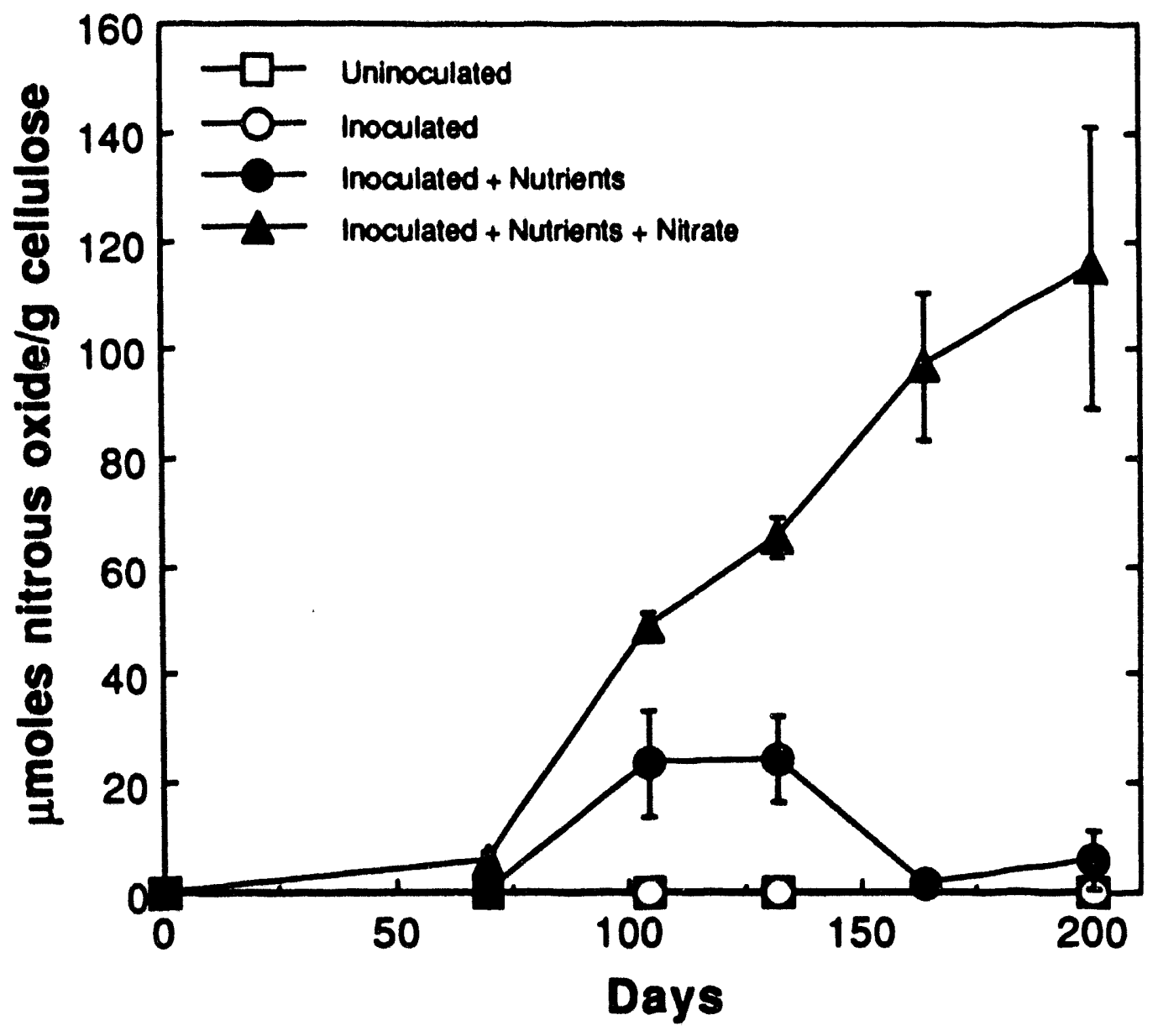

Figure 17. Nitrous oxide produced in samples incubated with an initial atmosphere of air. 
oxide was produced at the rate of $0.835 \mu \mathrm{mol}^{-1}$ cellulose day ${ }^{-1}$, reaching $115 \mu \mathrm{mol} \mathrm{g}^{-1}$ cellulose at 200 days.

In the presence of bentonite, nitrous oxide was not detected in uninoculated and inoculated unamended samples (see Table 18, Appendix D and Figure 18). The addition of nutrients to inoculated stimulated nitrous oxide production from 69 to 104 days at 1.00 $\mu \mathrm{mol} \mathrm{g}^{-1}$ cellulose day ${ }^{-1}$. Thereafter, $\mathrm{N}_{2} \mathrm{O}$ did not accumulate in the headspace, probably because of depletion of available nitrate, or rapid conversion of $\mathrm{N}_{2} \mathrm{O}$ to nitrogen gas. In the presence of excess nitrate, nitrous oxide was produced at a rate of $0.589 \mu \mathrm{mol} \mathrm{g} \mathrm{g}^{-1}$ cellulose day $^{-1}$, reaching a maximum $\left(82.7 \mu \mathrm{mol} \mathrm{g}^{-1}\right.$ cellulose $)$ at 200 days. The continued accumulation of nitrous oxide at 200 days was probably due to the abundance of available nitrate. Addition of bentonite did not result in a substantial accumulation of $\mathrm{N}_{2} \mathrm{O}$ in the headspace, suggesting that $\mathrm{N}_{2} \mathrm{O}$ was rapidly converted to $\mathrm{N}_{2}$ as soon as it was formed. Samples with and without bentonite exhibited the same trend (Figures 17 and 18), although less $\mathrm{N}_{2} \mathrm{O}$ was detected in samples containing bentonite.

\subsection{Anaerobic Treatments}

\subsubsection{Total Gas Production}

Figure 19 shows the total gas produced in samples incubated under anaerobic conditions in the presence of nitrogen. Uninoculated samples showed a slight loss of gas of about $3.20 \mathrm{~mL}$ sample $^{-1}$, presumably due to sampling. Inoculated samples without nutrients produced $0.59 \mathrm{~mL} \mathrm{~g}^{-1}$ cellulose at 200 days (see Table 19, Appendix D). After a lag of about 45 days, total gas production increased in inoculated samples containing nutrients, which produced $2.27 \mathrm{~mL} \mathrm{~g}^{-1}$ cellulose at a rate of $0.021 \mathrm{~mL} \mathrm{~g}^{-1}$ cellulose day. With nutrients plus excess nitrate, $5.44 \mathrm{~mL}$ of gas were produced at a rate of $0.039 \mathrm{~mL} \mathrm{~g}^{-1}$ cellulose day ${ }^{-1}$. 


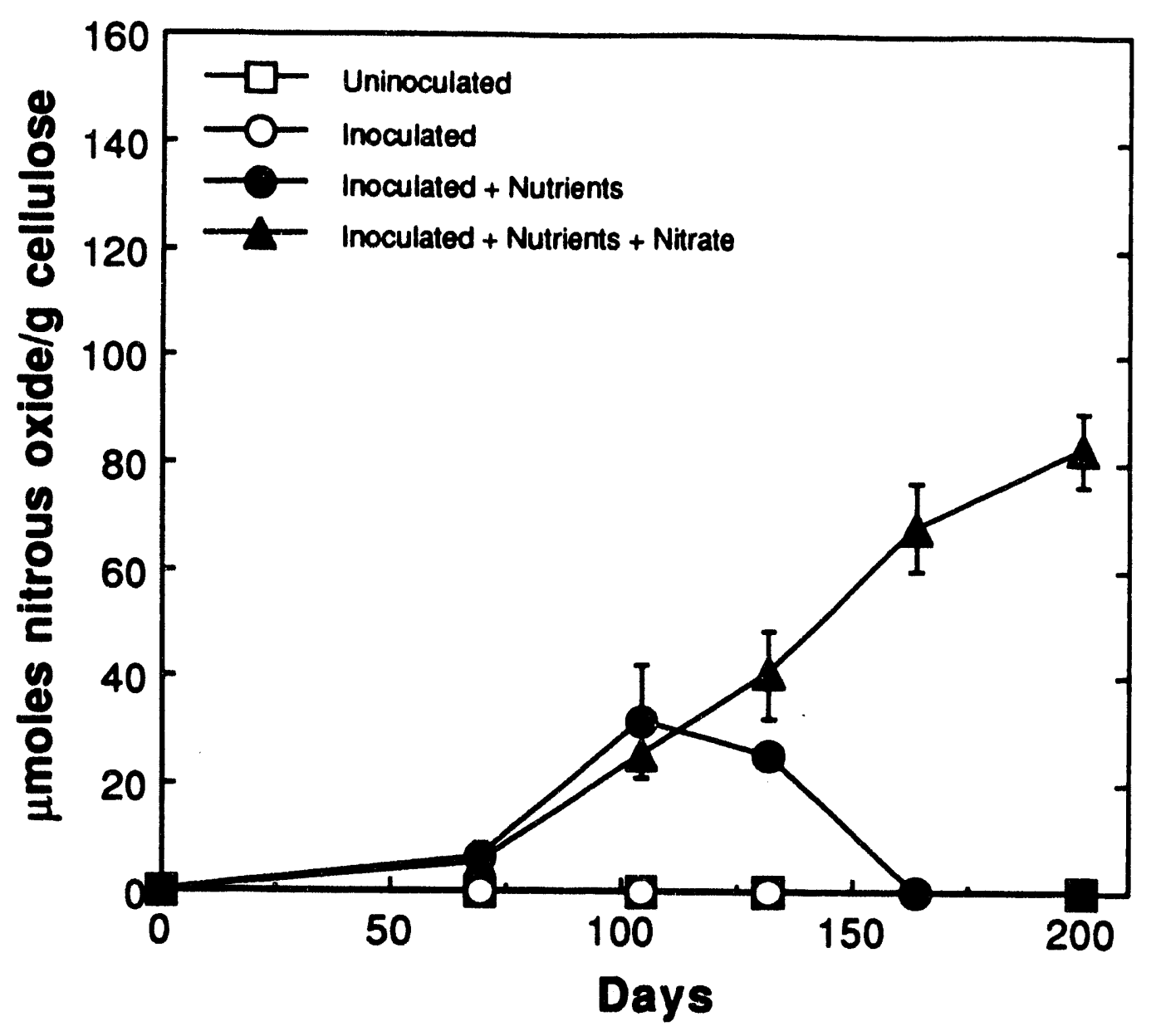

Figure 18. Nitrous oxide produced in samples containing bentonite incubated with an initial atmosphere of air. 


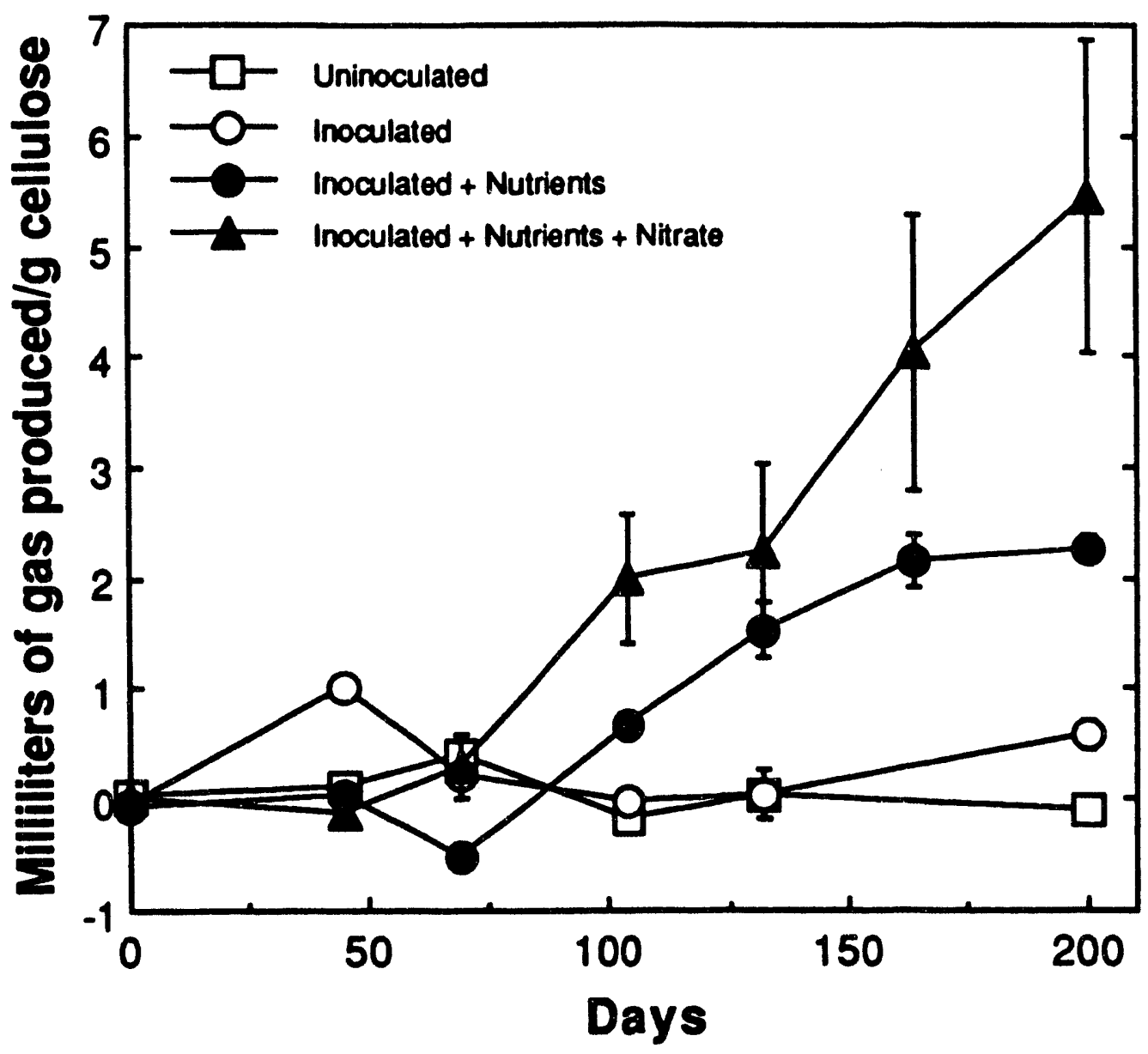

Figure 19. Total gas produced in anaerobic samples. 
Figure 20 shows total gas produced in anaerobic samples containing bentonite. Uninoculated unamended, samples showed a net loss at 200 days to $-0.28 \mathrm{~mL} \mathrm{~g}^{-1}$ cellulose (Table 20, Appendix D), due to a combination of sampling and data correction. inoculated unamended, samples produced $0.81 \mathrm{~mL} \mathrm{~g}^{-1}$ cellulose after a lag of 69 days, at a rate of 0.007

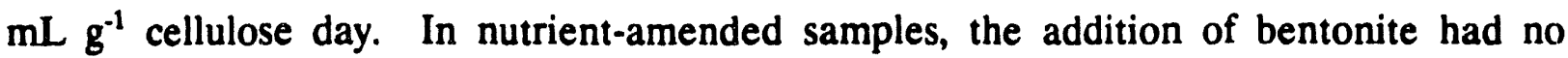
significant effect and it was similar to samples without bentonite (Figure 19). In contrast the addition of bentonite increased gas production in aerobic-amended samples. Inoculated amended samples produced $1.92 \mathrm{~mL}$ of gas at a rate of $0.013 \mathrm{~g}^{-1}$ cellulose day ${ }^{-1}$, and inoculated samples with excess nitrate produced $3.52 \mathrm{~mL}$ of gas at a rate of $0.025 \mathrm{~g}^{-1}$ cellulose day'.

\subsubsection{Carbon Dioxide Production}

Uninoculated samples produced only about $3.59 \mu \mathrm{mol}$ carbon dioxide $\mathrm{g}^{-1}$ cellulose over 200 days (Figure 21), but in the presence of inoculum, carbon dioxide increased to 5.47 $\mu \mathrm{mol} \mathrm{g}^{-1}$ cellulose (Table 21, Appendix D). After a lag of 69 days, inoculated samples amended with nutrients produced $26.0 \mu \mathrm{mol}$ carbon dioxide at a rate of $0.198 \mu \mathrm{mol} \mathrm{g}^{-1}$ cellulose day ${ }^{-1}$ (Table 21, Appendix D). Addition of excess nitrate stimulated carbon dioxide production to $61.4 \mu \mathrm{mol}$ at the rate of $0.422 \mu \mathrm{mol} \mathrm{g}^{-1}$ cellulose day ${ }^{-1}$.

Figure 22 shows carbon dioxide production in anaerobic samples containing bentonite. Uninoculated unamended samples produced $0.22 \mu \mathrm{mol} \mathrm{g} \mathrm{g}^{-1}$ cellulose at 200 days, while inoculated unamended samples produced $8.28 \mu \mathrm{mol} \mathrm{g}^{-1}$ cellulose. The addition of bentonite enhanced the background (abiotic) carbon dioxide concentration by about $40.0 \mu \mathrm{mol}$ ( Table 22, Appendix D). Inoculated samples plus nutrients produced $31.8 \mu \mathrm{mol}$ carbon dioxide $\mathrm{g}^{-1}$ cellulose over 200 days at a rate of $0.236 \mu \mathrm{mol}^{-1}$ cellulose day ${ }^{-1}$. Inoculated samples with nutrients plus excess nitrate produced $35.0 \mu \mathrm{mol}$ carbon dioxide $\mathrm{g}^{-1}$ cellulose over 200 days at a rate of $0.252 \mu \mathrm{mol} \mathrm{g}^{-1}$ cellulose day ${ }^{-1}$. 


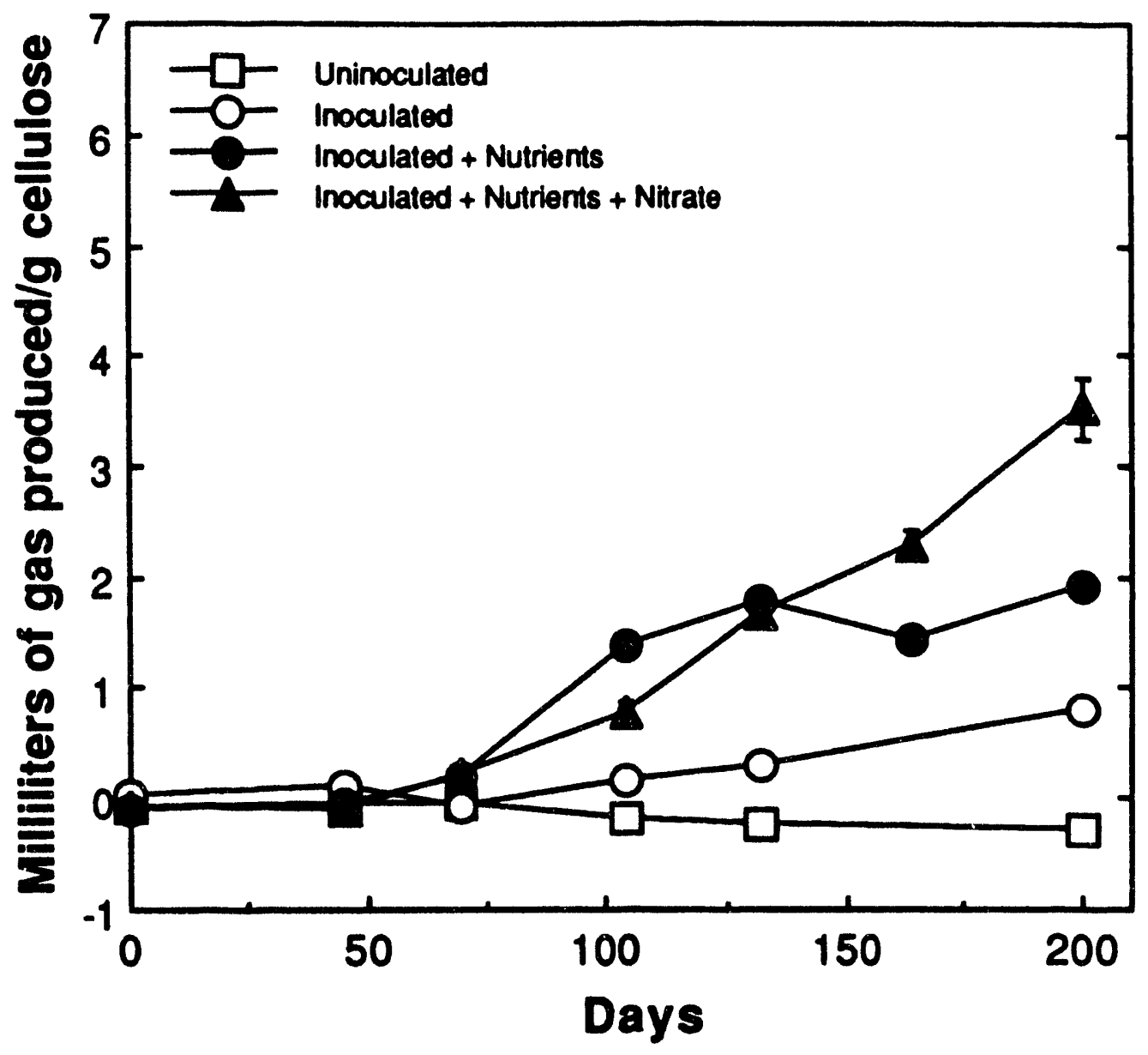

Figure 20. Total gas produced in anaerobic samples containing bentonite. 


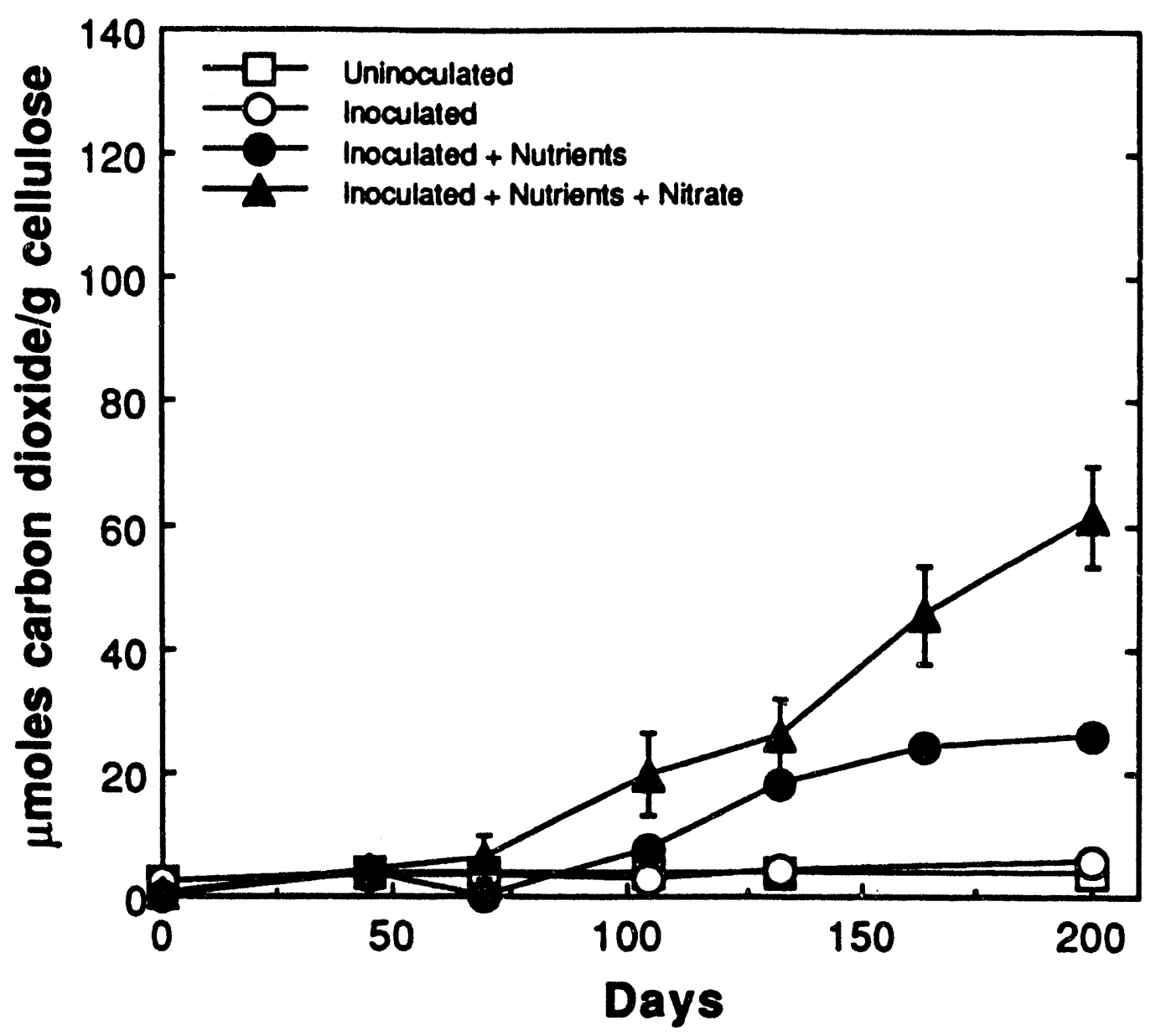

Figure 21. Carbon dioxide produced in anaerobic samples. 


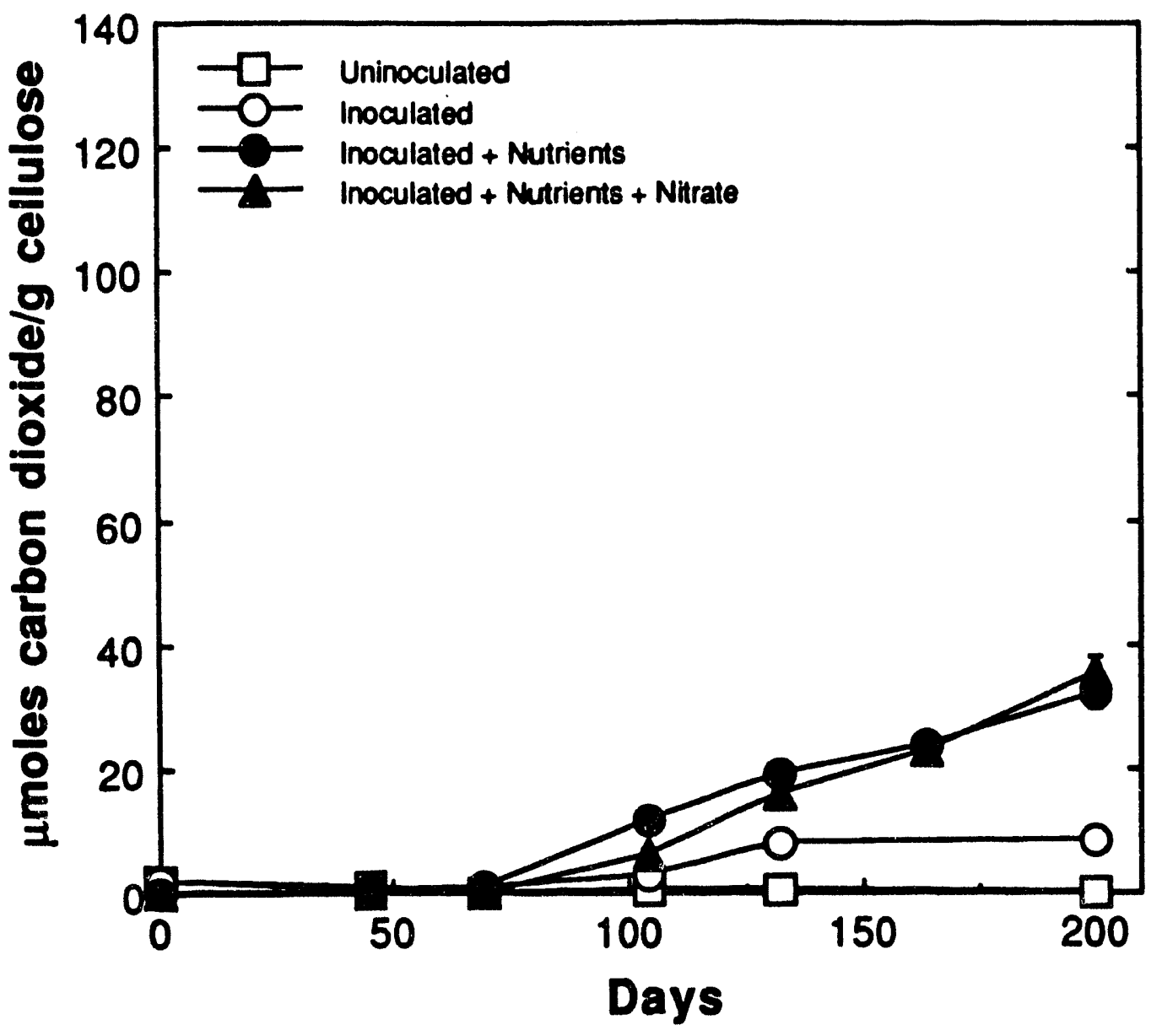

Figure 22. Carbon dioxide produced in anaerobic samples containing bentonite. 


\subsubsection{Nitrous Oxide Production}

The rate of nitrous oxide accumulation in anaerobic samples is shown in Figure 23. Nitrous oxide was not detected in either uninoculated or inoculated samples (Table 23, Appendix D). In the inoculated amended samples, nitrous oxide accumulated to $15.5 \mu \mathrm{mol}$ after 100 days and remained relatively unchanged up to 200 days. In the presence of excess nitrate, nitrous oxide was produced after 69 days at a rate of $0.602 \mu \mathrm{mol} \mathrm{g}^{-1}$ cellulose day-1, reaching a concentration of $79 \mu \mathrm{mol}$ at 200 days. In contrast, nitrous oxide accumulation was higher in aerobic samples (see Figure 15) than anaerobic samples.

Figure 24 shows nitrous oxide production in anaerobic samples containing bentonite. Nitrous oxide was not detected in uninoculated and inoculated samples (see Table 24, Appendix D). In inoculated samples with nutrients, only trace amounts of nitrous oxide were detected at 104 and 164 days. In the inoculated samples containing excess nitrate, nitrous oxide was produced at a rate of $0.647 \mu \mathrm{mol} \mathrm{g}^{-1}$ cellulose day $^{-1}$ after 104 days and reached $62.1 \mu \mathrm{mol} \mathrm{g}^{-1}$ cellulose at 200 days. In comparison to treatments without bentonite, less nitrous oxide accumulated when bentonite present. This may be caused by either an enhancement of denitrification activity (enabling the complete conversion of nitrous oxide to nitrogen without accumulation of nitrous oxide) or suppression of denitrification activity.

\subsection{SUMMARY}

Gas generation from microbial degradation of a mixture of cellulosic waste was investigated. Cellulosic waste consisting of a mixture of filter paper, paper towels, and Kimwipes were incubated in the presence of WIPP brine with and without a mixed inoculum, nutrients, or nutrients plus excess nitrate and bentonite. Abiotic (control) samples were treated with formalin and showed no microbial activity. Nitrogen (anaerobic) or aircontaining (aerobic) samples with cellulose showed an increase in total gas, $\mathrm{CO}_{2}$ and $\mathrm{N}_{2} \mathrm{O}$ when inoculated with a mixed inoculum without any added nutrients, or nutrients plus excess nitrate, and bentonite. In particular, samples which received nutrients plus excess nitrate 


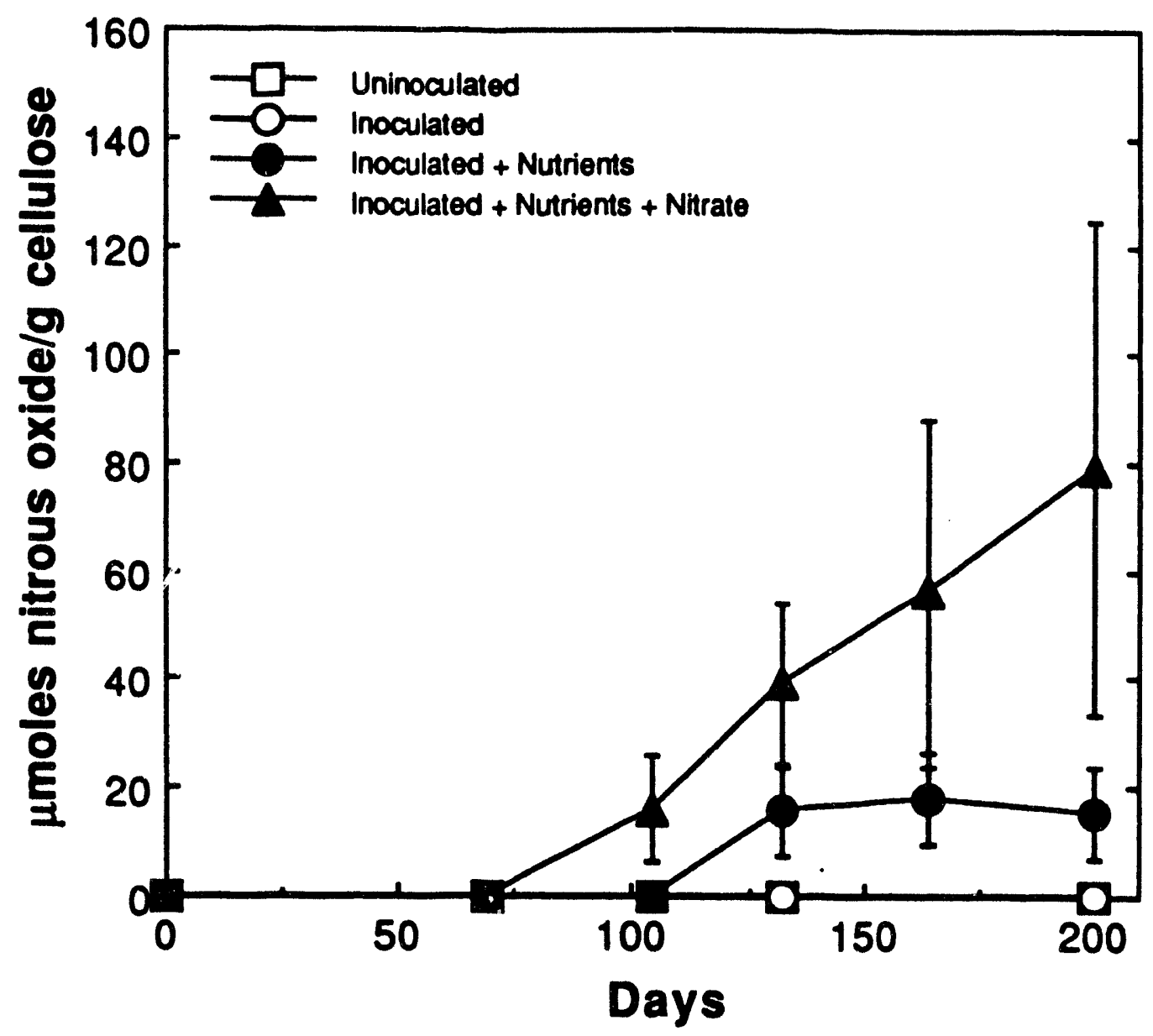

Figure 23. Nitrous oxide produced in anaerobic samples. 


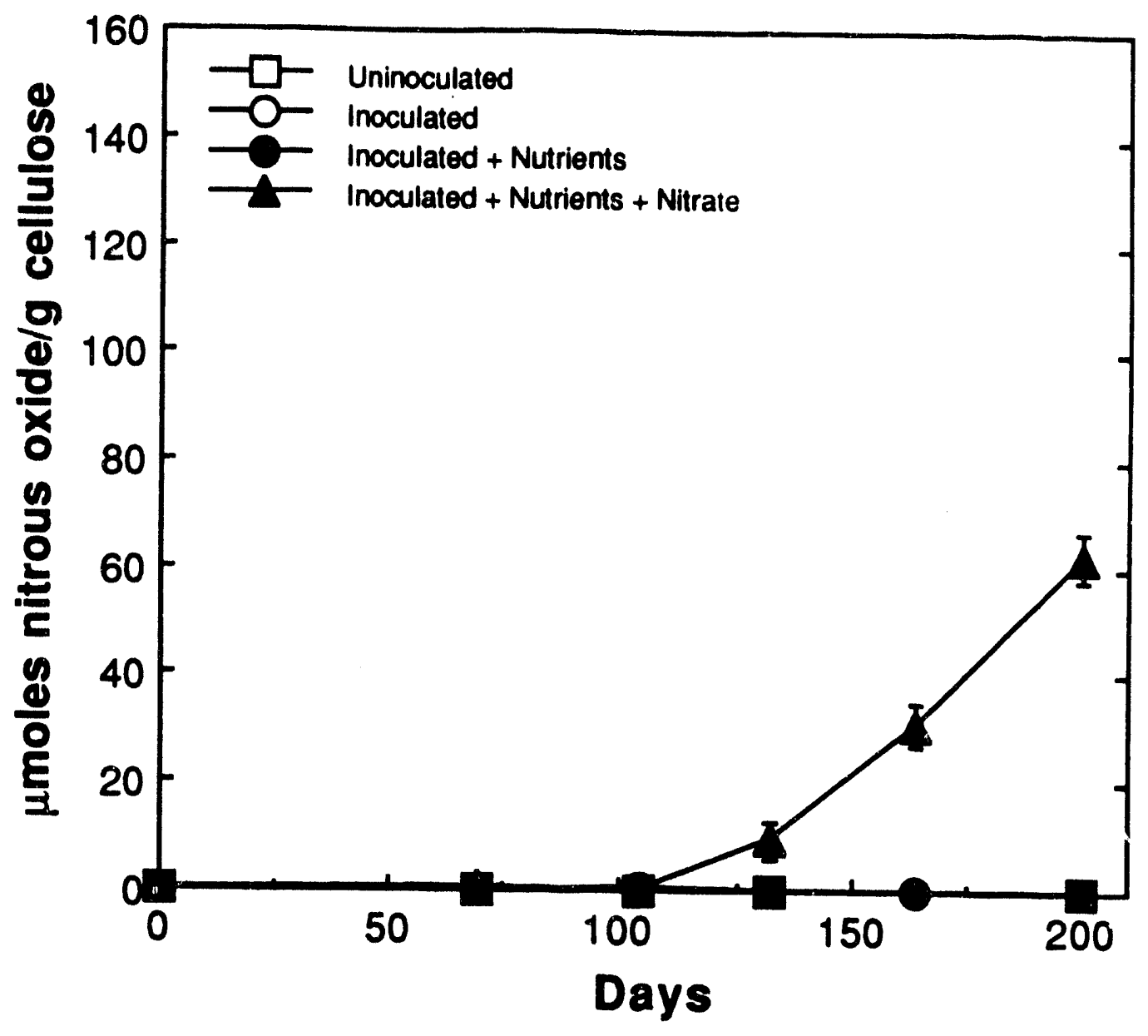

Figure 24. Nitrous oxide produced in anaerobic samples containing bentonite. 
produced much more gas, $\mathrm{CO}_{2}$, and $\mathrm{N}_{2} \mathrm{O}$ than samples which did not. Bentonite increased the background level of $\mathrm{CO}_{2}$ concentration due to abiotic reactions and it also appears that bentonite has a stimulatory effect on aerobic microbial activity.

Table 14 summarizes the rate and extent of gas production due to the presence of cellulose for the period between 69 and 200 days ( 131 days). Before 69 days, gas production in most treatments was not directly attributable to the presence of cellulose because the samples without cellulose also produced gas due to carry over of nutrients in the mixed inoculum, and metabolism of added nutrients. After 69 days, gas production in samples with cellulose exceeded those without cellulose. Gas production rates were calculated from the linear slope between 69 and 200 days. Negative values in the table denote a loss in gas volume. The negative rate reported for carbon dioxide in uninoculated treatments is the result of inactivity in these samples, and should be interpreted as "zero".

The total volume of gas produced in air-containing (aerobic) samples was highest in the presence of bentonite. Gas was produced at a rate of $0.028 \mathrm{~mL} \mathrm{~g}^{-1}$ cellulose day $^{-1}$ in inoculated, nutrient-amended samples, and at $0.034 \mathrm{~mL} \mathrm{~g}^{-1}$ cellulose day in inoculated, nutrient-amended samples containing excess nitrate. The highest amount of gas was produced in the presence of excess nitrate $\left(6.07 \mathrm{~mL} \mathrm{~g}^{-1}\right.$ cellulose).

In anaerobic samples, gas production was highest in the absence of bentonite and was the lowest when it was present. Gas was produced at a rate of $0.021 \mathrm{~mL} \mathrm{~g}^{-1}$ cellulose day ${ }^{-1}$ in inoculated nutrient-amended samples, and $0.039 \mathrm{ml} \mathrm{g}^{-1}$ cellulose day ${ }^{-1}$ in inoculated nutrient amended samples containing excess nitrate.

The concentration of carbon dioxide was highest in aerobic treatments in the presence of bentonite. In samples containing excess nitrate, $116 \mu \mathrm{mol} \mathrm{CO}_{2} \mathrm{~g}^{-1}$ cellulose was produced at a rate of $0.869 \mu \mathrm{mol} \mathrm{g}^{-1}$ cellulose day ${ }^{-1}$. Inoculated unamended samples of this treatment also showed the highest amount of carbon dioxide, with $21.5 \mu \mathrm{mol} \mathrm{g}^{-1}$ cellulose produced over 200 days. In the absence of bentonite, aerobic samples that were inoculated with 
Table 14. Summary of Rate and Net Gas Production in Samples Containing Cellulose

\begin{tabular}{|c|c|c|c|c|c|c|}
\hline \multirow[b]{2}{*}{ Sample } & \multicolumn{2}{|c|}{ Total Volume of Gas } & \multicolumn{2}{|c|}{ Carbon Dioxide } & \multicolumn{2}{|c|}{ Nitrous Oxide } \\
\hline & $\begin{array}{c}\text { Rate* } \\
(\mathrm{ml} / \mathrm{g} \text { cell. } / \text { day })\end{array}$ & $\begin{array}{l}\text { Total Produced } \\
\text { at } 200 \text { Days } \\
\text { (m/ } / \mathrm{g} \text { cell.) } \\
\end{array}$ & $\begin{array}{c}\text { Rate* } \\
\text { (umol/g cell. /doy) }\end{array}$ & $\begin{array}{c}\text { Total Produced } \\
\text { at } 200 \text { Days } \\
\text { ( } \mathrm{rmol} / \mathrm{g} \text { cell. }) \\
\end{array}$ & $\begin{array}{c}\text { Rate* } \\
(\mu \mathrm{mol} / \mathrm{g} \text { cell. } / \text { doy })\end{array}$ & $\begin{array}{c}\text { Total Produced } \\
\text { at } 200 \text { Days } \\
(\mu \mathrm{mol} / \mathrm{g} \text { cet. })\end{array}$ \\
\hline \multicolumn{7}{|l|}{ Aerobe } \\
\hline Uninoculated & 0.001 & -0.18 & -0.001 & 4.00 & -- & ND \\
\hline Inoculated & -0.001 & -0.34 & 0.033 & 8.30 & -- & ND \\
\hline Inoc. + Nutrients & 0.008 & 0.86 & 0.283 & 40.8 & $0.674 * * * *$ & 24.4 \\
\hline Inoc. + Nut. + Nitr. & $0.023^{* * *}$ & 4.42 & $0.484 * * * *$ & 95.6 & 0.835 & 115 \\
\hline \multicolumn{7}{|l|}{ Aerobe + Bentonite } \\
\hline Uninoculated & 0.003 & 0.00 & -0.016 & 2.32 & -- & 0.048 \\
\hline Inoculated & 0.001 & -0.08 & 0.134 & 21.5 & -- & ND \\
\hline Inoc. + Nutrients & 0.028 & 4.38 & 0.533 & 69.8 & $1.00 * * * *$ & $31.8^{* * * *}$ \\
\hline Inoc. + Nut. + Nitr. & 0.034 & 6.07 & 0.869 & 116 & 0.589 & 82.7 \\
\hline \multicolumn{7}{|l|}{ Anaerobe } \\
\hline Uninoculated & -0.004 & -0.09 & -0.003 & 3.59 & -- & ND \\
\hline Inoculated & 0.003 & 0.59 & 0.016 & 5.47 & -- & ND \\
\hline Inoc. + Nutrients & 0.021 & 2.27 & 0.198 & 26.0 & $0.564 * * * * *$ & $15.8 * * * * *$ \\
\hline Inoc. + Nut. + Nitr. & 0.039 & 5.44 & 0.422 & 61.4 & 0.602 & 79.0 \\
\hline \multicolumn{7}{|l|}{ Anaerobe + Bentonite } \\
\hline Uninoculated & -0.003 & -0.28 & -0.005 & 0.22 & -- & ND \\
\hline Inoculated & 0.007 & 0.81 & 0.057 & 8.28 & -- & ND \\
\hline Inoc. + Nutrients & 0.013 & 1.92 & 0.236 & 31.8 & -- & ND \\
\hline Inoc. + Nut. + Nitr. & 0.025 & 3.52 & 0.252 & 35.0 & $0.647^{* * * * * * *}$ & $62.1 * * * * *$ \\
\hline
\end{tabular}

- Rate calculated from 69 days (end of lag phase) to 200 days (131 days) except where noted; rate assumed linear and averaged over available data.

**For an assumed average drum of transuranic waste, with $10 \mathrm{~kg}$ of cellulosic material, the followizg rate conversion factors are applicable:

$0.01 \mathrm{ml} / \mathrm{g} /$ day $=1.6 \mathrm{moles} / \mathrm{drum} /$ year

$1.0 \mu \mathrm{mole} / \mathrm{g} /$ day $=3.7 \mathrm{moles} / \mathrm{drum} /$ year

*** Lag phase not present, gas production started at $\mathrm{T}=0$

**** Nitrous oxide reached maximum at 104 days, rate is over 35 days

***** Nitrous oxide reached maximum concentration at 132 days. rate is over 32 days.

****** Lag phase lasted 104 days

Negative values denote gas volume loss or decrease in concentration over time.

ND - not detected 
nutrients produced $40.8 \mu \mathrm{mol} \mathrm{CO}_{2} \mathrm{~g}^{-1}$ cellulose, whereas the samples containing excess nitrate produced $95.6 \mu \mathrm{mol} \mathrm{CO}_{2} \mathrm{~g}^{-1}$ cellulose. Aerobic samples produced more carbon dioxide than anaerobic samples. In the absence of bentonite, anaerobic samples produced $0.422 \mu \mathrm{mol} \mathrm{CO} \mathrm{g}^{-1}$ cellulose day ${ }^{-1}$ with a total yield $61.4 \mu \mathrm{mol} \mathrm{CO}_{2} \mathrm{~g}^{-1}$ cellulose in the

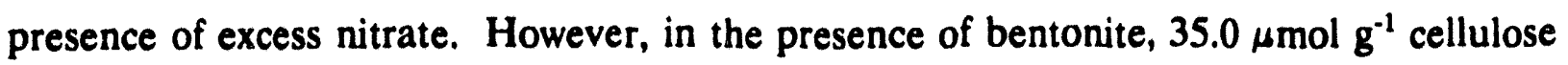
was produced in anaerobic samples containing excess nitrate. This is about one third of that produced in aerobic samples. Therefore, initially aerobic processes were more efficient in producing $\mathrm{CO}_{2}$.

In the presence of cellulose and nutrients, there is significantly greater amount of gas production than in samples without nutrients. In the absence of nutrients, microbial activity was minimal. Aerobic, denitrifying, and anaerobic primarily the fermentative activities were the predominant microbial processes noted to date.

Production of nitrous-oxide correlated with the presence of excess nitrate $(1240 \mu \mathrm{mol}$ $\mathrm{g}^{-1}$ cellulose), and $115 \mu \mathrm{mol}^{-1}$ cellulose was produced in aerobic samples without bentonite. Nitrous oxide did not accumulate in nutrient-amended samples which contained $0.1 \%$ nitrate (250 $\mu \mathrm{mol} \mathrm{g}^{-1}$ cellulose); it quickly disappeared after about 30 days. Bentonite did not stimulate the accumulation of nitrous-oxide, but instead, was correlated with a lower accumulation of $\mathrm{N}_{2} \mathrm{O}$.

The long-term inundated experiments showed enhanced halophilic bacterial activity in the presence of cellulose under aerobic and anaerobic conditions. Up to 200 days, gas production was highest in nutrient-amended including excess nitrate treatments containing an initial concentration of oxygen; this was enhanced by the addition of bentonite.

Table 15 presents gas production data for total gas and carbon dioxide scaled up to drum $^{-1}$ of waste year ${ }^{-1}$. Nitrous oxide is not presented because the production of this gas, while significant as a marker of microbial activity, is subject to conversion to nitrogen which affects the production rate. The rates drum $^{-1}$ of waste year ${ }^{-1}$ were calculated on the basis 
Table 15. Summary of Gas Production Rates Expressed as per g Cellulose/Day and Scaled up to per Drum/Year.

\begin{tabular}{|c|c|c|c|c|}
\hline \multirow[b]{2}{*}{ Sample } & \multicolumn{2}{|c|}{ Total Volume of Gas } & \multicolumn{2}{|c|}{ Carbon Dioxide } \\
\hline & $\begin{array}{c}\text { Rate* } \\
(\mathrm{m} / \mathrm{g} \text { cell./day) }\end{array}$ & $\begin{array}{l}\text { Calculated Amount } \\
\text { Produced } \\
\text { per Waste Drum** } \\
\text { (moles/drum/yea) } \\
\end{array}$ & $\begin{array}{c}\text { Rate* } \\
(\mathrm{ymo} / \mathrm{g} \text { cell./doy) }\end{array}$ & $\begin{array}{l}\text { Calculated Amount } \\
\text { Produced } \\
\text { per Waste Drum** } \\
\text { (moles/dum/yea) }\end{array}$ \\
\hline \multicolumn{5}{|l|}{ Aerobe } \\
\hline Uninoculated & 0.001 & 0.16 & -0.001 & - \\
\hline Inoculated & -0.001 & -0.16 & 0.033 & 0.12 \\
\hline Inoc. + Nutrients & 0.008 & 1.28 & 0.283 & 1.05 \\
\hline Inoc. + Nut. + Nitr. & $0.023^{* * *}$ & 3.68 & $0.484 * * *$ & 1.79 \\
\hline \multicolumn{5}{|l|}{ Aerobe + Bentonite } \\
\hline Uninoculated & 0.003 & 0.48 & -0.016 & - \\
\hline Inoculated & 0.001 & 0.16 & 0.134 & 0.5 \\
\hline Inoc. + Nutrients & 0.028 & 4.48 & 0.533 & 1.97 \\
\hline Inoc. + Nut. + Nitr. & 0.034 & 5.44 & 0.869 & 3.21 \\
\hline \multicolumn{5}{|l|}{ Anaerobe } \\
\hline Uninoculated & -0.004 & -0.64 & -0.003 & -- \\
\hline Inoculated & 0.003 & 0.48 & 0.016 & 0.06 \\
\hline Inoc. + Nutrients & 0.021 & 3.36 & 0.198 & 0.73 \\
\hline Inoc. + Nut. + Nitr. & 0.039 & 6.24 & 0.422 & 1.56 \\
\hline \multicolumn{5}{|l|}{ Anaerobe + Bentonite } \\
\hline Uninoculated & -0.003 & -0.48 & -0.005 & - \\
\hline Inoculated & 0.007 & 1.12 & 0.057 & 0.21 \\
\hline Inoc. + Nutrients & 0.013 & 2.08 & 0.236 & 0.87 \\
\hline Inoc. + Nut. + Nitr. & 0.025 & 4.00 & 0.252 & 0.93 \\
\hline
\end{tabular}

- Rate calculated from 69 days (end of lag phase) to 200 days (131 days) except where noted; rate assumed linear and averaged over available data.

* For an assumed average drum of transuranic waste, with $10 \mathrm{~kg}$ of cellulosic material, the following rate conversion factors were used:

$0.01 \mathrm{ml} / \mathrm{g} /$ day $=1.6 \mathrm{moles} / \mathrm{drum} /$ year

$1.0 \mathrm{umole} / \mathrm{g} /$ day $=3.7 \mathrm{moles} / \mathrm{drum} /$ year

*** Lag phase not present, gas production started at $\mathrm{T}=0$

Negative values denote gas volume loss or decrease in concentration over time 
an assumed average drum of transuranic waste with about $10 \mathrm{Kg}$ of cellulosic materials. A total gas generation rate of $0.01 \mathrm{~mL}$ of gas $\mathrm{g}^{-1}$ cellulose day ${ }^{-1}$ corresponds to a gas generation rate of $1.6 \mathrm{~mol}_{\text {of gas drum }}{ }^{-1}$ year ${ }^{-1}$. A carbon dioxide gas generation rate of $1.0 \mu \mathrm{mol} \mathrm{CO}$ $\mathrm{g}^{-1}$ cellulose day ${ }^{-1}$ corresponds to a gas generation rate of $1.6 \mathrm{~mol}_{\text {gas }} \mathrm{drum}^{-1}$ year $^{-1}$.

The data contained in this report is a summarization of work in progress, (a status report) and should not be interpreted as final values. Most of the long-term studies are still in progress. Gas production rates will undoubtedly be modified after long-term data, up to about two years or longer, are obtained and analyzed. The preliminary data included herein, and resultant gas production rates, should only be used for preliminary interpretations and tentative conclusions. Further data and interpretation from this microbial degradation-gas generation study will be documented in the future. 


\subsection{REFERENCES}

Balderston, W.L., B. Sherr, and W.J. Payne. 1976. "Blockage by Acetylene of Nitrous Oxide Reduction in Pseudomonas perfectomarinus," Applied Environmental Microbiology. Vol. 31, No.4, 504-508.

Barnhart, B.J., E.W. Campbell, E. Martinez, D.E. Caldwell, and R. Hallett. 1980. Potential Microbial Impact on Transuranic Wastes Under Conditions Expected in the Waste Isolation Pilot Plant (WIPP), Annual Report, October 1, 1978 - September 30, 1979. LA-8297-PR. Los Alamos National, NM: Los Alamos Scientific Laboratory.

Benoit, L., C. Cailliez, E. Petitdemange, and J. Gitton. 1992. "Isolation of Cellulolytic Mesophilic Clostridia from a Municipal Solid Waste Digestor," Microbial Ecology. Vol. 23, No.2, 117-125.

Black, J., X. Tong, and D. Grbic-Galic. 1991. Laboratory Studies of Microbial Degradation of Transuranic (TRU) Waste, Fin cress Report January 1, 1989 - April 30, 1991. Stanford, CA: Environmenta eering and Science, Department of Civil Engineering, Stanford University. (wopy on file in the Sandia WIPP Central Files, Waste Management and Transportation Library, Sandia National Laboratories, Albuquerque, NM).

Bott, T.L., and L.A. Kaplan. 1991. "Selection of Surrogates for a Genetically Engineered Microorganism with Cellulolytic Capability for Ecological Studies in Streams," Canadian Joumal of Microbiology. Vol. 37, No. 11, 848-857.

Brush, L.H. 1990. Test Plan for Laboratory and Modeling Studies of Repository and Radionuclide Chemistry for the Waste Isolation Pilot Plant. SAND90-0266. Albuquerque, NM: Sandia National Laboratories. 
Brush, L.H. 1991. "Appendix A: Current Estimates of Gas Production Rates, Gas Production Potentials, and Expected Chemical Conditions Relevant to Radionuclide Chemistry for the Long-Term WIPP Performance Assessment," Preliminary Comparison with 40 CFR Part 191, Subpart B for the Waste Isolation Pilot Plant, December 1991. Vol. 3: Reference Data. WIPP Performance Assessment Division. Eds. R.P. Rechard, A.C. Peterson, J.D. Schreiber, H.J. Iuzzolino, M.S. Tierny, and J.S. Sandha. SAND91-0893/3. Albuquerque, NM: Sandia National Laboratories. A-25 through A-36.

Brush, L.H. , D. Grbic-Galic, D.T. Reed, X. Tong, R.H. Vreeland, and R.E. Westerman. 1990. "Preliminary Results of Laboratory Studies of Repository Chemistry for the Waste Isolation Pilot Plant," Scientific Basic for Nuclear Waste Management XIV, Boston, MA, November 26-29, 1990. Eds. T.A. Abrajano, Jr. and L.H. Johnson. SAND901031C. Pittsburgh, PA: Materials Research Society. Vol. 212, 893-900.

Caldwell, D.E., R.C. Hallet, M.A. Molecke, E. Martinez, and B.J. Barnhart. 1988. Rates of $\mathrm{CO}_{2}$ Production from the Microbial Degradation of Transuranic Wastes Under Simulated Geologic Isolation Conditions. SAND87-7170. Albuquerque, NM: Sandia National Laboratories.

Christensen, S., and J.M. Tiedje. 1988. "Sub-Parts-Per-Billion Nitrate Method: Use of an $\mathrm{N}_{2} \mathrm{O}$-Producing Denitrifier to Convert $\mathrm{NO}_{3}-$ or ${ }^{15} \mathrm{NO}_{3}-$ to $\mathrm{N}_{2} \mathrm{O}$, " Applied Environmental Microbiology. Vol. 54, No. 6, 1409-1413.

Colberg, P.J., and L.Y. Young. "Biodegradation of Lignin-Derived Molecules Under Anaerobic Conditions," Canadian Joumal of Microbiology. Vol. 28, No.7, 886-889.

Coleman, A.W. 1980. "Enhanced Detection of Bacteria in Natural Environments by Fluorochrome Staining of DNA," Limnology and Oceanography. Vol. 25, No. 5, 948951. 
DeLong, E.F., G.S. Wickham, and N.R. Pace. 1989. "Phylogenetic Stains: Ribosomal RNA-Bbased Probes for the Identification of Single Cells," Science. Vol. 243, No.4896, 1360-1363.

Dicker, H.J., and D.W. Smith. "Effects of Organic Amendments on Sulfate Reduction Activity, $\mathrm{H}_{2}$ Consumption, and $\mathrm{H}_{2}$ Production in Salt Marsh Sediments," Microbial Ecology. Vol. 11, No. 4, 299-315.

Francis, A.J., S. Dobbs, and R.F. Doering. 1980a. "Biogenesis of Tritiated and Carbon-14 Methane from Low-Level Radioactive Waste," Nuclear Chemical Waste Management. Vol. 1, No. 1, 153-159.

Francis, A.J., S. Dobbs, and B.J. Nine. 1980b. "Microbial Activity of Trench Leachates from Shallow-Lland, Low-Level Radioactive Waste Disposal Sites," Applied and Environmental Microbiology. Vol. 40, No. 1, 108-113.

Francis, A.J. 1985. Low-level Radioactive Wastes in Subsurface Soils," Soil Reclamation Processes: Microbiological Analyses and Applications. Eds. R.L. Tate III and D.A. Klein, New York, NY: Marcel Decker, Inc., 279-331.

Francis, A.J., J.M. Slater, and C.J. Dodge. 1989. "Denitrification in Deep Subsurface Sediments," Geomicrobiology Journal. Vol. 7, No. 1-2, 103-116.

Francis, A.J. 1990. "Microbial Dissolution and Stabilization of Toxic Metals and Radionuclides in Mixed Wastes," Experientia. Vol. 46, No. 8, 840-851.

Francis, A.J., C.J. Dodge, J.B. Gillow, and J.E. Cline. 1991. "Microbial Transformations of Uranium in Wastes," Radiochimica Acta. Vol. 52/53, pt. 2, 311-316. 
Hope, C.F.A., and R.G. Burns. 1985. "The Barrier-Ring Plate Technique for Studying Extracellular Enzyme Diffusion and Microbial Growth in Model Soil Environments," Joumal of General Microbiology. Vol. 131, pt. 5, 1237-1243.

Hrmová, M., E. Petráková and P.Belly. 1991. "Induction of Cellulose- and Xylan-Degrading Enzyme Systems in Aspergillus terreus by Homo- and Hetero-Disaccharides Composed of Glucose and Xylose," Journal of General Microbiology. Vol. 137, pt. 3, 541-547.

Javor, B.J. 1984. "Growth Potential of Halophilic Bacteria Isolated from Solar Salt Environments: Carbon Sources and Salt Requirements," Applied and Environmental Microbiology. Vol. 48, No.2, 352-360.

Kearns, J.T., C.R. Clayton, G.P. Halala, J.B. Gillow, and A.J. Francis. 1992. "Application of XPS to the Study of MIC," Materials Performance. Vol 31, No. 10, 48-51.

Kushner, D.J., and M. Kamekura. 1988. "Chapter 5: Physiology of Halophilic Eubacteria," Halophilic Bacteria. Ed. F. Rodriquez-Valera. Boca Raton, FL: CRC Press, Inc. Vol I, 110.

Lappin, A.R., R.L. Hunter, D.P. Garber, and P.B. Davies, eds. 1989. Systems Analysis, Long-Term Radionuclide Transport, and Dose Assessments, Waste Isolation Pilot Plant (WIPP), Southeastern New Mexico; March 1989. SAND89-0462, Albuquerque, NM: Sandia National Laboratories.

Laube, V.M., and S.M. Martin. 1981. "Conversion of Cellulose to Methane and Carbon Dioxide by Triculture of Acetovibrio cellulyticus, Desulfovibrio sp., and Methanosarcina barkeri,' Applied and Environmental Microbiology, Vol. 42, No. 3, 413-420. 
Lovely, D.R., E.J. Phillips, Y.A. Gorby, and E.R. Landa. 1992. "Microbial Reduction of Uranium," Nature. Vol. 350, 413-416.

Lorowitz, W.H., D.P. Nagle, Jr., and R.S. Tanner. 1992. "Anaerobic Oxidation of Elemental Metals Coupled to Methanogenesis by Methanobacterium thermoautotrophicum," Environmental Science and Technology. Vol. 26, No. 8, 1606-1610.

Lynd, L.R., H.E. Grethlein, and R.H. Wolkin. 1989. "Fermentation of Cellulosic Substrates in Batch and Continuous Culture by Clostridium thermocellum," Applied and Environmental Microbiology. Vol. 55, No. 12, 3131-3139.

Molecke, M.A. 1979. Gas Generation from Transuranic Waste Degradation: Data Summary and Interpretation. SAND79-1245. Albuquerque, NM: Sandia National Laboratories.

Molecke, M.A. 1983. A Comparison of Brines Relevant to Nuclear Waste Experimentation. SAND83-0516. Albuquerque, NM: Sandia National Laboratories.

Ng, T.K., P.J. Weimer, and J.G. Zeikus. 1977. "Cellulolytic and Physiological Properties of Clostridium thermocellum," Archives Microbiology. Vol. 114, No. 1, 1-7.

Pavlostathis, S.G., and E. Giraldo-Gomez. 1991. "Kinetics of Anaerobic Treatment: A Critical Review," Critical Reviews in Environmental Control. Vol. 21, No. 5-6, 411-490.

Pavlostathis, S.G., T.L. Miller, and M.J. Wolin. 1988. "Fermentation of Insoluble Cellulose by Continuous Cultures of Ruminococcus albus," Applied and Environmental Microbiology. Vol. 54, No. 11, 2655-2659. 
Postgate, J.R. 1984. The Sulphate-Reducing Bacteria. 2nd ed. New York, NY: Cambridge University Press. 56-100.

Poulsen, O.M., and L.W. Petersen. . 1992. "Degradation of Microcrystalline Cellulose: Synergism Between Different Endoglucanases of Cellulomonas sp. ATCC 21399," Biotechnology and Bioengineering. Vol. 39, No.1, 121-123.

Priest, F.G. 1984. Extracellular Enzymes. Wokingham Berkshire, England: Van Nostrad Reinhold (UK) Co. Ltd. 42-43.

Rodriquez-Valera, F., ed. 1988. Halophilic Bacteria. Boca Raton, FL: CRC Press, Inc. Vol I, 72.

Ross, H.N.M., M.D. Collins, B.J. Tindall, and W.D. Grant. 1981. "A rapid procedure for the Detection of Archaebacterial Lipids in Halophilic Bacteria," Journal of General Microbiology. Vol. 123, pt. 1, 75-80.

Skujins, J. 1976. "Extracellular Enzymes in Soil," CRC Critical Reviews in Microbiology. Vol. 4, No. 4, 383-421.

Tiedje, J.M. 1988. "Ecology of Denitrification and Dissimilatory Nitrate Reduction to Ammonium," Biology of Anaerobic Microorganisms. Ed. A.J.B. Zehnder, New York, NY: John Wiley and Sons. 179-186.

Tomlinson, G.A., L.L Jahnke, and L.I. Hochstein. 1986. "Halobacterium denitrificans sp. nov., an Extremely Halophilic Denitrifying Bacterium," International Journal of Syst. Bacteriology. Vol. 36, No. 1, 66-70. 
Ventosa, A. 1988. "Chapter 3: Taxonomy of Moderately Halophilic Heterotrophic Eubacteria," Halophilic Bateria. Ed. F. Rodriquez-Valera. Boca Raton, FL: CRC Press, Inc. Vol. I, 72.

Vreeland, R. et al., 1991. West Chester University, to be published.

Wanner H., P. Wersin, and N. Sierro. 1992. Thermodynamic modelling of beutonite-ground interaction and implications for near field chemistry in a repository for spent fuel. SKB Technical Report 92-37. Stockholm, Sweden: Swedish Nuclear Fuel and Waste Management, Co. 1-6.

Weimer, P.J., J.M. Lopez-Guisa, and A.D. French. 1990. "Effect of Cellulose Fine Structure on Kinetics of its Digestion by Mixed Ruminal Microorganisms in Vitro," Applied and Environmental Microbiology. Vol. 56, No. 8, 2421-2419.

Yoshinari, T., and R. Knowles. 1976. "Acetylene Inhibition of Nitrous Oxide Reduction by Denitrifying Bacteria," Biochemical Biophysical Research Communications. Vol. 69, No. 3, 705-710.

Z.ehnder, A.J., and W. Stumm. 1988. "Geochemistry and Biogeochemistry of Anaerobic Habitats," Biology of Anaerobic Microorganisms. Ed. A. J. Zehnder. New York, NY: John Wiley and Sons. 19.

Zhilina, T.N., and G.A. Zavarzin. 1990. "Extremely Halophilic Methylotrophic, Anaerobic Bacteria," FEMS Microbiology Reviews. Vol. 87, No. 3-4, 315-322. 
APPENDIX A: DETAILS OF THE SHORT-TERM ACTIVITY MEASUREMENTS 


\section{APPENDIX A: DETAILS OF THE SHORT-TERM ACTIVITY MEASUREMENTS}

The short-term experiments were developed to determine the activity of specific groups of organisms (aerobes, anaerobes, and denitrifiers) by using WIPP salt from the underground and Nash Draw brine as a basal medium and inoculum.

A concentrated stock solution of nutrients $(20 \mathrm{x})$ was srepared and $0.5 \mathrm{~mL}$ dispensed into $20-\mathrm{mL}$ serum bottles. Medium for anaerobes (glucose fermenters) and denitrifiers was dispensed and sealed inside a nitrogen-filled glove box. Medium for aerobes was prepared outside of the glove box in air. The samples were capped with butyl rubber stoppers and aluminum crimps and autoclaved $\left(120^{\circ} \mathrm{C}, 20 \mathrm{psi}, 15\right.$ minutes $)$.

The nutrient solution was added prior to the addition of inoculum to achieve a final concentration of nutrients in the samples as follows:

\section{Aerobe and Anaerobe Series}

glucose

$5.0 \mathrm{~g} / \mathrm{L}$

yeast extract

$0.5 \mathrm{~g} / \mathrm{L}$

potassium phosphate

$1.0 \mathrm{~g} / \mathrm{L}$

ammonium nitrate

$1.0 \mathrm{~g} / \mathrm{L}$

inoculum

$9.5 \mathrm{~mL} /$ bottle

$\mathrm{pH}=6.8$

\section{Denitrifier Series}

sodium succinate

$$
\begin{gathered}
5.0 \mathrm{~g} / \mathrm{L} \\
0.5 \mathrm{~g} / \mathrm{L} \\
1.0 \mathrm{~g} / \mathrm{L} \\
1.0 \mathrm{~g} / \mathrm{L} \\
1.0 \mathrm{~g} / \mathrm{L} \\
9.5 \mathrm{~mL} / \mathrm{bottle}
\end{gathered}
$$

yeast extract

potassium phosphate (dibasic)

ammonium nitrate

potassium nitrate

inoculum

$\mathrm{pH}=6.8$

To determine denitrification, $2 \mathrm{~mL}$ of acetylese was injected into the headspace and nitrous oxide production was determined by gas chromatography.

Cellulose degradation was investigated by replacing the carbon source with $0.5 \mathrm{~g}$ Whatman \#1 fiiter paper. 
A large volume of inoculum was prepared by dissolving $200 \mathrm{~g}$ of $\$ 2180$, W30 muck pile salt from the WIPP underground workings into $1 \mathrm{~L}$ of sterile water. A $450 \mathrm{~mL}$ aliquot was poured into a sterile beaker and $10 \mathrm{~mL}$ of Laguna Cinco mud slurry and $50 \mathrm{~mL}$ of Laguna Cinco brine from Nash Draw were added. This was done inside the anaerobic glove box. A total of $510 \mathrm{~mL}$ of inoculum was prepared; $9.5 \mathrm{~mL}$ of this inoculum was added to each bottle of sterile nutrient medium through a sterile needle and syringe to attain a final volume of $10 \mathrm{~mL}$ in each bottle. The pressure was equalized after the addition of inoculum with a sterile syringe and $0.22 \mu \mathrm{m}$ filter.

A total of 6 samples were prepared per series. Two of the 6 were treated with $1 \mathrm{~mL}$ of $10 \%$ formalin to serve as a control. Six samples were also prepared without nutrient additions, 2 treated with formalin.

Samples were incubated at $30^{\circ} \mathrm{C}$ and analyzed for gas production (total gas, carbon dioxide and nitrous oxide) at specific time periods. 


\section{APPENDIX B: GAS ANALYSIS}

B-1 


\section{APPENDIX B: GAS ANALYSIS}

\section{Total Gas}

Headspace pressure was measured with a Wallare \& Tiernan $^{\star}$ digital pressure model 661-D/A035 gauge calibrated to National Institute of Standards and Technology (NIST) standards.

\section{Carbon Dioxide}

Carbon dioxide was analyzed using a gas chromatograph equipped with a thermal conductivity detector. Instrument conditions are listed below:

Column

Column temp $\left({ }^{\circ} \mathrm{C}\right)$

Carrier gas

Carrier flow (mL/min)

Injector temp $\left({ }^{\circ} \mathrm{C}\right)$

Manifold temp $\left({ }^{\circ} \mathrm{C}\right)$

Detector temp $\left({ }^{\circ} \mathrm{C}\right)$

Detector current (mA)

Detection limit (nmol/mL)
SS $12^{\prime} \times 1 / 8 "$ Porapak QS

100

$\mathrm{He}$

35

150

210

250

225

1

Instrument calibrated with gas standards traceable to NIST.

\section{Nitrous Oxide}

Nitrous oxide was analyzed using a gas chromatograph equipped with an electron capture detector $\left({ }^{63} \mathrm{Ni}\right)$. Instrument conditions are listed below:

Column

Column temp $\left({ }^{\circ} \mathrm{C}\right)$

Carrier gas

Carrier flow $(\mathrm{mL} / \mathrm{min})$

Injector temp $\left({ }^{\circ} \mathrm{C}\right)$

Detector temp $\left({ }^{\circ} \mathrm{C}\right)$

Detector current (nA)

Detection limit $(\mathrm{pmol} / \mathrm{mL})$
SS $12^{\prime}$ x 1/8" Porapak QS

70

$\mathrm{N}_{2}$

30

270

270

2

100 
Instrument calibrated with gas standards traceable to NIST. 
APPENDIX C: DETAILS OF THE LONG-TERM EXPERIMENT

C-1 


\section{APPENDIX C: DETAILS OF THE LONG-TERM EXPERIMENT}

The following is a detailed description of the samples prepared for the long-term inundated experiment, including the number and chemical composition of treatments.

\section{Sample Preparation}

Detergent (Alconox ${ }^{\circ}$ ) and acid-washed $(10 \% \mathrm{HCl}) 160 \mathrm{~mL}$ serum bottles were rinsed with deionized water. They were then dried in a drying oven, covered with aluminum foil and autoclaved, thus completing preparation of the bottles.

Four paper types were used for the experiment:

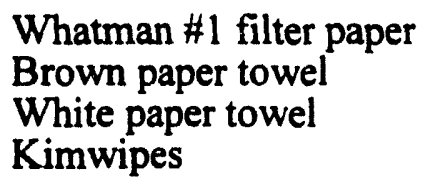

The papers were reduced to approximately $1 \mathrm{~cm}$ by $1 \mathrm{~cm}$ squares.

The bottles were filled with the processed paper. The papers were mixed together prior to filling and $1.25 \mathrm{~g}$ of each paper type were added to each bottle for a total of 5 grams of paper per bottle.

\section{Anaerobic Samples}

Ten liters of G-Seep \#9 were removed from storage at $4^{\circ} \mathrm{C}$ and equilibrated overnight to room temperature. Storage at $4^{\circ} \mathrm{C}$ was necessary in order to prevent microbial activity in the storage containers; which could possibly pre-enrich the brine with specific microbes.

Sixty filled bottles (w/ paper) were arranged and prepared for treatment as follows:

$36 \mathrm{w} / \mathrm{paper}:$ unamended (G-Seep w/o additions)

$18 \mathrm{w} / \mathrm{o}$ bentonite

$18 \mathrm{w} /$ bentonite

$12 \mathrm{w} /$ paper: amended (G-Seep w/ nutrients)

$6 \mathrm{w} / \mathrm{o}$ bentonite

$6 \mathrm{w} /$ bentonite 
12 w/paper: amended $w /$ excess nitrate (G-Seep $w /$ nutrients and excess nitrate)

$6 \mathrm{w} / \mathrm{o}$ bentonite

$6 \mathrm{w} /$ bentonite

Thirty-two bottles w/o paper were arranged and prepared for treatment as follows:

16 unamended (G-Seep w/o additions)

$8 \mathrm{w} / \mathrm{o}$ bentonite

$8 \mathrm{w} /$ bentonite

8 amended (G-Seep w/ nutrients)

$4 \mathrm{w} / \mathrm{o}$ bentonite

$4 \mathrm{w} /$ bentonite

8 amended $w /$ excess nitrate (G-Seep

$\mathrm{w} /$ nutrients and excess nitrate)

$4 \mathrm{w} / \mathrm{o}$ bentonite

$4 \mathrm{w} /$ bentonite

A total of 92 bottles were prepared for anaerobic treatment.

\section{Aerobic Samples}

Sixty filled bottles ( $w /$ paper) were arranged and prepared for treatment as follows:

$36 \mathrm{w} /$ paper: unamended (G-Seep w/o additions)

$18 \mathrm{w} / \mathrm{o}$ bentonite

$18 \mathrm{w} /$ bentonite

12 w/paper: amended (G-Seep w/nutrients)

$6 \mathrm{w} / \mathrm{o}$ bentonite

$6 \mathrm{w} /$ bentonite

12 w/paper: amended w/ excess nitrate (G-Seep w/nutrients and excess nitrate)

$6 \mathrm{w} / \mathrm{o}$ bentonite

$6 \mathrm{w} /$ bentonite

Thirty-two bottles w/o paper were arranged and prepared for treatment as follows:

16 unamended (G-Seep w/o additions)

$8 \mathrm{w} / \mathrm{o}$ bentonite

$8 \mathrm{w} /$ bentonite

8 amended (G-Seep w/ nutrients)

$4 \mathrm{w} / \mathrm{o}$ bentonite

$4 \mathrm{w} /$ bentonite 


\section{8 amended $w /$ excess nitrate (G-Seep \\ $w /$ nutrients and excess nivrate) \\ $4 \mathrm{w} / \mathrm{o}$ bentonite \\ $4 \mathrm{w} /$ bentonite}

A total of 92 bottles were prepared for aerobic treatment.

\section{Nutrient Additions}

The following lists the quantities added and final concentrations of nutrients in the samples. This list applies to both the aerobic and anaerobic samples with and without paper.

(a) Amended: The following quantities of nutrients were used for the amended treatments:
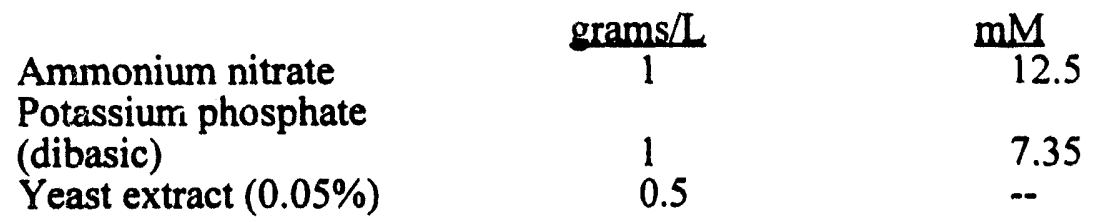

Each $100 \mathrm{~mL}$ sample contained the following final concentration of nutrients:

grams $/ 100 \mathrm{~mL} \quad$ umoles

\begin{tabular}{lll}
$\begin{array}{l}\text { Ammonium nitrate } \\
\text { Potassium phosphate } \\
\text { (dibasic) }\end{array}$ & 0.1 & 1250 \\
Yeast extract $(0.05 \%)$ & 0.1 & 735 \\
\hline
\end{tabular}

(b) Amended and excess nitrate added: Potassium nitrate was added in addition to the ammonium nitrate:

Ammonium nitrate Potassium phosphate (dibasic) Potassium nitrate Yeast extract $(0.05 \%)$
grams/L

1

1

5

0.5 $\mathbf{m M}$

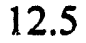

7.35

49.5

Each $100 \mathrm{~mL}$ sample contained the following final concentration of nutrients:

grams $/ 100 \mathrm{~mL}$

0.1

umoles

Ammonium nitrate Potassium phosphate (dibasic) Potassium nitrate Yeast extract $(0.05 \%)$
0.1

0.5

0.05
1250

735

4950

\section{C-4}


(c) Glucose added (instead of paper): Samples were prepared without paper with a glucose addition to determine the ability of the inoculum to grow in the amended samples. The treatment was composed of the following:

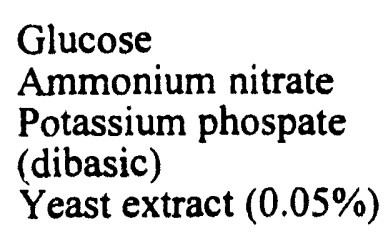

$$
\text { grams/L }
$$

5

1

1

0.5
$\mathrm{mM}$

27.7

12.5

7.35

Each $100 \mathrm{~mL}$ sample contains the following quantity of nutrients:

grams $/ 100 \mathrm{~mL}$

Glucose
Ammonium nitrate
Potassium phosphate
(dibasic)
Yeast extract $(0.05 \%)$
0.5

0.1

0.1

0.05 umoles

2770

1250

735

--

(d) Glucese added (instead of paper) and excess nitrate: Samples were prepared without paper with a glucose addition and additional nitrate. The treatment was composed of the following:

\section{$\operatorname{grams} / \mathrm{L} \quad \mathrm{mM}$}

\section{Glucose}

Ammonium nitrate

Potassium phospate

(dibasic)

Potassium nitrate

Yeast extract $(0.05 \%)$
5

1

1

5

0.5
27.7

12.5

7.35

49.5

Each $100 \mathrm{~mL}$ sample contained the following final concentration of nutrients:

$\operatorname{grams} / 100 \mathrm{~mL}$

0.5

Glucose

Ammonium nitrate

Potassium phosphate

(dibasic)

Potassium nitrate

Yeast extract $(0.05 \%)$
0.1

0.1

0.5

0.05 umoles

2770

1250

735

4950 


\section{Sample Volumes}

The final sample volume (displacement of liquid plus cellulose or liquid w/o cellulose) and the headspace volume of each treatment is as follows:

\begin{tabular}{lll} 
Cellulose Treatments & sample vol.(mL & hdsp. vol(mL* \\
\hline $\begin{array}{l}\text { U (uninoculated) } \\
\text { I (inoculated) }\end{array}$ & 110 & 50 \\
$\begin{array}{l}\text { UC (uninoculated } \\
\text { control) }\end{array}$ & 114 & 46 \\
$\begin{array}{l}\text { IC (inoculated } \\
\text { control) }\end{array}$ & 113 & 47 \\
"Ne paper" Treatments & 117 & 43 \\
\hline $\begin{array}{l}\text { NU (uninoculated) } \\
\text { NI (inoculated) }\end{array}$ & sample vol.(mL & hdsp. vol (mL* \\
NUC (uninoculated & 100 & 60 \\
$\quad$ control) & 104 & 56 \\
NIC (inoculated & 103 & 57 \\
$\quad$ control) & 107 & 53
\end{tabular}

*Headspace vol. (hdsp. vol) calculated by subtracting sample volume from volume of bottle $(160 \mathrm{ml})$.

Acetylene was not injected into the headspace of any of the samples in order to prevent pertubation of the headspace gas. 
APPENDIX D: GAS PRODUCTION DATA (GROSS AND NET) FOR THE LONG-TERM INUNDATED EXPERIMENT

D-1 


\section{APPENDIX D: GAS PRODUCTION DATA (GROSS AND NET) FOR THE LONG-TERM INUNDATED EXPERIMENT}

\section{i. Data Reduction}

Total gas, carbon dioxide, and nitrous oxide production by aerobic and anaerobic samples up to 200 days incubation is presented in Appendix D, Tables 1-12, on a per sample basis. This data was used to prepare Tables 13-24 in which total gas, carbon dioxide, and nitrous oxide production in aerobic and anaerobic treatments is presented on a per gram cellulose basis. Figures 13-24 are based on the data from Tables 13-24. The data in tables 13-24 have been corrected for gas production in the absence of cellulose by subtracting measured gas values in respective treatments prepared without cellulose. As an example, total gas production in aerobic samples was corrected (Table 13) by subtracting total gas production in treatments without cellulose (designated "NC", Appendix D, Table 1) from samples with cellulose (designated "C") at each time period. The resultant number was divided by the total amount of cellulose in each sample bottle ( 5 grams) in order to arrive at a value that represents the total gas produced per gram of cellulose. Tables 13 to 24 represent the gas produced strictly due to the presence of cellulose in the samples, and are corrected for gas produced due to metabolism of dissolved organic carbon present in the brine or in the nutrient addition as measured in specific control treatments. Carbon dioxide was produced in certain samples in the absence of cellulose, specifically prior to 69 days. After this period, gas production reported is that which is above and beyond the control treatments. Significant quantities of $\mathrm{N}_{2} \mathrm{O}$ were not detected in the absence of cellulose. Gas produced at time 0 was not subtracted from later values, as may seem obvious in order to normalize the starting values at 0 . This was not done because time 0 measurements were taken 3 days after sample preparation, therefore gas present at time 0 is due to evolution of dissolved gases and headspace equilibration. These processes contribute to the overall gas production.

Figures 13 to 24 present data from Table 13 to 24 . All data in these figures are presented as gas produced per gram cellulose, and have been corrected for gas production in the absence of 
cellulose. The data plotted are the mean values of three samples and error bars represent the standard error of the mean. In the legend: "uninoculated" refers to samples that have received no mixed inoculum or nutrients; "inoculated" refers to samples that have received mixed inoculum but no nutrients; "inoculated + nutrients" refers to samples that have received both mixed inoculum and nutrients (amended), and; "inoculated + nutrients + nitrate" refers to samples that have received (i) mixed inoculum, (ii) nutrients, and (iii) excess nitrate in the form of potassium nitrate (amended plus excess nitrate).

Data for treatments prepared with glucose to determine activity of the mixed inoculum are presented in Figures 25-30. Data for gas analysis of these samples, along with formalin treated controls for all cellulose and no-cellulose treatments, are presented in Appendix D, Tables 1(a) to 4(c).

Analysis of the samples will continue at select intervals (as determined by gas producing activity) past 200 days and up to 800 days. The analyses will then stop if activity ceases, as indicated by cessation of gas production, or be prolonged if gas producing activity continues in the samples. If this occurs in select samples only then these samples will be reserved for long term monitoring, and analyses of inactive samples will stop. 
Table 1. Gross Data for the Long-Term Inundated Experiment: Total Volume of Gas Produced in Aerobic Samples.

\begin{tabular}{|c|c|c|c|c|c|c|c|c|c|c|c|c|c|c|c|}
\hline \multirow{3}{*}{$\begin{array}{l}\text { Treatments* } \\
\text { [Brine] }\end{array}$} & \multirow{3}{*}{$\begin{array}{l}\text { Sample } \\
\text { Designation }\end{array}$} & \multicolumn{14}{|c|}{ Volume of Gas Produced (ml) } \\
\hline & & \multirow{2}{*}{\multicolumn{2}{|c|}{$\mathbf{0}$}} & \multirow{2}{*}{\multicolumn{2}{|c|}{45}} & \multicolumn{6}{|c|}{ Incubation Time (Days) } & \multirow{2}{*}{\multicolumn{2}{|c|}{164}} & \multirow{2}{*}{\multicolumn{2}{|c|}{200}} \\
\hline & & & & & & & 69 & 104 & & 132 & & & & & \\
\hline \multicolumn{16}{|l|}{ Unamended/Uninoculated (1) } \\
\hline Formalin treated, w/o cellulose & $1(N C)-f$ & 4.22 & \pm 0.13 & -0.35 & \pm 0.13 & -0.06 & \pm 0.45 & $-0.26 \pm 0.06$ & -0.13 & \pm & 0.13 & & NA & -1.44 & \pm 0.00 \\
\hline Formalin treated, with cellulose & $1(C)-f$ & 5.44 & \pm 0.32 & 4.09 & \pm 0.16 & 4.19 & \pm 0.10 & $2.08 \pm 1.06$ & 1.37 & \pm & 0.93 & & NA & 0.67 & \pm 0.90 \\
\hline As is, w/o cellulose & $1(\mathrm{NC})-\mathrm{a}$ & 4.39 & \pm 0.03 & 3.71 & \pm 0.03 & 3.84 & \pm 0.03 & $1.90 \pm 0.61$ & 1.33 & \pm & 0.85 & & NA & -0.61 & \pm 0.75 \\
\hline As is, with cellulose & $f(C)-a$ & 4.63 & \pm 0.10 & 2.28 & \pm 0.95 & 2.04 & \pm 0.92 & $0.34 \pm 0.68$ & 0.34 & \pm & 0.61 & & NA & -1.53 & \pm 0.51 \\
\hline \multicolumn{16}{|l|}{ Unamended!Inoculated (2) } \\
\hline Formalin treated, w/o cellulose & $2(N C)-f$ & 4.96 & \pm 0.02 & 2.88 & \pm 0.04 & 3.50 & \pm 0.00 & $2.49 \pm 0.04$ & 2.45 & \pm & 0.14 & & NA & 0.07 & \pm 0.25 \\
\hline Formalin treated, with cellulose & $2(C)-f$ & 4.89 & \pm 0.06 & 2.72 & \pm 0.38 & 1.76 & \pm 0.56 & $0.91 \pm 0.41$ & 0.41 & \pm & 0.53 & & NA & -0.50 & \pm 0.44 \\
\hline As is, w/o cellulose & $2(N C)-a$ & 3.56 & \pm 0.02 & 2.90 & \pm 0.15 & 2.21 & \pm 0.30 & $0.53 \pm 0.11$ & -0.91 & \pm & 0.04 & & NA & -2.86 & \pm 0.04 \\
\hline As is, with cellulose & $2(C)-a$ & 3.16 & \pm 0.03 & 2.97 & \pm 0.22 & 1.44 & \pm 0.16 & $-0.44 \pm 0.22$ & -1.28 & \pm & 0.25 & & NA & -4.57 & \pm 0.34 \\
\hline \multicolumn{16}{|l|}{ Amended/Inoculated (3) } \\
\hline As is, w/o cellulose & $3(N C)-a$ & 3.20 & \pm 0.04 & 1.37 & \pm 0.04 & 0.30 & \pm 0.00 & $0.11 \pm 0.04$ & -1.49 & \pm & 0.15 & -2.48 & \pm 0.38 & -4.53 & \pm 0.46 \\
\hline As is, with cellulose & $3(C)-a$ & 2.60 & \pm 0.16 & 0.03 & \pm 0.69 & -0.94 & \pm 0.31 & $1.91 \pm 1.53$ & 1.44 & \pm & 1.19 & 0.34 & \pm 0.63 & -0.22 & \pm 0.41 \\
\hline As is, with glucose & $3(G)-a$ & 3.73 & \pm 0.08 & 2.29 & \pm 0.15 & 1.83 & \pm 0.38 & $-1.79 \pm 0.34$ & -1.22 & \pm & 1.37 & 1.87 & \pm 2.63 & -1.83 & \pm 1.30 \\
\hline Excess nitrate, w/o cellulose & $3(N C)-x$ & 3.16 & \pm 0.08 & 0.84 & \pm 0.46 & -1.30 & \pm 0.08 & $-0.78 \pm 0.30$ & -1.14 & \pm & 0.04 & -1.80 & \pm 0.18 & -2.82 & \pm 0.27 \\
\hline Excess nitrate, with cellulose & $3(C)-x$ & 3.04 & \pm 0.06 & 0.94 & \pm 0.72 & 5.66 & \pm 3.04 & $11.9 \pm 4.4$ & 15.5 & \pm & 5.3 & 18.3 & \pm 6.1 & 19.3 & \pm 4.0 \\
\hline Excess nitrate, with glucose & $3(G)-x$ & 3.52 & \pm 0.02 & 2.74 & \pm 0.50 & 0.88 & \pm 0.76 & $-1.49 \pm 0.27$ & -1.30 & \pm & 0.04 & -0.86 & \pm 0.72 & 2.90 & \pm 2.02 \\
\hline
\end{tabular}

NA $=$ not analyzed 
Table 2. Gross Data for the Long-Term Inundated Experiment: Production of Carbon Dioxide* in Aerobic Samples

\begin{tabular}{|c|c|c|c|c|c|c|c|c|c|c|c|}
\hline \multirow{3}{*}{$\begin{array}{c}\text { Treatments } \\
\text { [Brine] }\end{array}$} & \multirow{3}{*}{$\begin{array}{l}\text { Sample } \\
\text { Designation }\end{array}$} & \multirow{2}{*}{\multicolumn{10}{|c|}{$\frac{\text { Carbon Dioxide ( } \mu \text { moles/sample) }}{\text { Incubation Time (Days) }}$}} \\
\hline & & \multirow[b]{2}{*}{0} & \multirow[b]{2}{*}{45} & & & Incubation Tir & e (Day) & & & & \\
\hline & & & & \multicolumn{2}{|r|}{69} & 104 & \multicolumn{2}{|c|}{132} & \multicolumn{2}{|r|}{164} & 200 \\
\hline \multicolumn{12}{|l|}{ Unamended/Uninoculated (1) } \\
\hline Formalin treated, w/o cellulose & $1(N C)-f$ & $2.59 \pm 0.01$ & $2.50 \pm 0.01$ & 3.40 & \pm 0.40 & $3.32 \pm 0.00$ & 3.61 & \pm 0.00 & & NA & $3.68 \pm 0.01$ \\
\hline Formalin treated, with cellulose & $1(C)-f$ & $30.5 \pm 2.7$ & $40.8 \pm 0.1$ & 44.4 & \pm 0.2 & $40.6 \pm 0.8$ & 41.8 & \pm 0.3 & & NA & $41.8 \pm 0.5$ \\
\hline As is, w/o cellulose & $1(N C)-a$ & $1.38 \pm 0.01$ & $1.49 \pm 0.01$ & 0.94 & \pm 0.00 & $1.66 \pm 0.01$ & 1.83 & \pm 0.06 & & NA & $2.18 \pm 0.04$ \\
\hline As is, with cellulose & $1(C)-a$ & $13.8 \pm 0.5$ & $21.1 \pm 0.3$ & 22.0 & \pm 0.1 & $21.3 \pm 0.1$ & 23.1 & \pm 0.1 & & NA & $22.2 \pm 0.1$ \\
\hline \multicolumn{12}{|l|}{ Unamended/Inoculated (2) } \\
\hline Formalin treated, w/o cellulose & $2(N C)-f$ & $4.97 \pm 0.45$ & $4.38 \pm 0.29$ & 4.70 & \pm 0.11 & $4.88 \pm 0.3$ & 5.02 & \pm 0.30 & & NA & $4.94 \pm 0.27$ \\
\hline Formalin treated, with cellulose & $2(C)-f$ & $34.5 \pm 0.8$ & $35.6 \pm 0.0$ & 38.7 & \pm 0.7 & $34.3 \pm 0.6$ & 35.2 & \pm 0.1 & & NA & $33.2 \pm 1.1$ \\
\hline As is, w/o cellulose & $2(N C)-a$ & $2.30 \pm 0.02$ & $2.97 \pm 0.03$ & 2.92 & \pm 0.09 & $5.88 \pm 0.08$ & 6.56 & \pm 0.11 & & NA & $7.01 \pm 0.11$ \\
\hline As is, with cellulose & $2(C)-a$ & $12.1 \pm 0.3$ & $19.7 \pm 0.8$ & 22.6 & \pm 0.9 & $30.8 \pm 0.9$ & 40.9 & \pm 1.0 & & NA & $48.5 \pm 1.4$ \\
\hline \multicolumn{12}{|l|}{ Amended/Inoculated (3) } \\
\hline As is, w/o cellulose & $3(N C)-a$ & $2.87 \pm 0.03$ & $27.8 \pm 1.2$ & 72.9 & \pm 2.6 & $113 \pm 5$ & 130 & \pm 2 & 150 & \pm 1 & $142 \pm 1$ \\
\hline As is, with cellulose & $3(C)-\mathbf{a}$ & $2.80 \pm 0.10$ & $50.9 \pm 1.4$ & 91.8 & \pm 5.9 & $215 \pm 37$ & 278 & \pm 25 & 333 & \pm 21 & $346 \pm 27$ \\
\hline As is, with glucose & $3(G)-a$ & $2.41 \pm 0.03$ & $4.03 \pm 0.13$ & 30.8 & \pm 2.1 & $94.9 \pm 7.5$ & 167 & \pm 32 & 325 & \pm 108 & $323 \pm 95$ \\
\hline Excess nitrate, w/o cellulose & $3(N C)-x$ & $2.79 \pm 0.03$ & $17.2 \pm 1.9$ & 48.9 & \pm 0.2 & $92.2 \pm 0.59$ & 115 & \pm 3 & 131 & \pm 2 & $126 \pm 2$ \\
\hline Excess nitrate, with cellulose & $3(C)-x$ & $2.60 \pm 0.10$ & $51.6 \pm 0.0$ & 210 & \pm 21 & $399 \pm 18$ & 533 & \pm 13 & 612 & \pm 20 & $604 \pm 30$ \\
\hline Excess nitrate, with glucose & $3(G)-x$ & $2.51 \pm 0.01$ & $4.05 \pm 0.25$ & 24.1 & \pm 5.9 & $72.0 \pm 7.7$ & 121 & \pm 4 & 211 & \pm 6 & $296 \pm 20$ \\
\hline
\end{tabular}

*Dissolved carbon dioxide concentrations not included.

$\mathrm{NA}=$ not analyzed 
Table 3. Gross Data for the Long-Term Inundated Experiment: Production of Nitrous Oxide* in Aerobic Samples

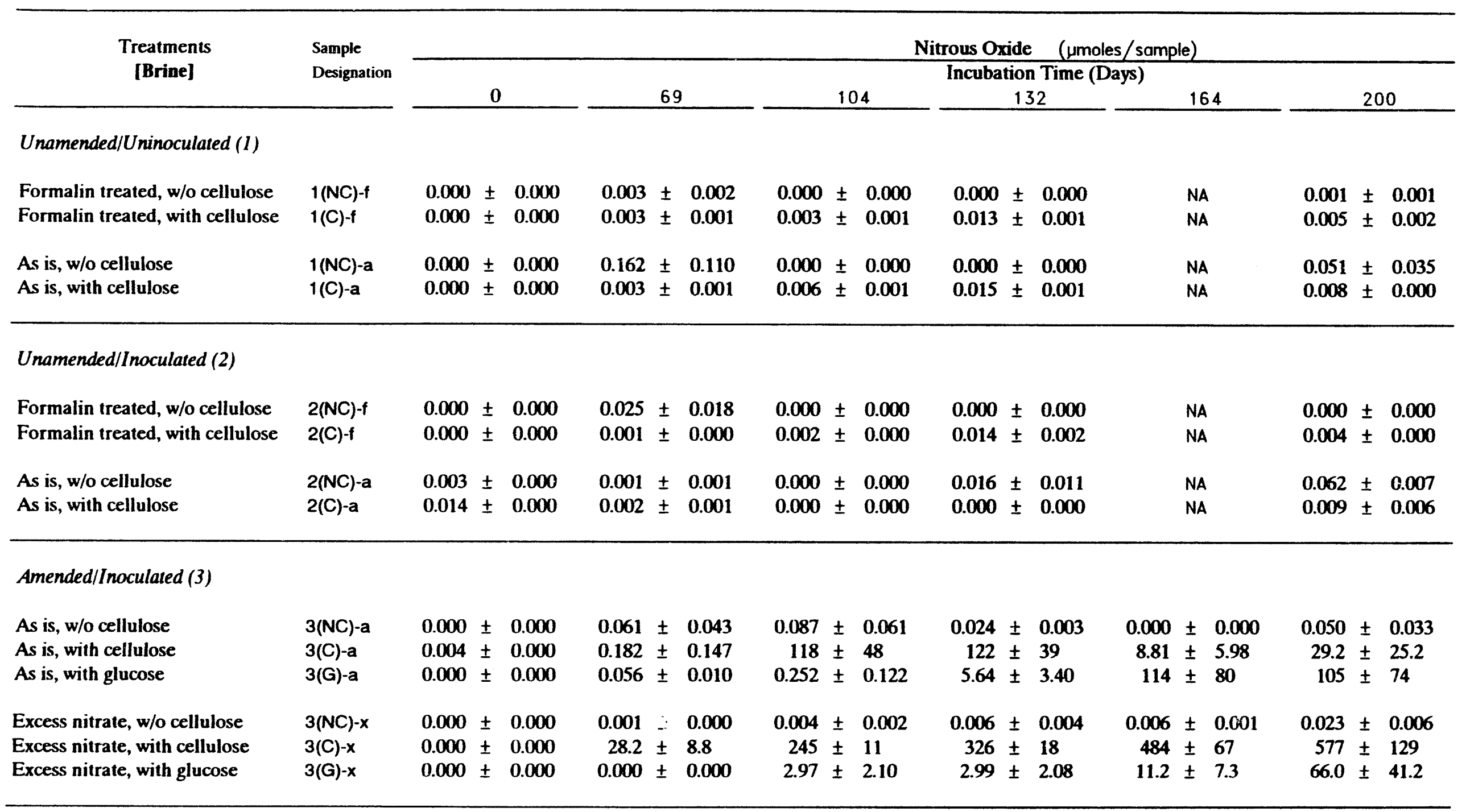

'Dissolved nitrous oxide concentrations not included.

$\mathrm{NA}=$ not analyzed 
Table 4. Gross Data for the Long-Term Inundated Experiment: Total Volume of Gas Produced in Aerobic Samples

\begin{tabular}{|c|c|c|c|c|c|c|c|c|c|c|c|c|c|c|}
\hline \multirow{3}{*}{$\begin{array}{c}\text { Treatments* } \\
\text { [Brine/Bentonite] }\end{array}$} & \multirow{3}{*}{$\begin{array}{l}\text { Sample } \\
\text { Designation }\end{array}$} & \multicolumn{13}{|c|}{ Volume of Gas Produced (ml) } \\
\hline & & \multirow{2}{*}{\multicolumn{2}{|c|}{$\mathbf{0}$}} & \multicolumn{8}{|c|}{ Incubation Time (Days) } & \multirow{2}{*}{\multicolumn{2}{|c|}{164}} & \multirow[b]{2}{*}{200} \\
\hline & & & & & 45 & & 69 & 104 & & 132 & & & & \\
\hline \multicolumn{15}{|l|}{ Unamended/Uninoculated (4) } \\
\hline Formalin treated, w/o cellulose & $4(N C)-f$ & 5.93 & \pm 0.04 & 1.24 & \pm 2.02 & 1.43 & \pm 1.74 & $1.09 \pm 1.05$ & -0.31 & \pm & 0.00 & & NA & $-2.17 \pm 0.00$ \\
\hline Formalin treated, with cellulose & $4(C)-f$ & 6.59 & \pm 0.16 & 4.38 & \pm 0.13 & 3.77 & \pm 0.13 & $1.82 \pm 0.13$ & 0.10 & \pm & 0.03 & & NA & $-1.98 \pm 0.03$ \\
\hline As is, w/o cellulose & $4(\mathrm{NC})-\mathrm{a}$ & 5.43 & \pm 0.04 & 3.63 & \pm 0.53 & 4.78 & \pm 0.78 & $2.65 \pm 0.45$ & 1.92 & \pm & 0.20 & & NA & $-0.82 \pm 0.20$ \\
\hline As is, with cellulose & $4(C)-a$ & 5.17 & \pm 0.10 & 3.74 & \pm 0.10 & 2.99 & \pm 0.20 & $1.67 \pm 0.24$ & 1.26 & \pm & 0.20 & & NA & $-0.82 \pm 0.27$ \\
\hline \multicolumn{15}{|l|}{ Unamended/Inoculated (5) } \\
\hline Formalin treated, w/o cellulose & $5(N C)-f$ & 5.08 & \pm 0.36 & 2.56 & \pm 0.83 & 1.19 & \pm 1.73 & $0.76 \pm 0.94$ & 0.54 & \pm & 0.65 & & NA & $-2.02 \pm 0.36$ \\
\hline Formalin treated, with cellulose & $5(C)-f$ & 5.65 & \pm 0.12 & 3.63 & \pm 0.03 & 2.72 & \pm 0.00 & $2.22 \pm 0.00$ & 0.88 & \pm & 0.15 & & NA & $-1.23 \pm 0.12$ \\
\hline As is, w/o cellulose & $5(N C)-a$ & 3.66 & \pm 0.30 & 3.62 & \pm 0.04 & 2.78 & \pm 0.08 & $1.64 \pm 0.15$ & 1.14 & \pm & 0.11 & & NA & $-2.06 \pm 0.34$ \\
\hline As is, with cellulose & $5(C)-a$ & 3.79 & \pm 0.06 & 3.13 & \pm 0.09 & 1.88 & \pm 0.19 & $0.16 \pm 0.66$ & -1.94 & \pm & 0.47 & & NA & $-2.47 \pm 0.78$ \\
\hline \multicolumn{15}{|l|}{ Amended/Inoculated (6) } \\
\hline As is, w/o cellulose & $6(\mathrm{NC})-\mathrm{a}$ & 3.85 & \pm 0.04 & 0.84 & \pm 0.84 & 1.52 & \pm 0.84 & $1.56 \pm 0.80$ & 0.11 & \pm & 0.53 & -1.49 & \pm 0.34 & $-3.47 \pm 0.15$ \\
\hline As is, with cellulose & $\sigma(C)-a$ & 2.60 & \pm 0.16 & 3.00 & \pm 0.06 & 5.07 & \pm 0.75 & $10.7 \pm 1.8$ & 14.9 & \pm & 1.5 & 18.9 & \pm 1.1 & $18.4 \pm 1.0$ \\
\hline As is, with glucose & $6(G)-a$ & 1.60 & \pm 0.04 & 1.10 & \pm 0.69 & 0.69 & \pm 0.50 & $-0.34 \pm 0.19$ & -1.07 & \pm & 0.27 & -1.62 & \pm 0.19 & $-1.52 \pm 0.61$ \\
\hline Excess nitrate, w/o cellulose & $6(N C)-x$ & 1.41 & \pm 0.08 & -1.45 & \pm 0.04 & -0.99 & \pm 0.08 & $0.00 \pm 0.00$ & -0.27 & \pm & 0.08 & -1.30 & \pm 0.04 & $-3.05 \pm 0.08$ \\
\hline Excess nitrate, with cellulose & $6(C)-x$ & 2.91 & \pm 0.06 & 2.82 & \pm 0.09 & 6.79 & \pm 0.09 & $11.2 \pm 1.2$ & 18.7 & \pm & 1.5 & 24.4 & \pm 0.9 & $27.3 \pm 0.2$ \\
\hline Excess nitrate, with glucose & $6(G)-x$ & 2.29 & \pm 0.23 & 2.51 & \pm 1.71 & 0.69 & \pm 0.57 & $-0.38 \pm 0.5$ & -0.53 & \pm & 0.11 & -1.49 & \pm 0.15 & $-1.94 \pm 0.69$ \\
\hline
\end{tabular}

NA = not analyzed 
Table 5. Gross Data for the Long-Term Inundated Experiment: Production of Carbon Dioxide* in Aerobic Samples

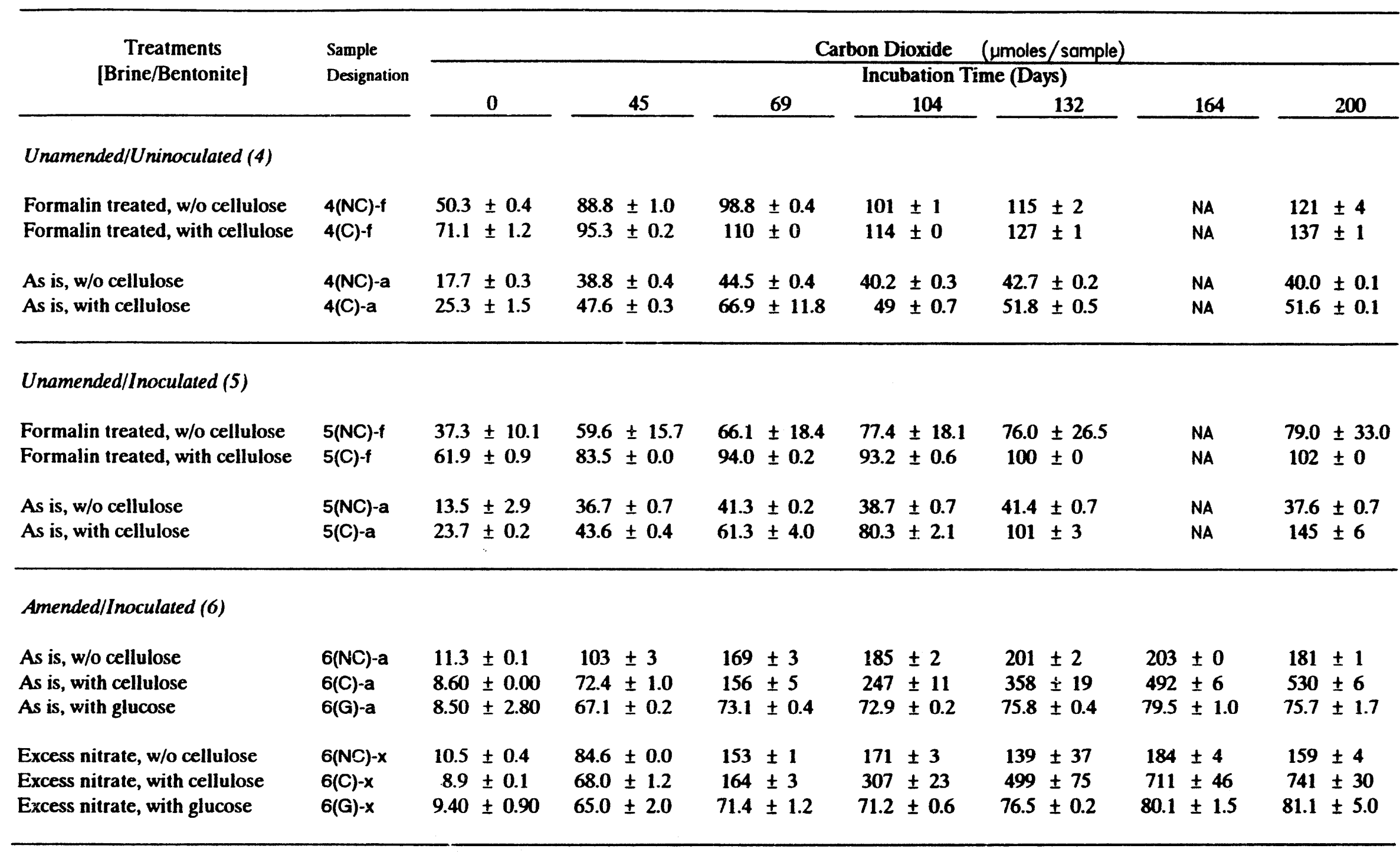

*Dissolved carbon dioxide concentrations not included.

NA = not analyzed 
Table 6. Gross Data for the Long-Term Inundated Experiment: Production of Nitrous Oxide* in Aerobic Samples

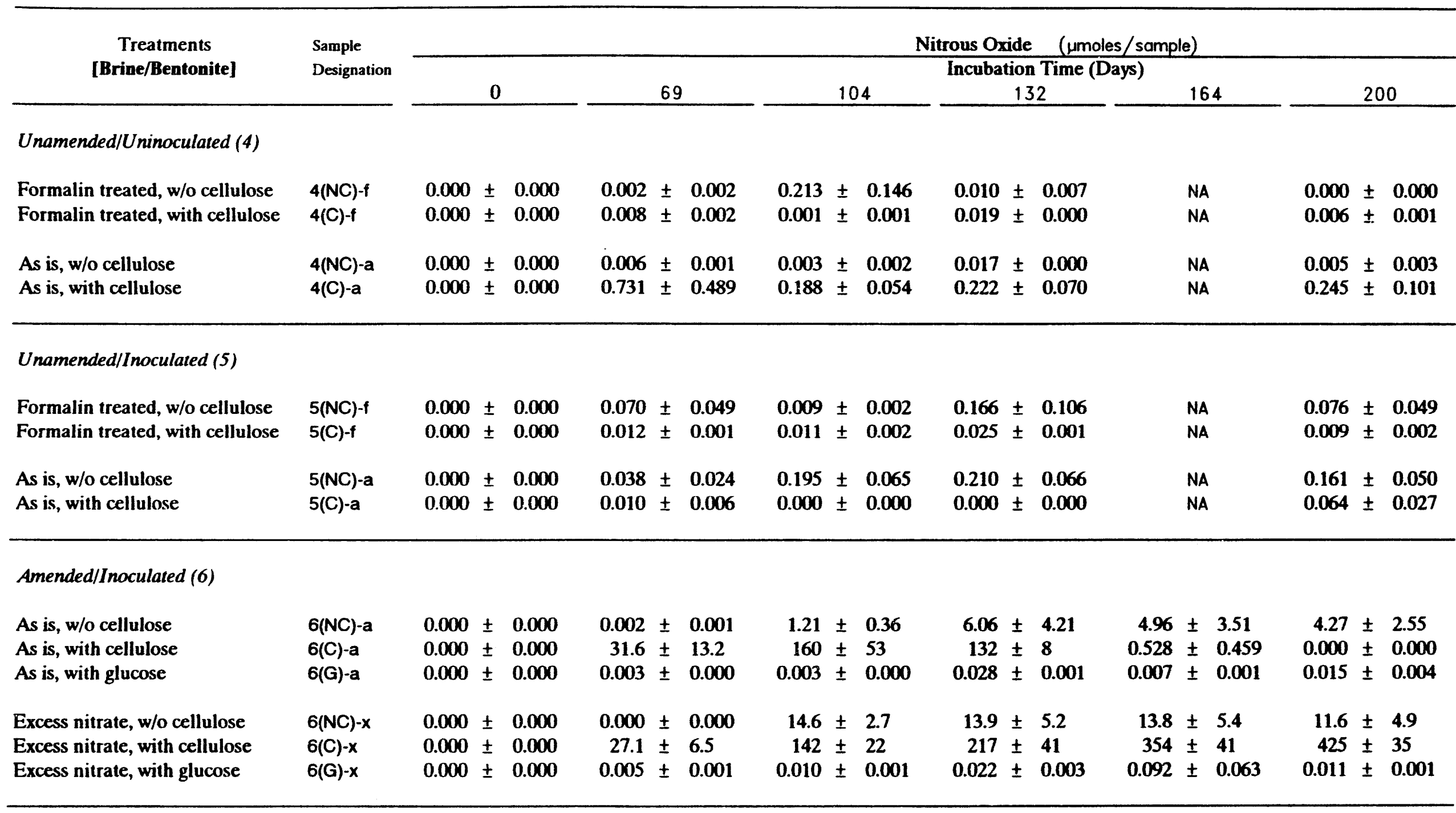

*Dissolved nitrous oxide concentrations not included.

NA $=$ not analyzed 
Table 7. Gross Data for the Long-Term Inundated Experiment: Total Volume of Gas Produced in Anaerobic Samples

\begin{tabular}{|c|c|c|c|c|c|c|c|c|c|c|c|c|c|c|c|}
\hline \multirow{3}{*}{$\begin{array}{l}\text { Treatments* } \\
\text { [Brine] }\end{array}$} & \multirow{3}{*}{$\begin{array}{l}\text { Sample } \\
\text { Designation }\end{array}$} & \multicolumn{14}{|c|}{ Volume of Gas Produced (ml) } \\
\hline & & \multirow{2}{*}{\multicolumn{2}{|c|}{0}} & \multirow{2}{*}{\multicolumn{2}{|c|}{45}} & \multicolumn{6}{|c|}{ Incubation Time (Days) } & \multirow{2}{*}{\multicolumn{2}{|c|}{164}} & \multirow{2}{*}{\multicolumn{2}{|c|}{200}} \\
\hline & & & & & & & 69 & 104 & & 132 & & & & & \\
\hline \multicolumn{16}{|l|}{ Unamended/Uninoculated (7) } \\
\hline Formalin treated, w/o cellulose & $7(N C)-f$ & 2.99 & \pm 0.10 & 2.65 & \pm 0.10 & 2.01 & \pm 0.03 & $1.09 \pm 0.06$ & 1.66 & \pm & 0.00 & & NA & 0.06 & $\pm \mathbf{0 . 0 3}$ \\
\hline Formalin treated, with cellulose & $7(C)-f$ & 4.28 & \pm 0.06 & 3.49 & \pm 0.06 & 3.10 & \pm 0.03 & $1.95 \pm 0.03$ & 2.37 & \pm & 0.03 & & NA & 1.37 & \pm 0.00 \\
\hline As is, w/o cellulose & $7(N C)-a$ & 3.20 & \pm 0.34 & 2.96 & \pm 0.07 & 0.99 & \pm 0.14 & $2.2 \dot{4} \pm 0.00$ & 2.07 & \pm & 0.10 & & NA & 0.65 & \pm 0.31 \\
\hline As is, with cellulose & $7(C)-a$ & 3.37 & \pm 0.27 & 3.47 & \pm 0.10 & 2.99 & \pm 0.07 & $1.33 \pm 0.34$ & 2.28 & \pm & 1.17 & & NA & 0.20 & \pm 0.17 \\
\hline \multicolumn{16}{|l|}{ Unamended/Inoculated (8) } \\
\hline Formalin treated, w/o cellulose & $8(N C)-f$ & 3.79 & \pm 0.04 & 2.31 & \pm 0.07 & 1.73 & \pm 0.18 & $0.76 \pm 0.11$ & 1.55 & \pm & 0.11 & & NA & -0.07 & \pm 0.11 \\
\hline Formalin treated, with cellulose & $8(C)-f$ & 3.89 & \pm 0.03 & 3.39 & \pm 0.09 & 2.54 & \pm 0.15 & $1.58 \pm 0.00$ & 2.14 & \pm & 0.06 & & NA & 1.02 & \pm 0.03 \\
\hline As is, w/o cellulose & $8(N C)-a$ & 3.66 & \pm 0.08 & -1.37 & \pm 0.99 & 1.41 & \pm 0.23 & $1.87 \pm 0.08$ & 2.10 & \pm & 0.08 & & NA & -0.50 & \pm 0.00 \\
\hline As is, with cellulose & $8(C)-a$ & 3.47 & \pm 0.06 & 3.63 & \pm 0.13 & 2.53 & \pm 0.16 & $1.78 \pm 0.13$ & 2.22 & \pm & 0.06 & & NA & 2.44 & \pm 0.63 \\
\hline \multicolumn{16}{|l|}{ Amended/Inoculated (9) } \\
\hline As is, w/o cellulose & $9(N C)-a$ & 3.77 & \pm 0.04 & 3.35 & \pm 0.08 & 6.63 & \pm 0.30 & $7.96 \pm 1.33$ & 9.07 & \pm & 0.88 & 8.41 & \pm 0.48 & 8.04 & \pm 0.46 \\
\hline As is, with cellulose & $9(C)-a$ & 3.35 & \pm 0.09 & 3.44 & \pm 0.16 & 4.04 & \pm 0.03 & $11.3 \pm 0.5$ & 16.7 & \pm & 1.3 & 19.2 & \pm 1.2 & 19.4 & \pm 0.6 \\
\hline As is, with glucose & $9(G)-a$ & 2.97 & \pm 0.08 & 2.59 & \pm 0.15 & 2.36 & \pm 0.15 & $1.64 \pm 0.15$ & 1.52 & \pm & 0.27 & 0.18 & \pm 0.16 & -1.26 & \pm 0.30 \\
\hline Excess nitrate, w/o cellulose & $9(N C)-x$ & 3.24 & \pm 0.04 & 2.86 & \pm 0.08 & 4.30 & \pm 0.23 & $6.59 \pm 0.76$ & 9.18 & \pm & 0.23 & 8.65 & \pm 0.67 & 6.93 & \pm 0.27 \\
\hline Excess nitrate, with cellulose & $9(C)-x$ & 3.29 & \pm 0.13 & 2.28 & \pm 0.38 & 5.76 & \pm 1.47 & $16.6 \pm 2.9$ & 14.2 & \pm & 3.9 & 28.9 & \pm 6.2 & 34.1 & \pm 7.1 \\
\hline Excess nitrate, with glucose & $9(G)-x$ & 3.01 & \pm 0.11 & 0.61 & \pm 0.15 & 0.19 & \pm 0.11 & $0.46 \pm 0.04$ & 0.46 & \pm & 0.61 & 1.33 & \pm 2.08 & 1.14 & \pm 2.90 \\
\hline
\end{tabular}

NA = not analyzed 
Table 8. Gross Data for the Long-Term Inundated Experiment: Production of Carbon Dioxide* in Anaerobic Samples

\begin{tabular}{|c|c|c|c|c|c|c|c|c|c|c|c|c|c|c|c|}
\hline \multirow{3}{*}{$\begin{array}{c}\text { Treatments } \\
\text { [Brine] }\end{array}$} & \multirow{3}{*}{$\begin{array}{l}\text { Sample } \\
\text { Designation }\end{array}$} & \multirow{3}{*}{\multicolumn{2}{|c|}{0}} & \multicolumn{12}{|c|}{ Carbon Dioxide (umoles/sample) } \\
\hline & & & & \multicolumn{12}{|c|}{ Incubation Time (Days) } \\
\hline & & & & & 45 & & 69 & & 104 & & 132 & & 164 & & 200 \\
\hline \multicolumn{16}{|l|}{ Unamended/Uninoculated (7) } \\
\hline Formalin treated, w/o cellulose & $7(N C)-f$ & 2.26 & \pm 0.01 & 1.92 & \pm 0.03 & 2.20 & \pm 0.20 & 2.24 & \pm 0.04 & 2.33 & \pm 0.01 & & NA & 2.39 & \pm 0.01 \\
\hline Formalin treated, with cellulose & $7(C)-f$ & 31.7 & \pm 0.5 & 38.0 & \pm 0.1 & 38.0 & $\pm 0 . i$ & 35.0 & \pm 0.2 & 36.4 & \pm 0.1 & & NA & 36.3 & \pm 0.1 \\
\hline As is, w/o cellulose & $7(N C)-a$ & 1.12 & \pm 0.01 & 0.58 & \pm 0.13 & 0.90 & $\pm \mathbf{0 . 0 0}$ & 1.37 & \pm 0.01 & 1.35 & \pm 0.01 & & NA & 1.46 & \pm 0.03 \\
\hline As is, with cellulose & $7(C)-a$ & 13.0 & \pm 0.4 & 19.3 & \pm 0.1 & 20.5 & \pm 0.1 & 19.5 & \pm 0.1 & 20.5 & \pm 0.2 & & NA & 19.4 & \pm 0.2 \\
\hline \multicolumn{16}{|l|}{ Unamended/Inoculated (8) } \\
\hline Formalin treated, w/o cellulose & $8(N C)-f$ & 4.42 & \pm 0.01 & 3.88 & \pm 0.08 & 3.89 & \pm 0.13 & 3.88 & \pm 0.04 & 3.99 & \pm 0.03 & & NA & 3.97 & \pm 0.03 \\
\hline Formalin treated, with cellulose & $8(C)-f$ & 32.1 & \pm 0.7 & 34.3 & \pm 0.4 & 33.5 & \pm 0.2 & 31.2 & \pm 0.0 & 32.5 & \pm 0.5 & & NA & 32.8 & \pm 0.4 \\
\hline As is, w/o cellulose & $8(N C)-a$ & 1.96 & \pm 0.02 & 1.37 & \pm 0.01 & 2.29 & \pm 0.02 & 2.75 & \pm 0.01 & 2.86 & \pm 0.01 & & NA & 2.74 & \pm 0.01 \\
\hline As is, with cellulose & $8(C)-a$ & 12.5 & \pm 0.2 & 18.4 & \pm 0.2 & 19.0 & \pm 0.1 & 17.8 & \pm 0.7 & 22.7 & \pm 0.5 & & NA & 30.1 & \pm 1.7 \\
\hline \multicolumn{16}{|l|}{ Amended/Inoculated (9) } \\
\hline As is, w/o cellulose & $9(N C)-a$ & 3.02 & \pm 0.00 & 6.86 & \pm 0.02 & 58.9 & \pm 3.1 & 95.9 & \pm 9.5 & 109 & \pm 4 & 119 & \pm 3 & 120 & \pm 1 \\
\hline As is, with cellulose & $9(c)-a$ & 2.70 & \pm 0.00 & 25.8 & \pm 0.2 & 42.5 & \pm 1.7 & 132 & \pm 3 & 200 & \pm 7 & 240 & \pm 3 & 250 & \pm 4 \\
\hline As is, with glucose & $9(G)-a$ & 2.25 & \pm 0.01 & 3.36 & \pm 0.04 & 2.96 & \pm 0.04 & 3.50 & \pm 0.05 & 3.88 & \pm 0.06 & 4.26 & \pm 0.09 & 4.31 & \pm 0.07 \\
\hline Excess nitrate, w/o cellulose & $9(N C)-x$ & 3.07 & \pm 0.03 & 5.17 & \pm 0.28 & 35.3 & \pm 5.3 & 94.5 & \pm 4.4 & 120 & \pm 1 & 125 & \pm 1 & 123 & \pm 1 \\
\hline Excess nitrate, with cellulose & $9(C)-x$ & 5.40 & $\pm \mathbf{0 . 0 0}$ & 26.6 & \pm 0.2 & 65.8 & \pm 17.1 & 193 & \pm 33 & 249 & \pm 32 & 352 & \pm 40 & 430 & \pm 41 \\
\hline Excess nitrate, with glucose & $9(G)-x$ & 1.81 & \pm 0.27 & 2.88 & \pm 0.19 & 2.65 & \pm 0.25 & 8.64 & \pm 3.62 & 23.6 & \pm 13.3 & 53.6 & \pm 31.4 & 74.9 & \pm 40.9 \\
\hline
\end{tabular}

*Dissolved carbon dioxide concentrations not included.

NA = not analyzed 
Table 9. Gross Data for the Long-Term Inundated Experiment: Production of Nitrous Oxide* in Anaerobic Samples

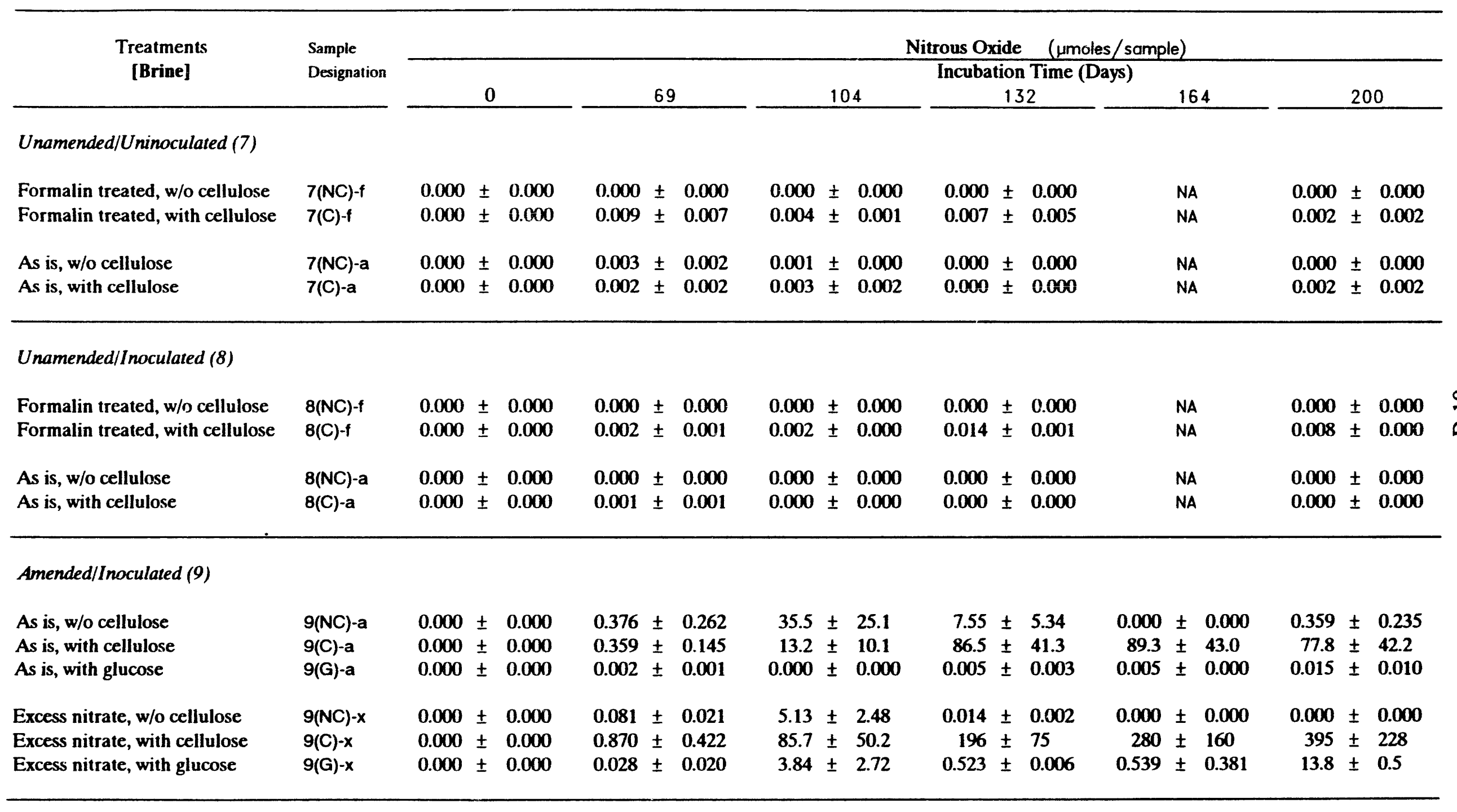

*Dissolved nitrous oxide concentrations not included.

NA = not analyzed 
Table 10. Gross Data for the Long-Term Inundated Experiment: Total Volume of Gas Produced in Anaerobic Samples.

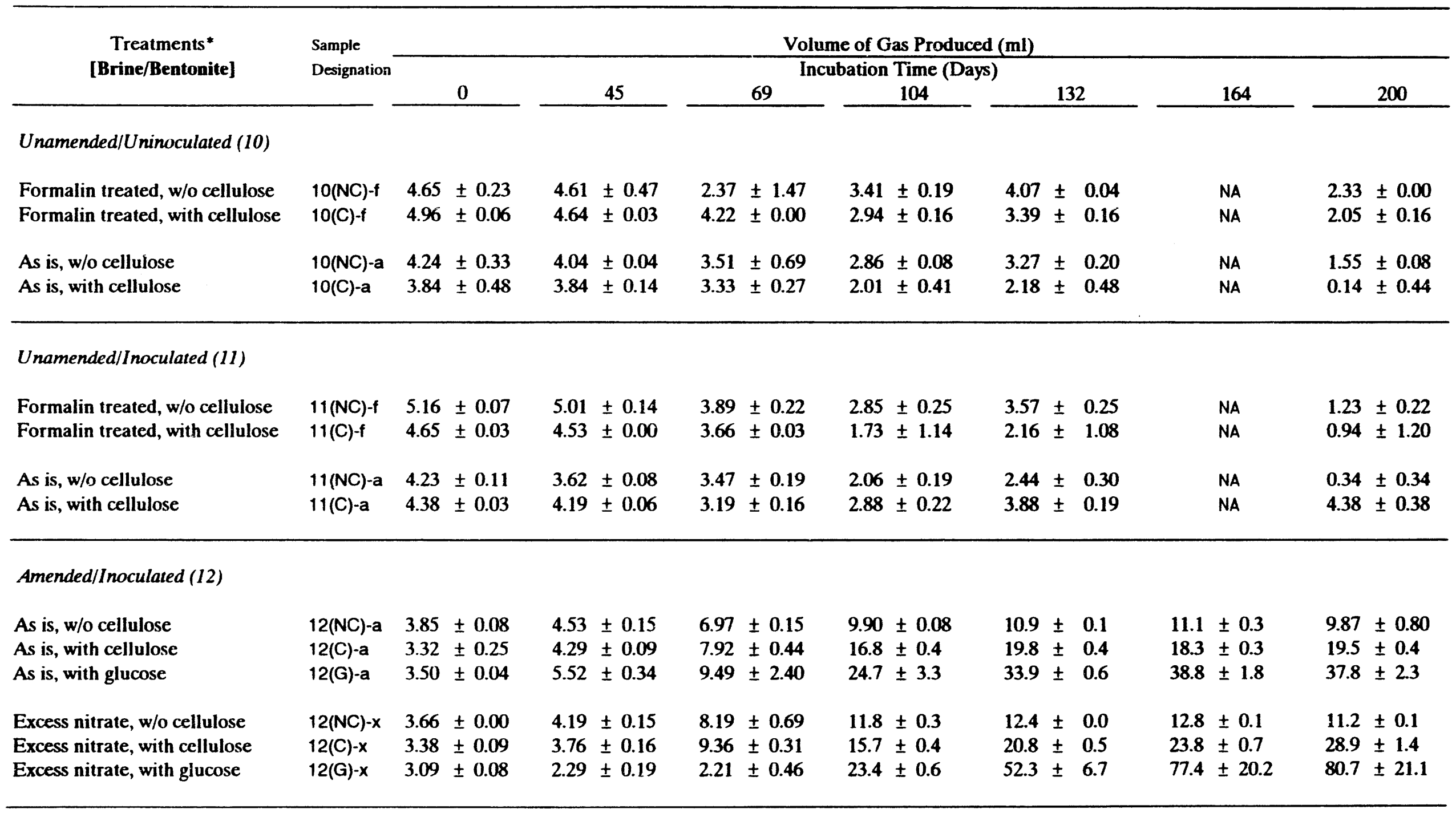

$\mathrm{NA}=$ not analyzed 
Table 11. Gross Data for the Long-Term Inundated Experiment: Production of Carbon Dioxide* in Anaerobic Samples

\begin{tabular}{|c|c|c|c|c|c|c|c|c|}
\hline \multirow{3}{*}{$\begin{array}{c}\text { Treatments } \\
\text { ¿Brine/Bentonite }\end{array}$} & \multirow{3}{*}{$\begin{array}{l}\text { Sample } \\
\text { Designation }\end{array}$} & \multicolumn{7}{|c|}{ Carbon Dioxide ( $\mu$ moles/sample) } \\
\hline & & \multirow[b]{2}{*}{0} & \multicolumn{6}{|c|}{ Incubation Time (Days) } \\
\hline & & & 45 & 69 & 104 & 132 & 164 & 200 \\
\hline \multicolumn{9}{|l|}{ Unamended/Uninoculated (10) } \\
\hline Formalin treated, w/o cellulose & $10(N C)-f$ & $55.8 \pm 0.6$ & $82.9 \pm 1.1$ & $85.5 \pm 0.8$ & $86.4 \pm 1.7$ & $92.8 \pm 2.0$ & NA & $94.9 \pm 1.1$ \\
\hline Formalin treated, with cellulose & $10(C)-f$ & $65.5 \pm 1.0$ & $85.5 \pm 0.2$ & $88.6 \pm 0.4$ & $81.9 \pm 0.3$ & $88.7 \pm 0.9$ & NA & $90.2 \pm 0.3$ \\
\hline As is, w/o cellulose & $10(N C)-a$ & $16.4 \pm 0.4$ & $37.7 \pm 0.0$ & $38.4 \pm 0.1$ & $38.1 \pm 0.3$ & $39.8 \pm 0.3$ & NA & $40.0 \pm 0.4$ \\
\hline As is, with cellulose & $10(C)-a$ & $26.6 \pm 0.5$ & $42.6 \pm 0.2$ & $43.0 \pm 0.4$ & $41.3 \pm 0.2$ & $43.1 \pm 0.5$ & NA & $41.1 \pm 0.2$ \\
\hline \multicolumn{9}{|l|}{ Unamended/Inoculated (11) } \\
\hline Formalin treated, w/o cellulose & $11(N C)-f$ & $53.0 \pm 0.2$ & $76.9 \pm 0.6$ & $80.2 \pm 0.4$ & $76.5 \pm 0.0$ & $83.7 \pm 0.6$ & NA & $83.5 \pm 0.2$ \\
\hline Formalin treated, with cellulose & $11(C)-f$ & $64.4 \pm 1.3$ & $76.3 \pm 0.5$ & $78.6 \pm 0.2$ & $75.1 \pm 1.9$ & $78.6 \pm 1.6$ & NA & $80.4 \pm 0.8$ \\
\hline As is, w/o cellulose & $11(N C)-a$ & $20.8 \pm 0.0$ & $35.0 \pm 0.1$ & $36.3 \pm 0.1$ & $35.2 \pm 0.2$ & $19.6 \pm 11.9$ & NA & $36.2 \pm 0.2$ \\
\hline As is, with cellulose & $11(C)-a$ & $30.1 \pm 0.6$ & $38.1 \pm 0.2$ & $40.5 \pm 0.1$ & $48 \pm 2.5$ & $59.9 \pm 0.7$ & NA & $77.6 \pm 1.0$ \\
\hline \multicolumn{9}{|l|}{ Amended/Inoculated (12) } \\
\hline As is, w/o cellulose & $12(N C)-a$ & $14.0 \pm 0.0$ & $60.2 \pm 0.2$ & $99.8 \pm 4.7$ & $150 \pm 4$ & $16.6 \pm 0.4$ & $177 \pm 1$ & $179 \pm 0$ \\
\hline As is, with cellulose & $12(\mathrm{C})-\mathrm{a}$ & $12.0 \pm 0.8$ & $55.0 \pm 0.3$ & $104 \pm 5$ & $209 \pm 2$ & $260 \pm 8$ & $295 \pm 10$ & $338 \pm 10$ \\
\hline As is, with glucose & $12(G)-a$ & $15.2 \pm 0.6$ & $76.0 \pm 2.4$ & $144 \pm 28$ & $375 \pm 36$ & $590 \pm 15$ & $691 \pm 20$ & $786 \pm 25$ \\
\hline Excess nitrate, w/o cellulose & $12(N C)-x$ & $13.9 \pm 0.3$ & $69.2 \pm 0.0$ & $121 \pm 3$ & $166 \pm 1$ & $186 \pm 2$ & $196 \pm 2$ & $196 \pm 2$ \\
\hline Excess nitrate, with cellulose & $12(C)-x$ & $10.3 \pm 0.6$ & $57.4 \pm 1.7$ & $122 \pm 3$ & $195 \pm 5$ & $264 \pm 6$ & $309 \pm 7$ & $371 \pm 14$ \\
\hline Excess nitrate, with glucose & $12(G)-x$ & $15.1 \pm 0.0$ & $69.4 \pm 1.2$ & $111 \pm 4$ & $422 \pm 12$ & $916 \pm 35$ & $1370 \pm 19$ & $1610 \pm 43$ \\
\hline
\end{tabular}

*Dissolved carbon dioxide concentrations net included.

$\mathrm{NA}=$ not analyzed 
Table 12. Gross Data for the Long-Term Inundated Experiment: Production of Nitrous Oxide* in Anaerobic Samples

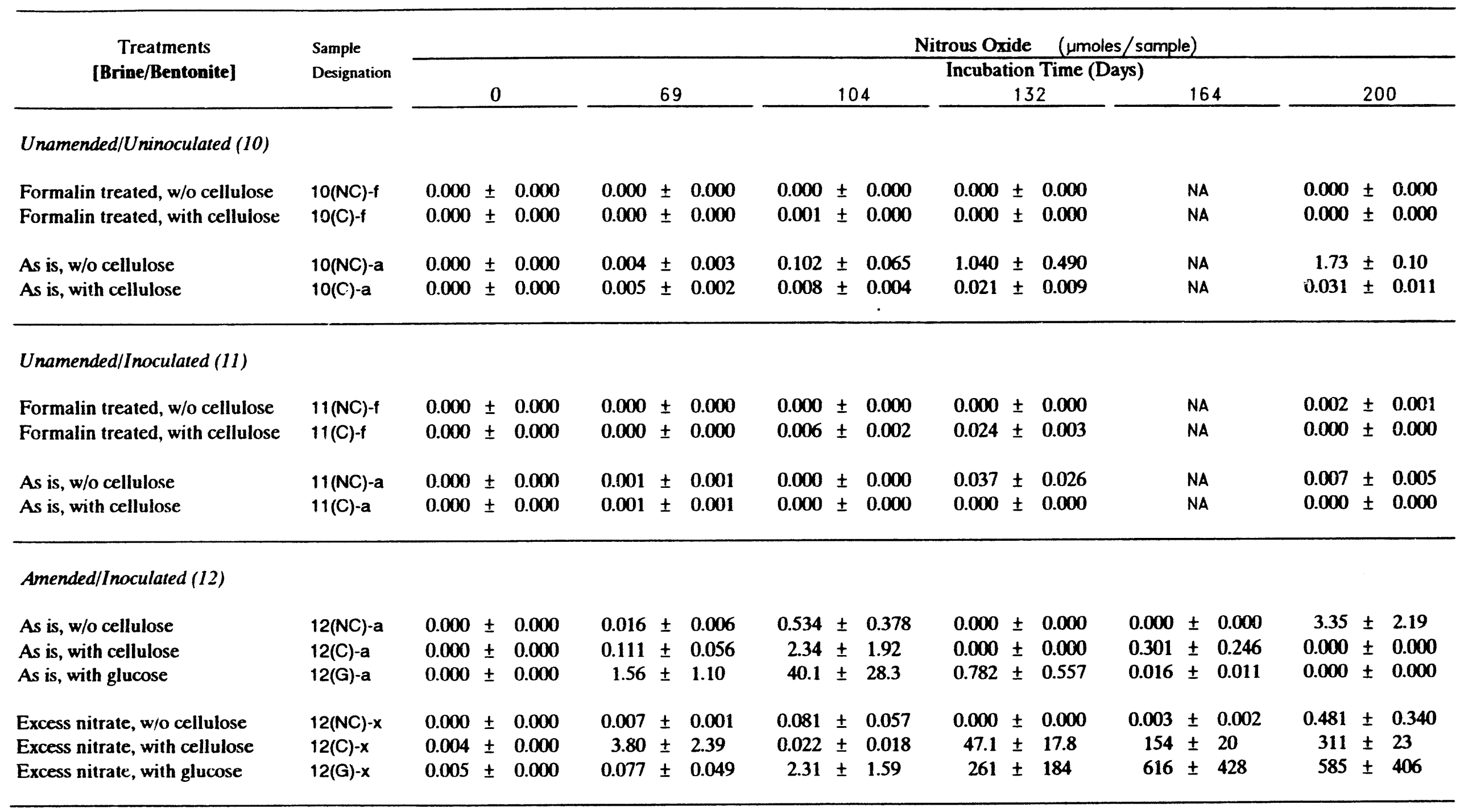

*Dissolved nitrous oxide concentrations not included.

NA = not analyzed 
Table 13. Total Volume of Gas Produced in Aerobic Samples in the Presence of Cellulose*

\begin{tabular}{|c|c|c|c|c|c|c|c|c|c|c|c|}
\hline \multirow{3}{*}{$\begin{array}{c}\text { Treatments } \\
\text { [Brtae] }\end{array}$} & \multirow{3}{*}{$\begin{array}{l}\text { Sample } \\
\text { Deaig. }\end{array}$} & \multicolumn{10}{|c|}{ Milliliters of Gas Produced/Gram Cellulose } \\
\hline & & \multirow{2}{*}{\multicolumn{2}{|c|}{$\mathbf{0}$}} & \multicolumn{5}{|c|}{ Incubation Time (Days) } & \multirow[b]{2}{*}{132} & \multirow[b]{2}{*}{164} & \multirow[b]{2}{*}{200} \\
\hline & & & & & 45 & & 69 & 104 & & & \\
\hline \multicolumn{12}{|c|}{ Unamended/Uninoculated (1) } \\
\hline Formalin & $1(C)-f$ & 0.24 & \pm 0.06 & 0.89 & \pm 0.03 & 0.85 & \pm 0.02 & $0.42 \pm 0.21$ & $0.27 \pm 0.19$ & NA & $0.42 \pm 0.18$ \\
\hline As is & $1(C)-a$ & 0.05 & \pm 0.02 & -0.29 & \pm 0.19 & -0.36 & \pm 0.18 & $-0.31 \pm 0.14$ & $-0.20 \pm 0.12$ & NA & $-0.18 \pm 0.10$ \\
\hline \multicolumn{12}{|c|}{ Unamended/Inoculated (2) } \\
\hline Formalin & $2(C)-f$ & -0.01 & \pm 0.01 & -0.03 & \pm 0.08 & -0.35 & \pm 0.11 & $-0.32 \pm 0.08$ & $-0.41 \pm 0.11$ & NA & $-0.11 \pm 0.09$ \\
\hline As is & $2(C)-2$ & -0.08 & \pm 0.01 & 0.01 & \pm 0.04 & -0.15 & \pm 0.03 & $-0.11 \pm 0.04$ & $0.00 \pm 0.05$ & NA & $-0.34 \pm 0.07$ \\
\hline \multicolumn{12}{|c|}{ Amended/Inoculated (3) } \\
\hline As is & $3(C)-a$ & -0.12 & \pm 0.03 & -0.27 & \pm 0.14 & -0.25 & \pm 0.06 & $0.36 \pm 0.31$ & $0.29 \pm 0.24$ & $0.07 \pm 0.13$ & $0.86 \pm 0.08$ \\
\hline Exc. nitrate & $3(C)-x$ & -0.02 & \pm 0.01 & 0.02 & \pm 0.14 & 1.39 & \pm 0.61 & $2.38 \pm 0.87$ & $3.10 \pm 1.06$ & $4.02 \pm 1.21$ & $4.42 \pm 0.80$ \\
\hline
\end{tabular}

- All values have been corrected with specific controls for gas production in the absence of cellulose NA $=$ not analyzed 
Table 14. Total Volume of Gas Produced in Aerobic Samples in the Presence of Cellulose and Bentonite*

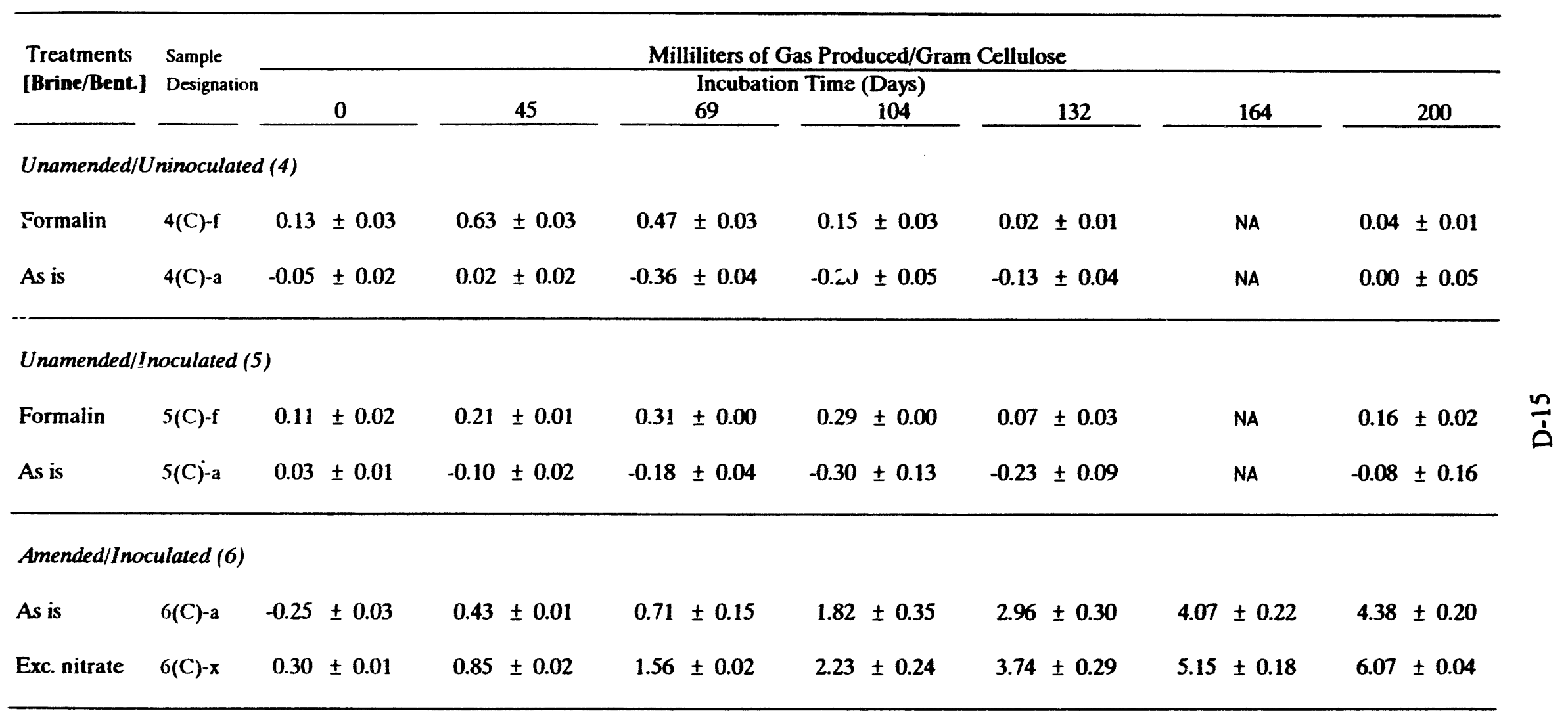

* All values have been corrected with specific controls for gas production in the absence of cellulose NA = not analyzed 
Table 15. Production of Carbon Dioxide in Aerobic Samples in the Presence of Cellulose*

\begin{tabular}{|c|c|c|c|c|c|c|c|c|c|c|c|}
\hline \multirow{3}{*}{$\begin{array}{l}\text { Treatments } \\
\text { [Brine] }\end{array}$} & \multirow{3}{*}{$\begin{array}{l}\text { Semple } \\
\text { Dexig. }\end{array}$} & \multicolumn{10}{|c|}{ Carbon Dioxide ( $\mu$ moles/gram cellulose) } \\
\hline & & \multirow{2}{*}{\multicolumn{2}{|c|}{$\mathbf{0}$}} & \multirow{2}{*}{\multicolumn{2}{|c|}{45}} & \multicolumn{3}{|c|}{ Inculsation Time (Days) } & \multirow[b]{2}{*}{132} & \multirow[b]{2}{*}{164} & \multirow[b]{2}{*}{200} \\
\hline & & & & & & & 69 & 104 & & & \\
\hline \multicolumn{12}{|c|}{ Unamended/Uninoculated (1) } \\
\hline Formalin & $1(C)-f$ & 5.58 & \pm 0.54 & 7.66 & \pm 0.02 & 8.20 & \pm 0.04 & $7.46 \pm 0.16$ & $7.64 \pm 0.06$ & NA & $7.62 \pm 0.10$ \\
\hline As is & $1(C)-a$ & 2.48 & \pm 0.10 & 3.92 & \pm 0.06 & 4.21 & \pm 0.02 & $3.93 \pm 0.02$ & $4.25 \pm 0.02$ & NA & $4.00 \pm 0.02$ \\
\hline \multicolumn{12}{|c|}{ Unamended/Inoculated (2) } \\
\hline Formalin & $2(\mathrm{C})-\mathrm{f}$ & 5.91 & \pm 0.16 & 6.24 & \pm 0.00 & 6.80 & \pm 0.14 & $5.88 \pm 0.12$ & $6.04 \pm 0.02$ & NA & $5.65 \pm 0.22$ \\
\hline As is & $2(C)-a$ & 1.96 & \pm 0.06 & 3.35 & \pm 0.16 & 3.94 & \pm 0.18 & $4.98 \pm 0.18$ & $6.87 \pm 0.20$ & NA & $8.30 \pm 0.28$ \\
\hline \multicolumn{12}{|c|}{ Amended/Inoculated (3) } \\
\hline As is & $3(C)-a$ & & ND & 4.62 & \pm 0.28 & 3.78 & \pm 1.18 & $20.4 \pm 7.4$ & $29.6 \pm 5$ & $36.6 \pm 4.2$ & $40.8 \pm 5.4$ \\
\hline Exc. nitrate & $3(C)-x$ & & ND & 6.88 & \pm 0.00 & 32.2 & \pm 4.2 & $61.4 \pm 3.6$ & $83.6 \pm 2.6$ & $96.2 \pm 4.0$ & $95.6 \pm 6.0$ \\
\hline
\end{tabular}

- All values have been corrected with specific controls for gas production in the absence of cellulose; dissolved gas concentration not included ND - not detected

NA - not analyzed 
Table 16. Production of Carbon Dioxide in Aerobic Samples in the Presence of Cellulose and Bentonite*

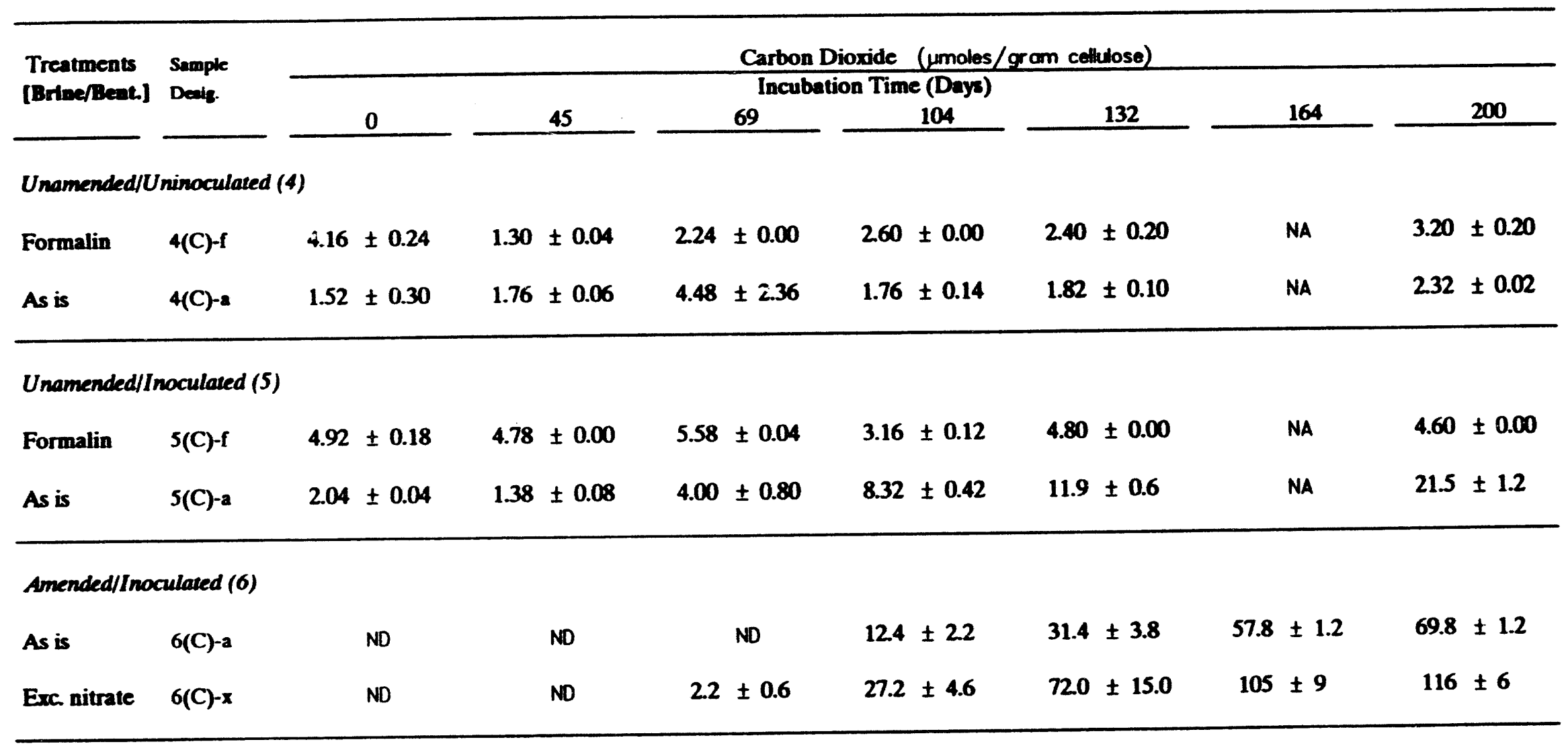

- All values have been corrected with specific controls for gas production in the absence of cellulose; dissolved gas concentration not included ND - not detected

NA - not analyzed 
Table 17. Production of Nitrous Oxide in Aerobic Samples in the Presence of Cellulose*

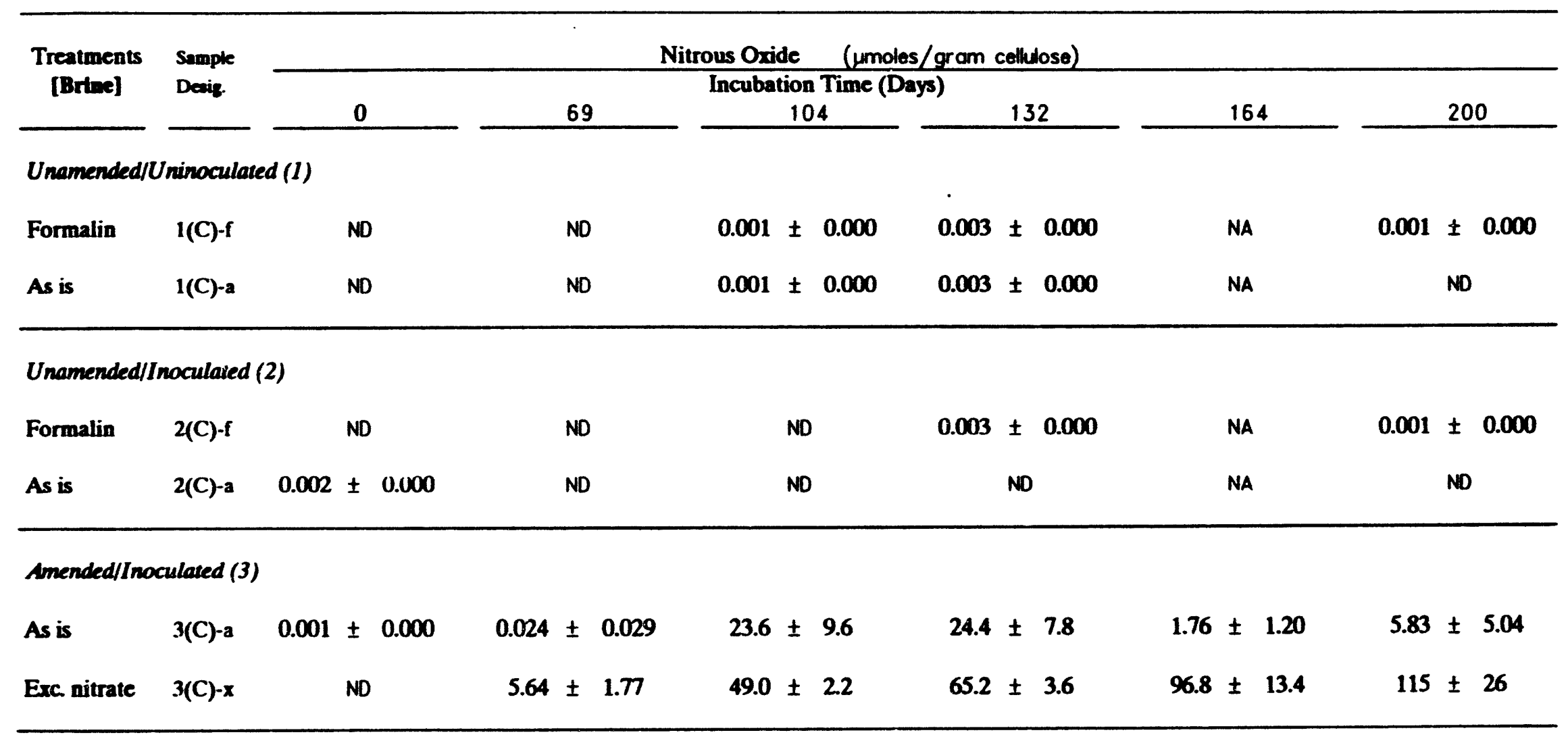

- All values have been corrected with specific controls for gas production in the absence of cellulose; dissolved gas concentration not included ND - not detected

NA - not analyzed 
Table 18. Production of Nitrous Oxide in Aerobic Samples in the Presence of Cellulose and Bentonite*

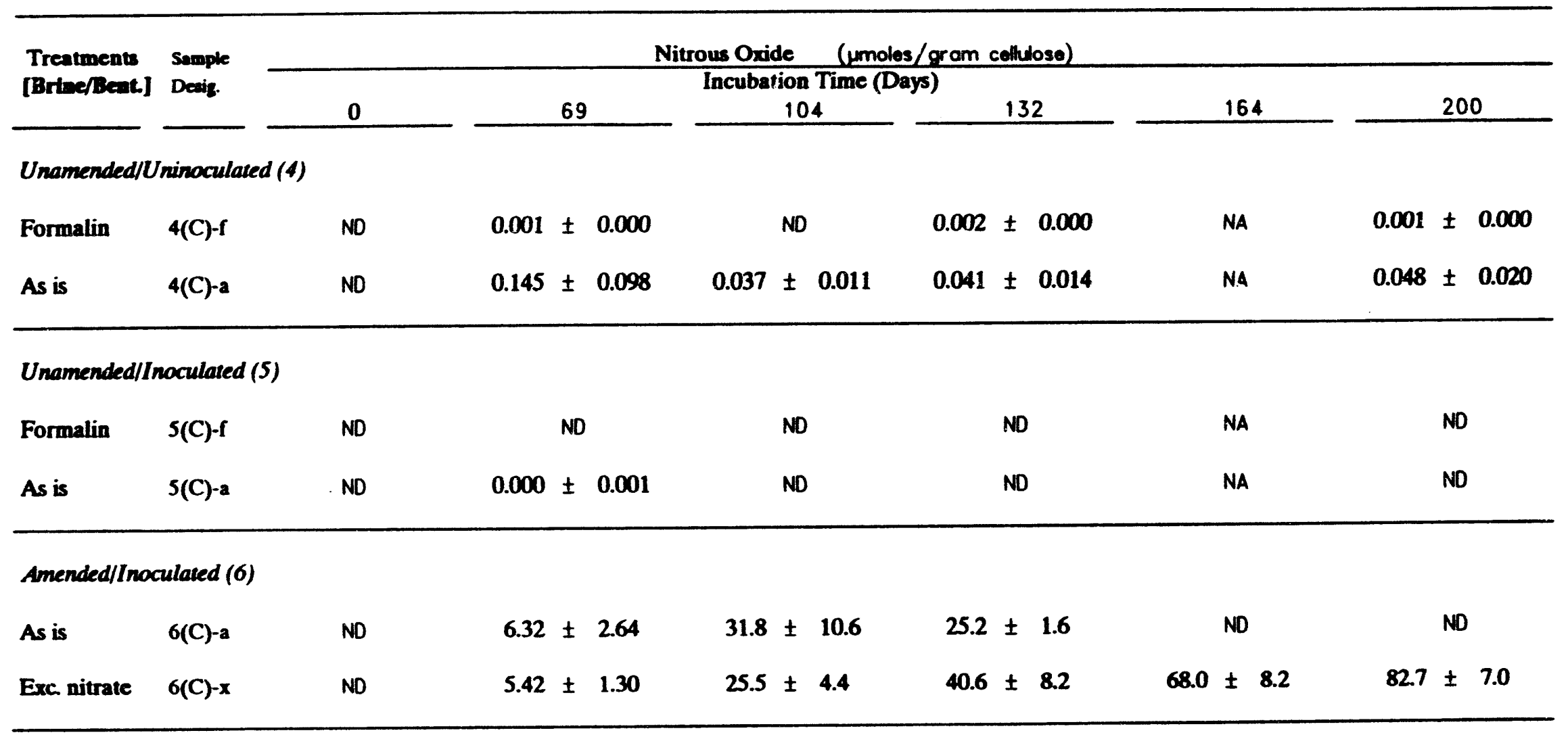

- All values have been corrected with specific controls for gas production in the absence of cellulose; dissolved gas concentration not included ND - not detected

NA - not analyzed 
Table 19. Total Volume of Gas Produced in Anaerobic Samples in the Presence of Cellulose*

\begin{tabular}{|c|c|c|c|c|c|c|c|c|c|c|}
\hline \multirow{3}{*}{$\begin{array}{c}\text { Treatments } \\
\text { [Brive] }\end{array}$} & \multirow{3}{*}{$\begin{array}{l}\text { Sample } \\
\text { Deaigantion }\end{array}$} & \multicolumn{9}{|c|}{ Milliliters of Gas Produced/Gram Cellulose } \\
\hline & & \multirow{2}{*}{\multicolumn{2}{|c|}{$\mathbf{0}$}} & \multirow{2}{*}{\multicolumn{2}{|c|}{45}} & \multicolumn{2}{|c|}{ Incubation Time (Days) } & \multirow[b]{2}{*}{132} & \multirow[b]{2}{*}{164} & \multirow[b]{2}{*}{200} \\
\hline & & & & & & 69 & 104 & & & \\
\hline \multicolumn{11}{|c|}{ Unamended/Uninoculated (7) } \\
\hline Formalin & $7(C)-f$ & 0.26 & \pm 0.01 & 0.17 & \pm 0.01 & $0.22 \pm 0.01$ & $0.17 \pm 0.01$ & $0.14 \pm 0.01$ & NA & $0.26 \pm 0.00$ \\
\hline As is & $7(C)-a$ & 0.03 & \pm 0.05 & 0.10 & \pm 0.02 & $0.40 \pm 0.01$ & $-0.18 \pm 0.07$ & $0.04 \pm 0.23$ & NA & $-0.09 \pm 0.03$ \\
\hline \multicolumn{11}{|c|}{ Unamended/Inoculated (8) } \\
\hline Formalin & $8(C)-f$ & 0.02 & \pm 0.01 & 0.22 & \pm 0.02 & $0.16 \pm 0.03$ & $0.16 \pm 0.00$ & $0.12 \pm 0.01$ & NA & $0.22 \pm 0.00$ \\
\hline As is & $8(C)-a$ & -0.04 & \pm 0.01 & 1.00 & \pm 0.03 & $0.22 \pm 0.03$ & $-0.02 \pm 0.03$ & $0.02 \pm 0.01$ & NA & $0.59 \pm 0.13$ \\
\hline \multicolumn{11}{|c|}{ Amended/Inoculated (9) } \\
\hline As is & $9(C)-a$ & -0.08 & \pm 0.02 & 0.02 & \pm 0.03 & $-0.52 \pm 0.01$ & $0.66 \pm 0.09$ & $1.52 \pm 0.25$ & $2.15 \pm 0.24$ & $2.27 \pm 0.12$ \\
\hline Erc nitrate & $9(C)-x$ & 0.01 & \pm 0.03 & -0.12 & \pm 0.08 & $0.29 \pm 0.29$ & $2.00 \pm 0.58$ & $2.24 \pm 0.78$ & $4.04 \pm 1.24$ & $5.44 \pm 1.42$ \\
\hline
\end{tabular}

- All values have been corrected with specific controls for gas production in the absence of cellulose NA $=$ not analyzed 
Table 20. Total Volume of Gas Produced in Anaerobic Samples in the Presence of Cellulose and Bentonite*

\begin{tabular}{|c|c|c|c|c|c|c|c|c|c|c|c|c|}
\hline \multirow{3}{*}{$\begin{array}{l}\text { Treatments } \\
\text { [Brine/Bent.] }\end{array}$} & \multirow{3}{*}{$\begin{array}{l}\text { Sample } \\
\text { Designation }\end{array}$} & \multicolumn{11}{|c|}{ Milliliters of Gas Produced/Gram Cellulose } \\
\hline & & \multirow{2}{*}{\multicolumn{2}{|c|}{$\mathbf{0}$}} & \multirow{2}{*}{\multicolumn{2}{|c|}{45}} & \multicolumn{3}{|c|}{ Incubation Time (Days) } & \multirow[b]{2}{*}{132} & \multirow{2}{*}{\multicolumn{2}{|c|}{164}} & \multirow[b]{2}{*}{200} \\
\hline & & & & & & & 69 & 104 & & & & \\
\hline \multicolumn{13}{|c|}{ Unamended/Uninoculated (10) } \\
\hline Formalin & $10(C)-f$ & 0.06 & \pm 0.01 & 0.01 & \pm 0.01 & 0.37 & \pm 0.00 & $-0.09 \pm 0.03$ & $-0.14 \pm 0.03$ & & NA & $-0.06 \pm 0.03$ \\
\hline As is & $10(C)-a$ & -0.08 & \pm 0.10 & -0.04 & \pm 0.03 & -0.04 & \pm 0.05 & $-0.17 \pm 0.08$ & $-0.22 \pm 0.10$ & & NA & $-0.28 \pm 0.09$ \\
\hline \multicolumn{13}{|c|}{ Unamended/Inoculated (11) } \\
\hline Formalin & $11(C)-f$ & -0.10 & \pm 0.01 & -0.10 & $\pm \mathbf{0 . 0 0}$ & -0.05 & \pm 0.01 & $-0.22 \pm 0.23$ & $-0.28 \pm 0.22$ & & NA & $-0.06 \pm 0.24$ \\
\hline As is & $11(C)-a$ & 0.03 & \pm 0.01 & 0.11 & \pm 0.01 & -0.06 & \pm 0.03 & $0.16 \pm 0.04$ & $0.29 \pm 0.04$ & & NA & $0.81 \pm 0.08$ \\
\hline \multicolumn{13}{|c|}{ Amended/Inoculated (12) } \\
\hline As is & $12(C)-a$ & -0.11 & \pm 0.05 & -0.05 & \pm 0.02 & 0.19 & \pm 0.09 & $1.39 \pm 0.09$ & $1.78 \pm 0.08$ & 1.44 & \pm 0.07 & $1.92 \pm 0.08$ \\
\hline Exc. nitrate & $12(C)-x$ & -0.06 & \pm 0.02 & -0.09 & \pm 0.03 & 0.23 & \pm 0.06 & $0.78 \pm 0.09$ & $1.68 \pm 0.10$ & 2.19 & \pm 0.14 & $3.52 \pm 0.28$ \\
\hline
\end{tabular}

- All values have been corrected with specific controls for gas production in the absence of cellulose NA = not analyzed 
Table 21. Production of Carbon Dioxide in Anaerobic Samples in the Presence of Cellulose*

\begin{tabular}{|c|c|c|c|c|c|c|c|c|c|}
\hline \multirow{3}{*}{$\begin{array}{l}\text { Treatments } \\
\text { [Brime] }\end{array}$} & \multirow{3}{*}{$\begin{array}{l}\text { Sample } \\
\text { Deaig. }\end{array}$} & \multicolumn{8}{|c|}{ Carbon Dioxide ( $\mu$ moles/gram cellulose) } \\
\hline & & \multirow[b]{2}{*}{$\mathbf{0}$} & \multirow[b]{2}{*}{45} & \multicolumn{3}{|c|}{ Incubation Time (Days) } & \multirow[b]{2}{*}{132} & \multirow[b]{2}{*}{164} & \multirow[b]{2}{*}{200} \\
\hline & & & & & 69 & 104 & & & \\
\hline \multicolumn{10}{|c|}{ Unamended/Uninoculated (7) } \\
\hline Formalin & $7(C)-f$ & $5.89 \pm 0.10$ & $7.22 \pm 0.02$ & 7.16 & \pm 0.02 & $6.55 \pm 0.04$ & $6.81 \pm 0.02$ & NA & $6.78 \pm 0.02$ \\
\hline As is & $7(C)-2$ & $2.38 \pm 0.08$ & $3.74 \pm 0.02$ & 3.92 & \pm 0.02 & $3.63 \pm 0.02$ & $3.83 \pm 0.04$ & NA & $3.59 \pm 0.04$ \\
\hline \multicolumn{10}{|c|}{ Unamended/Inoculated (8) } \\
\hline Formalin & $8(C)-f$ & $5.54 \pm 0.14$ & $6.08 \pm 0.08$ & 5.92 & \pm 0.04 & $5.46 \pm 0.00$ & $5.70 \pm 0.10$ & NA & $5.77 \pm 0.08$ \\
\hline As is & $8(C)-2$ & $2.11 \pm 0.04$ & $3.41 \pm 0.04$ & 3.34 & \pm 0.02 & $3.01 \pm 0.14$ & $3.97 \pm 0.10$ & NA & $5.47 \pm 0.34$ \\
\hline \multicolumn{10}{|c|}{ Amended/Inoculated (9) } \\
\hline As is & $9(C)-a$ & ND & $3.79 \pm 0.04$ & & ND & $7.22 \pm 0.60$ & $18.2 \pm 1.4$ & $24.2 \pm 0.6$ & $26.0 \pm 0.8$ \\
\hline Exc. nitrate & $9(C)-x$ & $0.47 \pm 0.00$ & $4.29 \pm 0.04$ & 6.10 & \pm 3.42 & $19.7 \pm 6.6$ & $25.8 \pm 6.4$ & $45.4 \pm 8.0$ & $61.4 \pm 8.2$ \\
\hline
\end{tabular}

- All values have been corrected with specific controls for gas production in the absence of cellulose; dissolved gas concentration not included ND - not detected

NA - not analyzed 
pazkieue jou - $\forall \mathbf{N}$ polosiop jou - GN

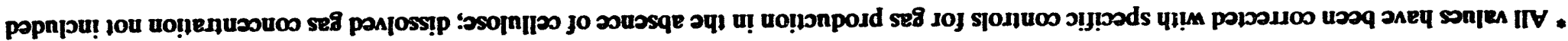

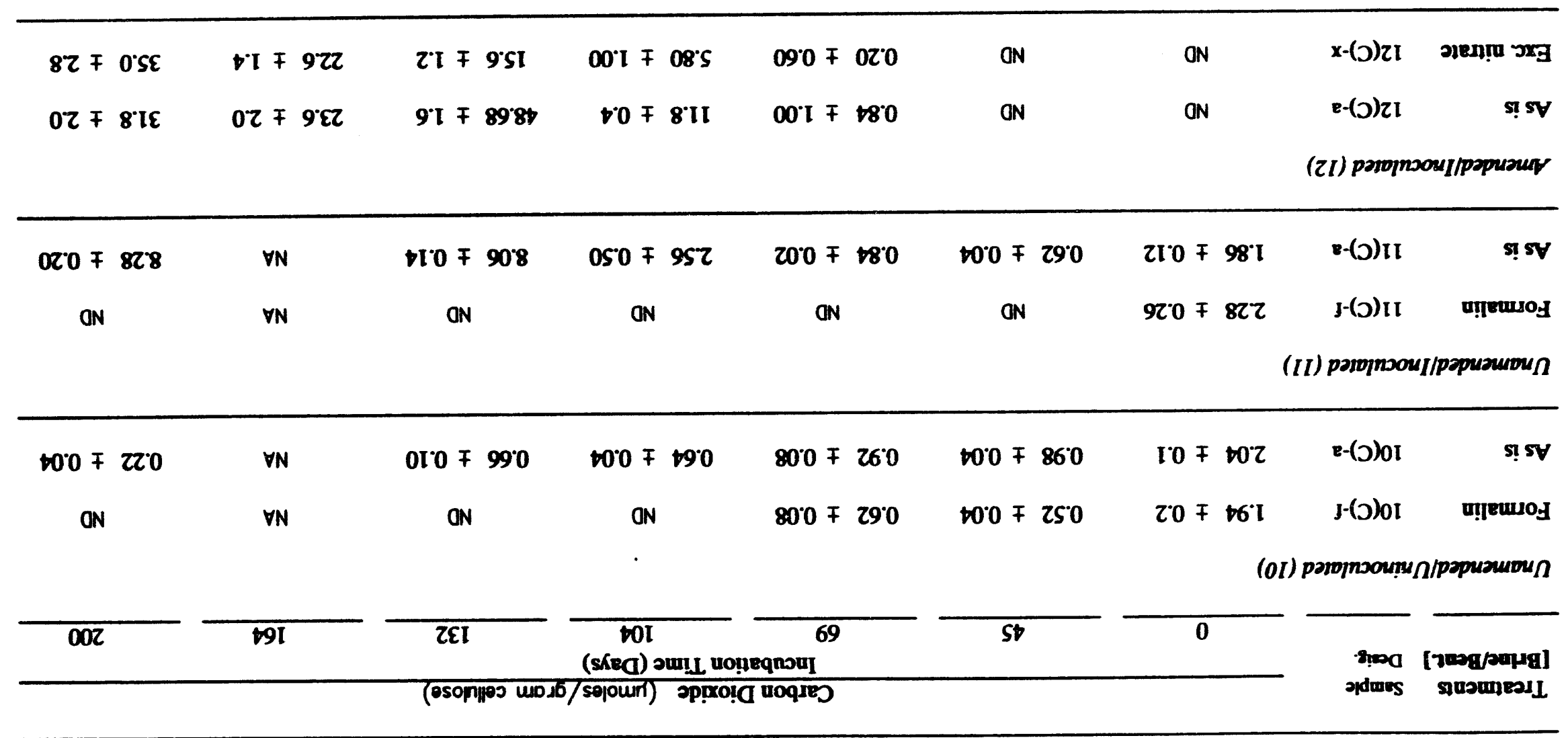

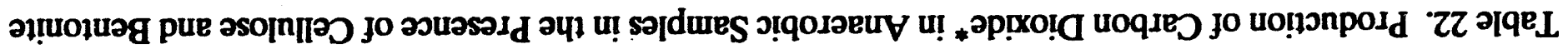


Table 23. Production of Nitrous Oxide in Anaerobic Samples in the Presence of Cellulose*

\begin{tabular}{|c|c|c|c|c|c|c|c|c|c|c|c|c|c|c|}
\hline \multirow{3}{*}{$\begin{array}{c}\text { Treatments } \\
\text { [Briac] }\end{array}$} & \multirow{3}{*}{$\begin{array}{l}\text { Sampie } \\
\text { Deaig. }\end{array}$} & \multicolumn{10}{|c|}{ Nitrous Oxide ( $\mu$ moles/gram cellulose) } & & & \\
\hline & & \multicolumn{10}{|c|}{ Incubation Time (Days) } & \multirow{2}{*}{\multicolumn{3}{|c|}{200}} \\
\hline & & $\mathbf{0}$ & \multicolumn{3}{|c|}{69} & \multicolumn{2}{|c|}{104} & \multicolumn{2}{|r|}{132} & \multicolumn{2}{|c|}{164} & & & \\
\hline \multicolumn{15}{|c|}{ Unamended/Uninoculased (7) } \\
\hline Formalin & $7(C)-f$ & ND & 0.002 & \pm & 0.001 & 0.001 & \pm 0.000 & 0.001 & \pm 0.001 & $N$ & & & ND & \\
\hline As is & $7(C)-a$ & ND & & ND & & & ND & & ND & $\mathbf{N}$ & & & ND & \\
\hline \multicolumn{15}{|c|}{ Unamended/Inoculated (8) } \\
\hline Formalin & $8(C)-f$ & ND & & ND & & & ND & 0.003 & \pm 0.000 & N & & 0.002 & \pm & 0.000 \\
\hline As is & $8(C)-a$ & ND & & ND & & & ND & & ND & N & & & ND & \\
\hline \multicolumn{15}{|c|}{ Amended/Inoculated (9) } \\
\hline As is & $9(C)-a$ & ND & & ND & & & ND & 15.8 & \pm 8.3 & $17.9 \pm$ & 8.6 & 15.5 & \pm & 8.4 \\
\hline Exc. nitrate & $9(C)-x$ & ND & 0.158 & \pm & 0.084 & $16.1=$ & \pm 10.0 & 39.2 & \pm 15.0 & $56.0 \pm$ & 32.0 & 79.0 & \pm & 45.6 \\
\hline
\end{tabular}

- All values have been corrected with specific controls for gas production in the absence of cellulose; dissolved gas concentration not included ND - not detected

NA - not analyzed 
Table 24. Production of Nitrous Oxide* in Anaerobic Samples in the Presence of Cellulose and Bentonite

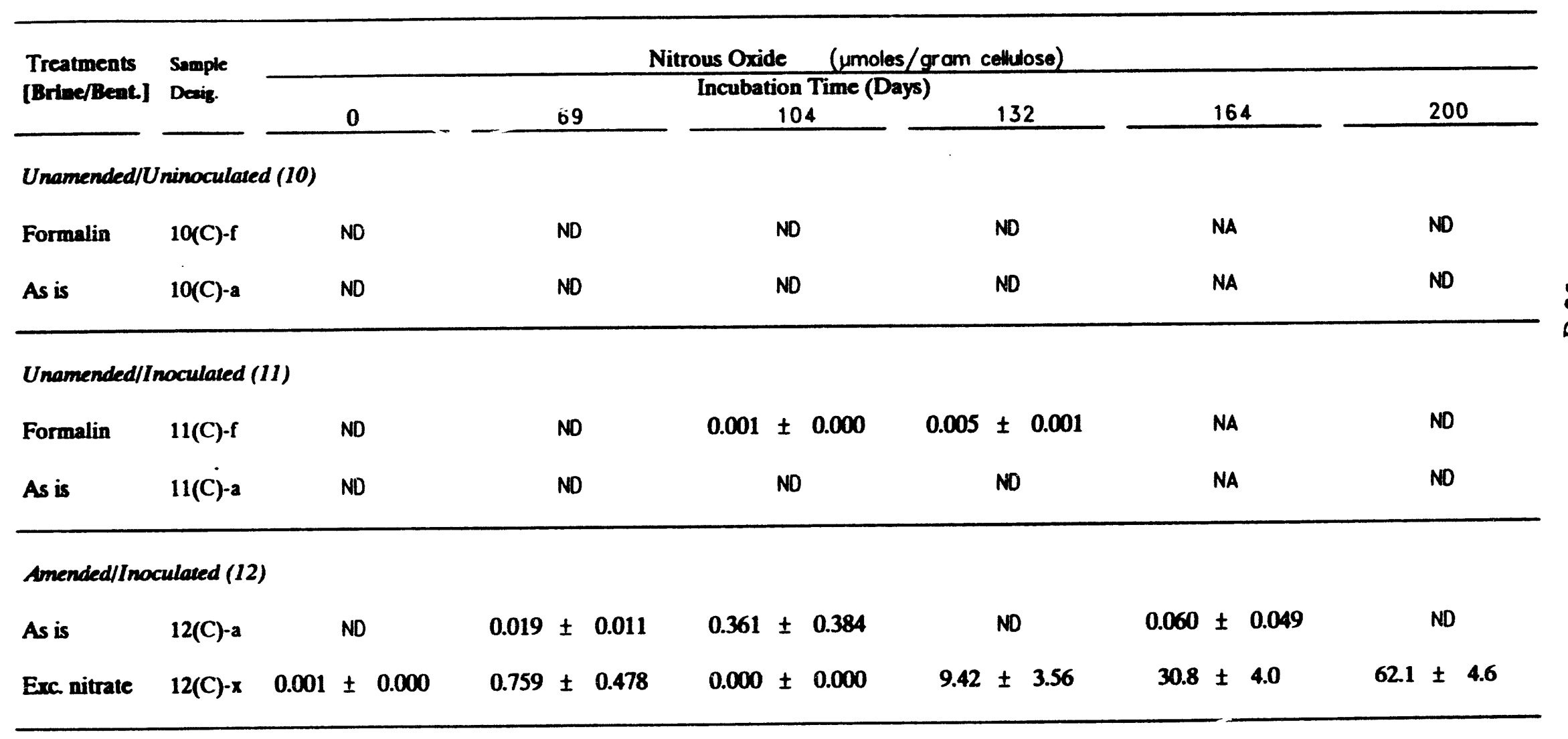

- All values have been corrected with specific controls for gas production in the absence of cellulose; dissolved gas concentration not included ND - not detected

NA - not analyzed 


\section{APPENDIX E: MEASUREMENTS OF MIXED INOCULUM ACTIVITY}

To determine the activity of the mixed inoculum, brine samples were incubated with glucose with an initial air and $\mathrm{N}_{2}$ atmosphere. Total gas, $\mathrm{CO}_{2}$ and $\mathrm{N}_{2} \mathrm{O}$ were periodically monitored.

\section{Aerobic Samples}

\section{Total Gas Production}

Samples containing glucose, nutrients, excess nitrates with and without bentonite did not show an increase in total gas production (Figure 25, Tables 1(a)-2(a) Appendix D).

\section{Carbon Dioxide Production}

Production of carbon dioxide was evident after 132 days in amended and in amended plus excess nitrate samples without bentonite. After 200 days, amended samples produced $323 \mu \mathrm{mol}$ of $\mathrm{CO}_{2}$, whereas amended plus excess nitrate samples produced $296 \mu \mathrm{mol} \mathrm{CO}_{2}$ Samples with bentonite did not produce significant amounts of $\mathrm{CO}_{2}$ beyond the initial background level ( $\sim 70-80 \mu \mathrm{mol})$ (Figure 26, Tables 1(b)-2(b) Appendix D).

\section{Nitrous Oxide Production}

Nitrous oxide was detected at 132 days in aerobic samples without bentonite (Figure 27, Tables 1(c)-2(c) Appendix D). Less $\mathrm{N}_{2} \mathrm{O}$ was detected in amended samples with excess nitrate, and in samples containing bentonite, $\mathrm{N}_{2} \mathrm{O}$ was not detected. 


\section{Anaerobic Samples}

\section{Total Gas Production}

Amended and amended samples with excess nitrate showed no increase in total gas production. However, in the presence of bentonite, production in amended samples increased after 45 day of incubation and reached to $37.8 \mathrm{~mL}$ at 200 days (Figure 28, Tables 3(a)-4(a) Appendix D). Amended samples plus excess nitrate produced more gas (80.65 mL of gas at $\mathbf{2 0 0}$ days) than the other samples.

\section{Carbon Dioxidé Production}

Production of carbon dioxide was not detected in the amended samples, whereas the amended samples with excess nitrate produced a small amount of $\mathrm{CO}_{2}$. Carbon dioxide production in samples containing bentonite was significant (Figure 29, Tables 3(b)-4(b) Appendix D). Amended samples containing excess nitrate produced $1610 \mu \mathrm{mol} \mathrm{of} \mathrm{CO}_{2}$ at 200 days while the basic amended samples produced 786 moles. Carbon dioxide production was much higher in the glucose/bentonite samples than in the cellulose/bentonite samples, indicating the potential of the microorganisms to produce significant amounts of $\mathrm{CO}_{2}$ under hypersaline conditions when a simple sugar is present. In addition, bentonite seems to enhance the overall gas production.

\section{Nitrous OxIde Production}

Accumulation of nitrous oxide was detected only in samples containing bentonite (Figure 30, Tables 3(c)-4(c) Appendix D). With excess nitrate, the $\mathrm{N}_{2} \mathrm{O}$ concentration reached $585 \mu \mathrm{mol}$ and then started to decline. 


\section{Summary}

We examined glucose metabolism by the mixed inoculum used in the long-term experiments. Total gas production in samples incubated under aerobic conditions was not evident, but anaerobic samples produced significant amounts of gas, especially the samples with bentonite plus excess nitrate. Production of carbon dioxide in the aerobic samples was observed only in the amended and excess-nitrate samples without bentonite. Bentonite enhanced the activity of anaerobes. Carbon-dioxide production in anaerobic samples with excess nitrate reached a higher amount than any of the totals reached thus far in the longterm inundated experiment. Substantial amounts of $\mathrm{N}_{2} \mathrm{O}$ also accumulated in the headspace of these samples. 


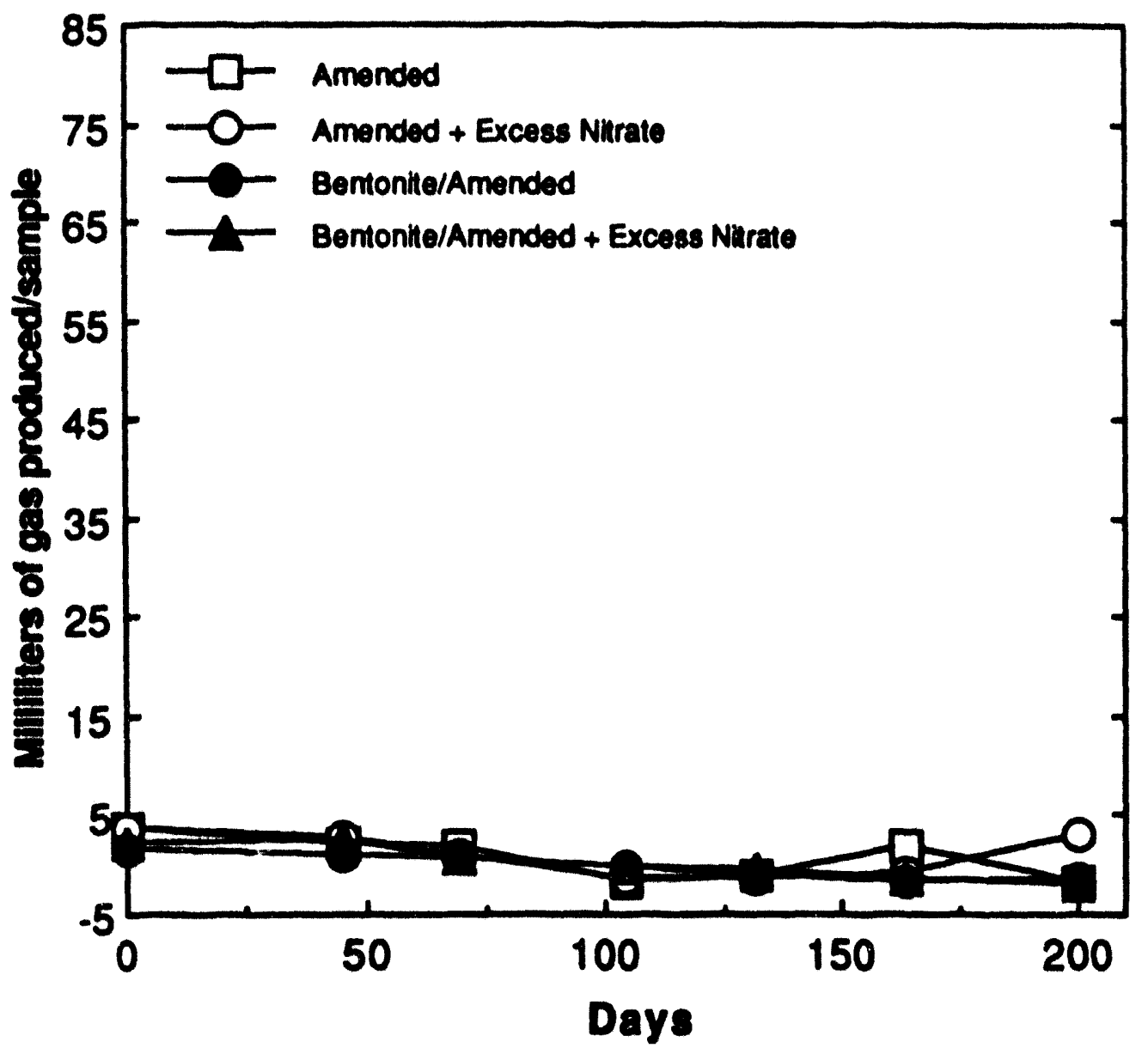

Figure 25. Total gas produced in samples containing glucose incubated with an initial atmosphere of air. 


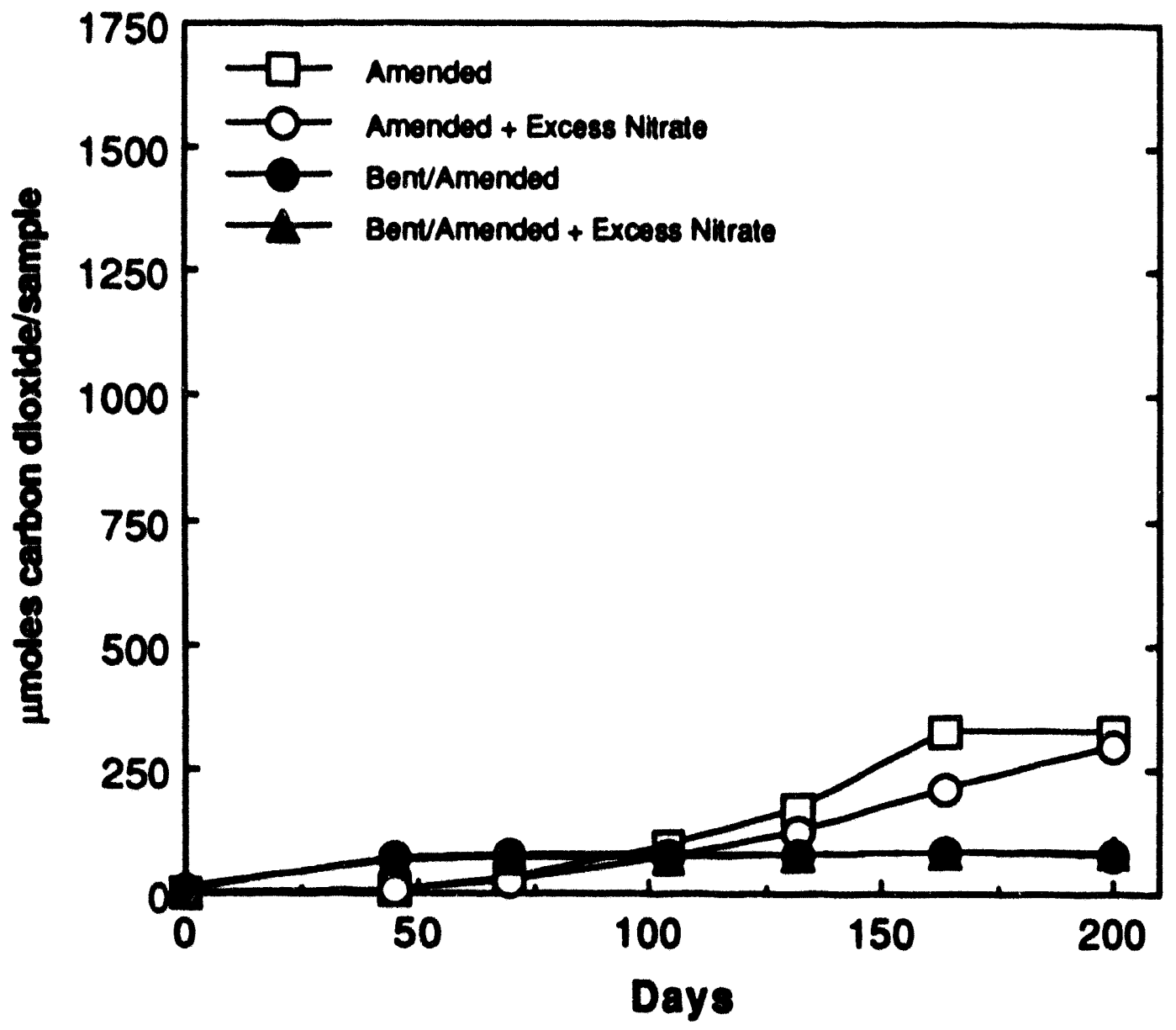

Figure 26. Carbon dioxide produced in samples containing glucose incubated with an initial atmosphere of air. 


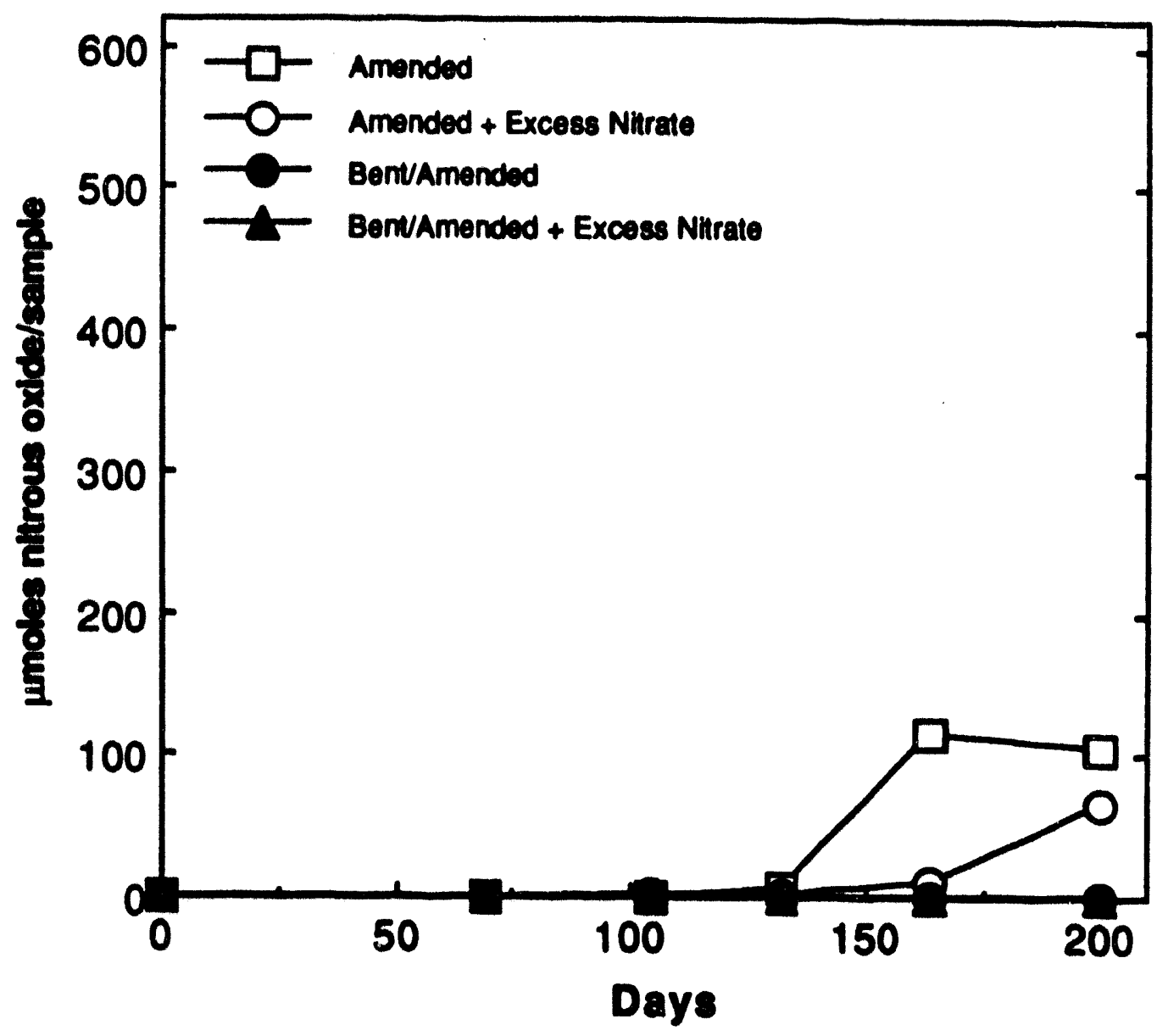

Figure 27. Nitrous oxide produced in samples containing glucose incubated with an initial atmosphere of air. 


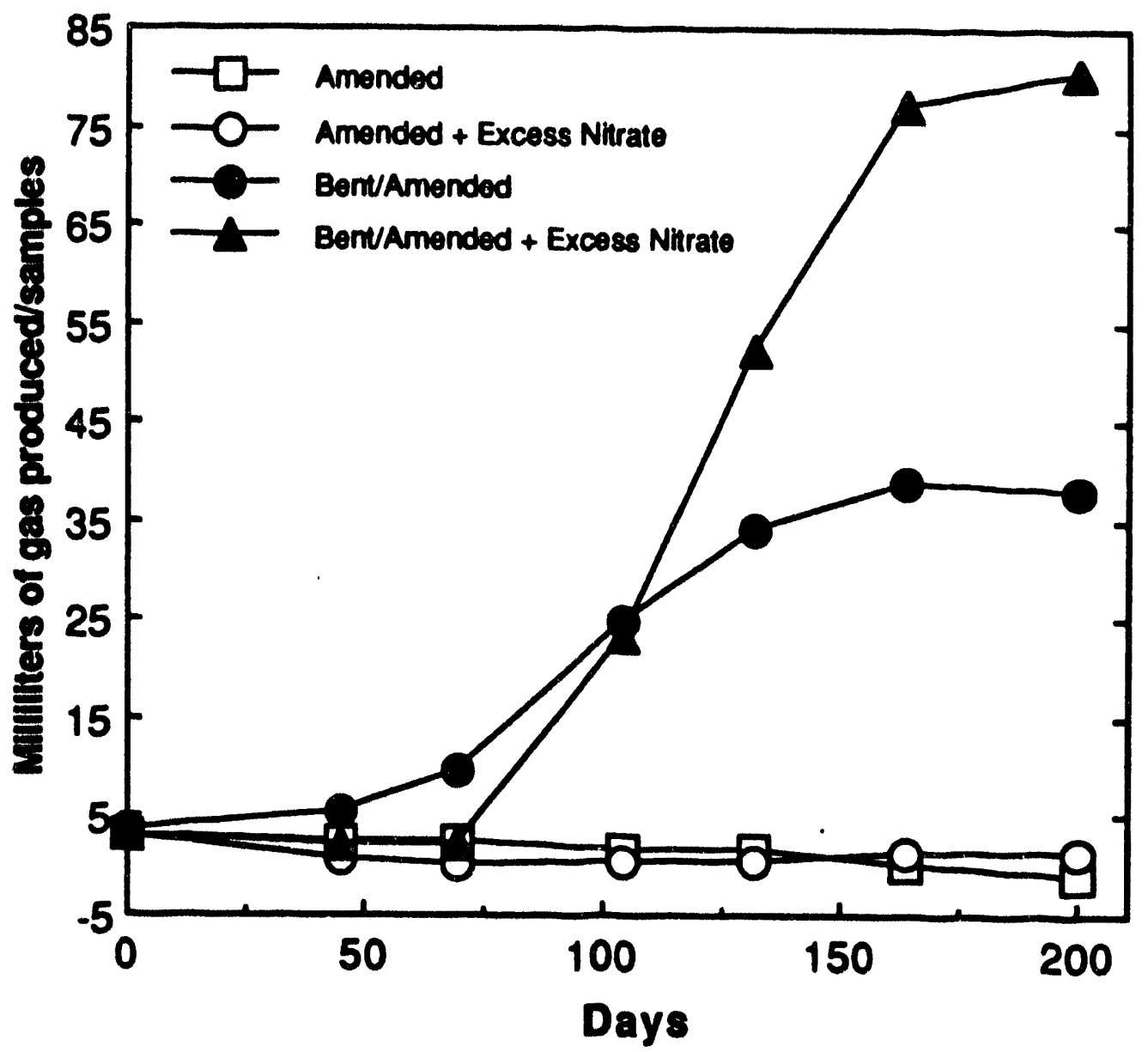

Figure 28. Total gas produced in anaerobic samples containing glucose. 


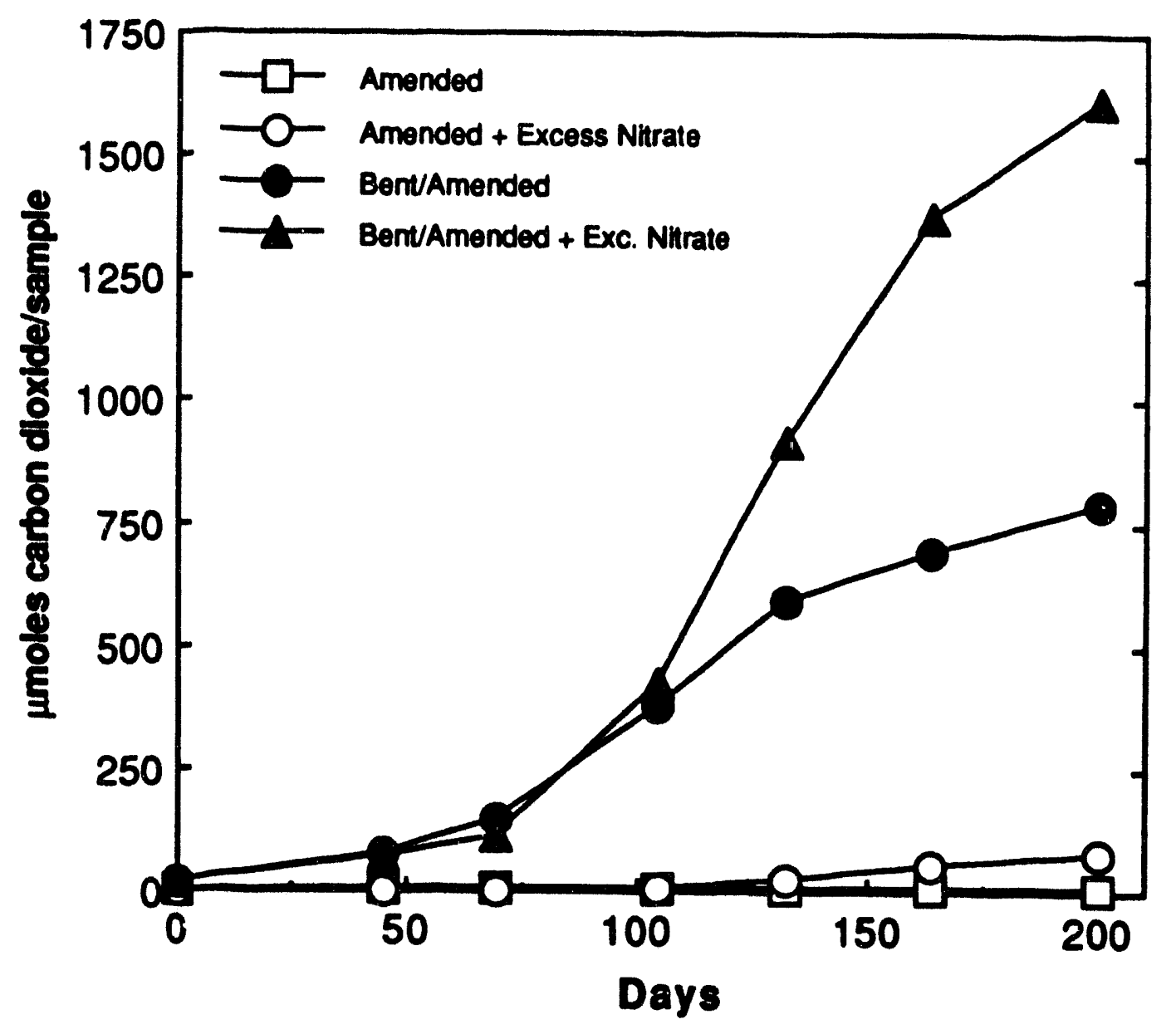

Figure 29. Carbon dioxide produced in anaerobic samples containing glucose. 


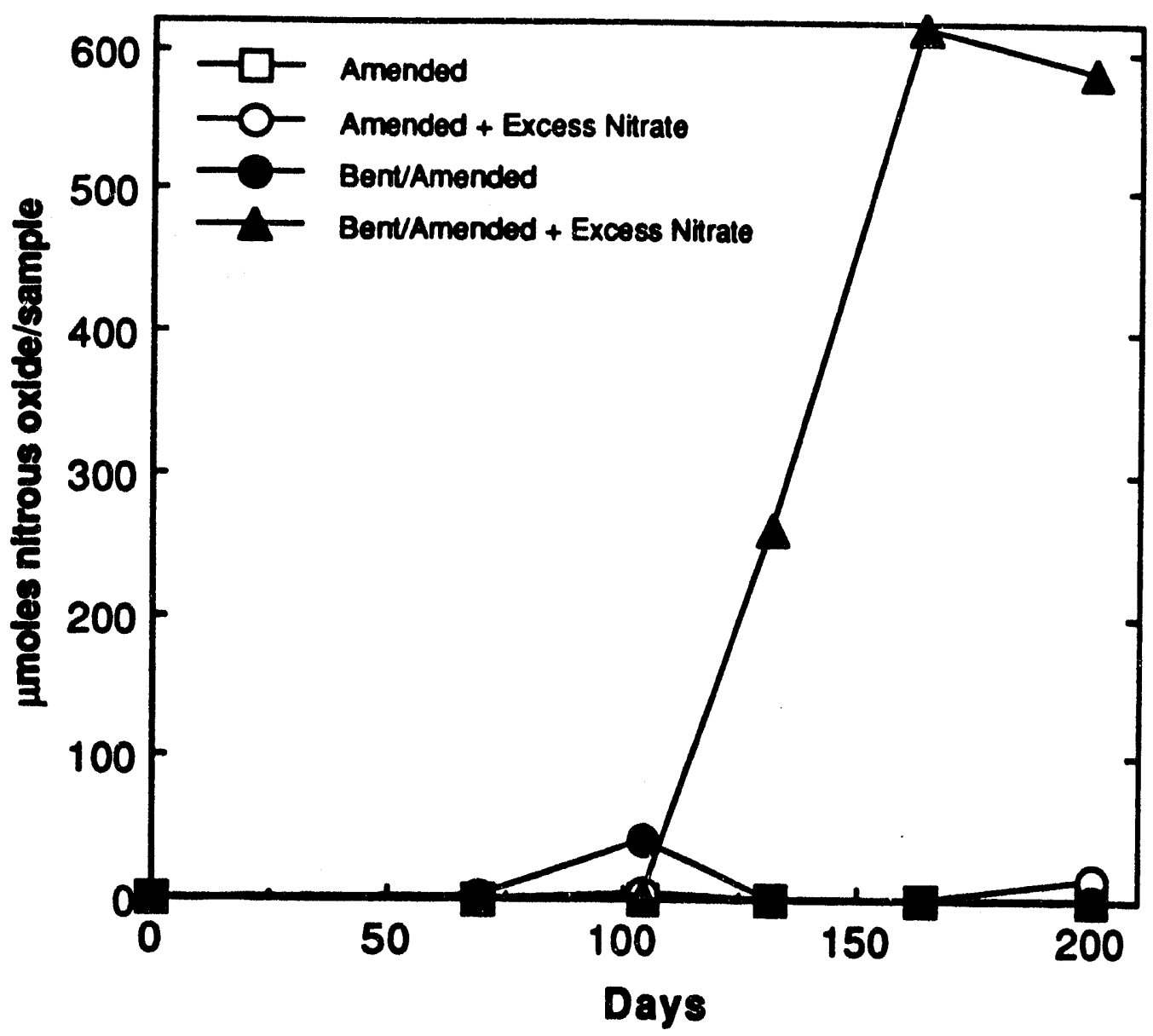

Figure 30. Nitrous oxide produced in anaerobic samples containing glucose.

E- 9 

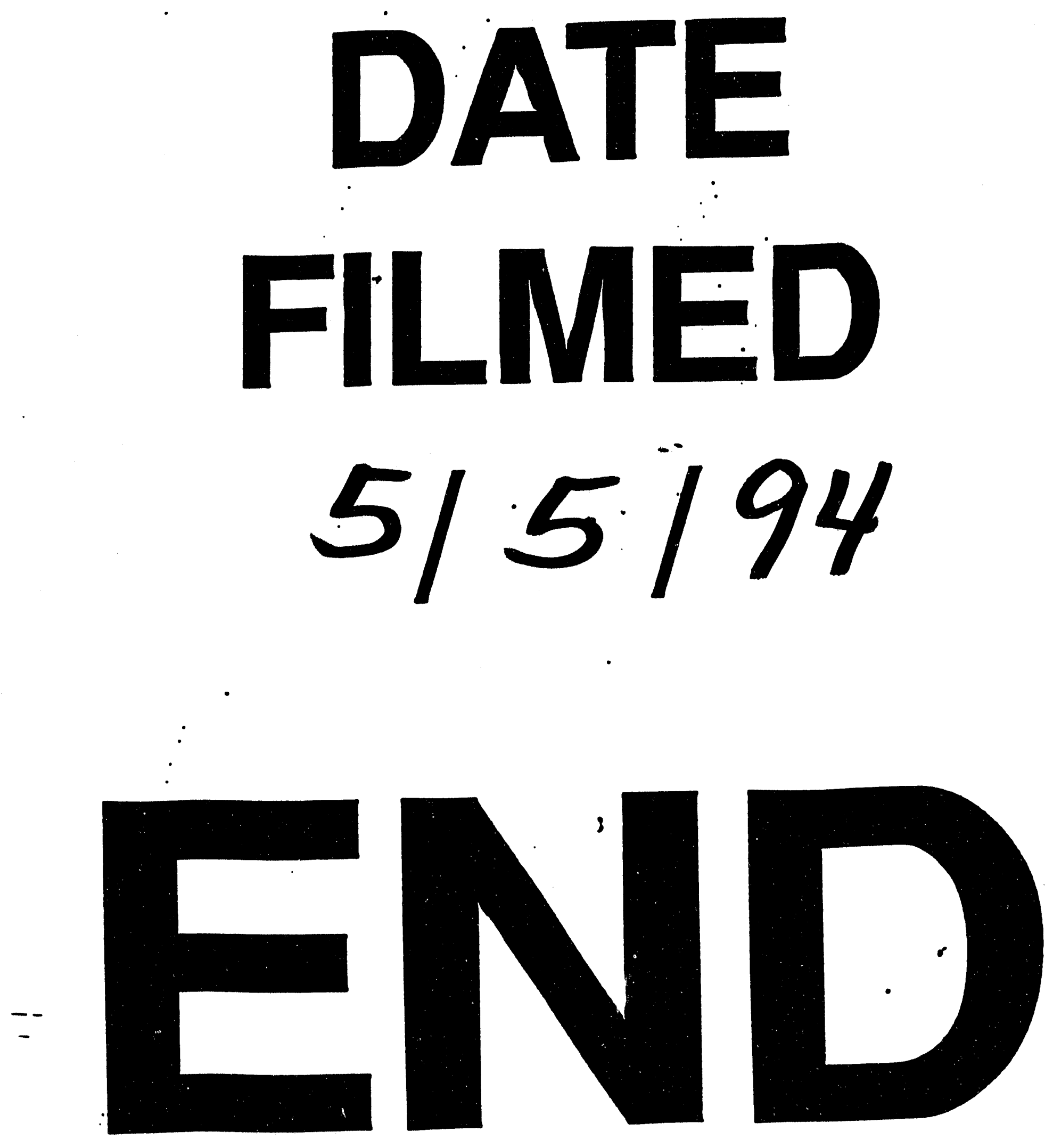
